University of New Hampshire

University of New Hampshire Scholars' Repository

Fall 2003

\title{
Conceptualizing and measuring the life space and its relation to openness to experience
}

Marc A. Brackett

University of New Hampshire, Durham

Follow this and additional works at: https://scholars.unh.edu/dissertation

\section{Recommended Citation}

Brackett, Marc A., "Conceptualizing and measuring the life space and its relation to openness to experience" (2003). Doctoral Dissertations. 176.

https://scholars.unh.edu/dissertation/176

This Dissertation is brought to you for free and open access by the Student Scholarship at University of New Hampshire Scholars' Repository. It has been accepted for inclusion in Doctoral Dissertations by an authorized administrator of University of New Hampshire Scholars' Repository. For more information, please contact Scholarly.Communication@unh.edu. 


\author{
MARC A. BRACKETT \\ BA, Rutgers University, 1991 \\ MA, John Jay College of Criminal Justice (CUNY), 1996
}

MA, University of New Hampshire, 2001

\title{
DISSERTATION
}

Submitted to the University of New Hampshire in Partial Fulfillment of

The Requirements for the Degree of

Doctor of Philosophy

in

Psychology

September, 2003 
UMI Number: 3097782

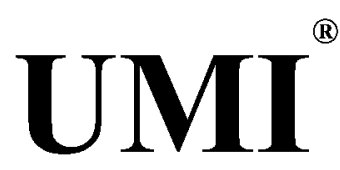

UMI Microform 3097782

Copyright 2003 by ProQuest Information and Learning Company.

All rights reserved. This microform edition is protected against unauthorized copying under Title 17, United States Code.

ProQuest Information and Learning Company 300 North Zeeb Road

P.O. Box 1346

Ann Arbor, MI 48106-1346 
This dissertation has been examined and approved.

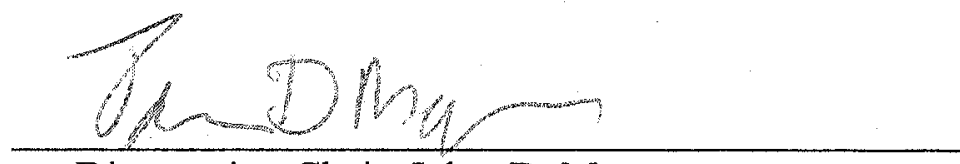

Dissertation Chair, John. D. Mayer,

Professor of Psychology

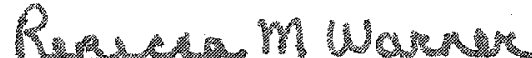

Rebecca M. Warner, Professor of Psychology

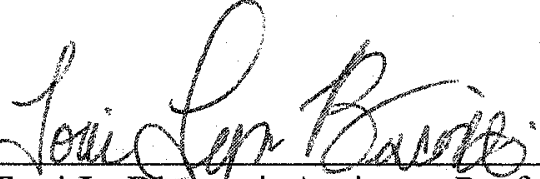

Toni L. Biscohti, Assistant Professor of Psychology

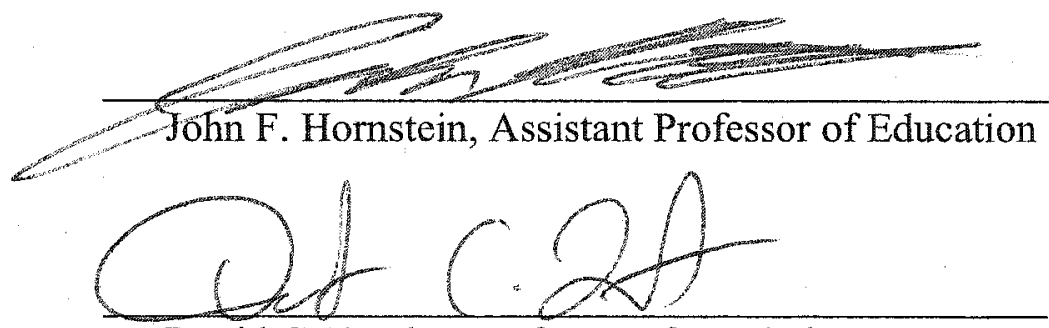

David C. Funder, Professor of Psychology,

University of California, Riverside 


\section{DEDICATION}

I want to dedicate this dissertation to my partner, Horacio Marquinez, to my mom, the late Diane Brackett, to my dad, William Brackett, and to my uncle, Marvin Maurer. Horacio, much more than the data in this dissertation, has taught me the importance of being Open to Experience. He has also enriched my Life Space in ways that words cannot describe. My mom, had she had the opportunities that were afforded to me, would have been a gifted psychologist. Imagining her feelings of joy at my defense makes me happier than the feelings that will accompany the award of the doctorate itself. My dad is a neverending source of support and encouragement. He has taught me by example how perseverance coupled with hard work brings great rewards. Finally, the single most influential person on my decision to become a psychologist is my uncle Marvin. By watching Marvin I have learned that passion and compassion are vital to achieving one's personal and professional goals. Most importantly, I dedicate this dissertation to Marvin because he, more than anyone else, has helped me to find my purpose in life. 


\section{ACKNOWLEDGMENTS}

First, I have to thank Dr. Jack Mayer, my advisor, who has enriched my life with two fascinating areas of research (Life Space and Emotional Intelligence). I am indebted to Dr. Rebecca Warner, my second advisor, who has spent countless hours making sure my graduate school experience was a great success. I also thank my other committee members, Dr. John Hornstein, Dr. David Funder, and in particular, Dr. Toni Bisconti, who showed me that "cool" and intelligent are not orthogonal. I can't imagine what graduate school would have been like without my friend Zorana Ivcevic. We have spent countless hours together discussing personal and professional matters and her support is greatly appreciated. The administrative staff in the psychology department, including Janice Chadwick, Donna Hardy, Robin Scholefield, and Anne Kendal, in particular, made each day at Conant Hall enjoyable. Dr. Ed O'Brien is appreciated for providing me with unlimited research participants. I thank my undergraduate assistants for helping me through each stage of this dissertation. Special kudos goes to the Glidden family for adopting me into their family for the last four years. There are no words to describe my love and appreciation for my family and friends who have supported me in graduate school: Horacio Marquinez, William and Jane Brackett, Steven and Leticia Nadler, David Nadler, Ellyn Solis, Marvin and Phyllis Maurer, Richard and Lisa Maurer, Sandra Price, Jack Weinstock, and Michael D'Aloia. There are also dozens of coffee shops between New York and Maine that should be acknowledged for losing profits so that I could write this dissertation. I especially want to thank Carla's in York, Maine. Finally, the financial assistance of the Institute for Policy and Social Science Research at the University of New Hampshire is greatly appreciated. 


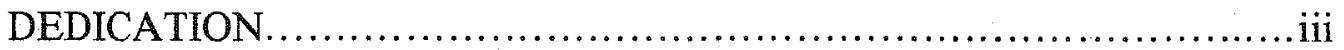

ACKNOWLEDGEMENTS...............................................

LIST OF TABLES ....................................................... vi

LIST OF FIGURES................................................... vii

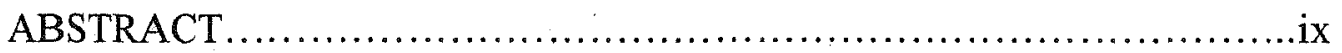

CHAPTER $\quad$ PAGE

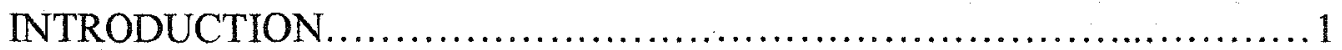

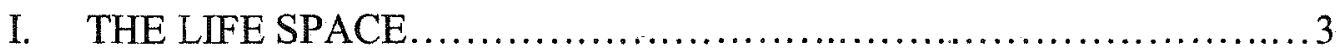

Initial Conceptions of the Life Space...................................... 3

Initial Measurement of the Life Space..................................... 4

College Student Life Space Scale........................................ 6

Life Space Data.................................................. 9

II. PILOT STUDY: DEVELOPMENT OF THE REVISED COLEGE STUDENT LIFE SPACE SCALE .................................... 14

Gathering of New Life Space Items..................................14

The Final Life Space Scale ............................................ 16

III. STUDY 1: DEVELOPMENT OF FIRST- AND SECOND-ORDER.

LIFE SPACE SCALES................................................

Methods................................................................. 17

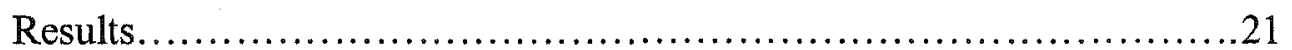

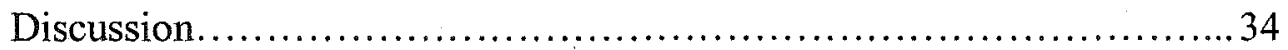

IV. OPENNESS TO EXPERIENCE .................................. 43

Openness on the NEO PI-R...................................... 44

Correlates of Openness............................................... 45

V. PILOT STUDY: EXPLORING OPENNESS AND ITS

CORRELATES IN THE LIFE SPACE..................................48

Gender Differences in Openness and the Life Space......................48

Correlations Between Openness and the Life Space...................... 49

VI. STUDY 2: OPENNESS EXPRESSED IN THE LIFE SPACE.......... 52

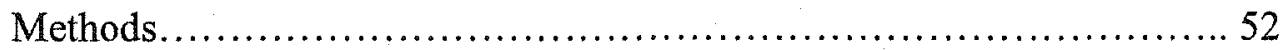

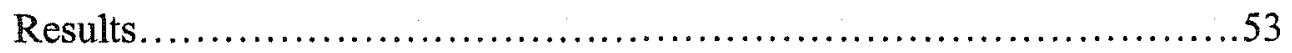

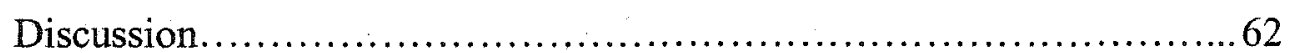

VII. GENERAL DISCUSSION........................................... 66

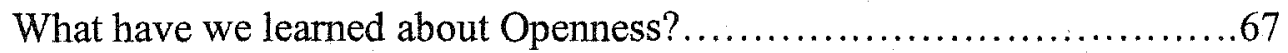

Limitations and future directions.......................................67 67

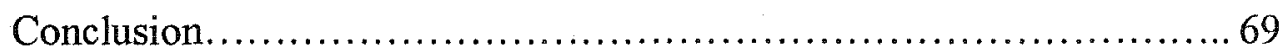

LIST OF REFERENCES ................................................... 71

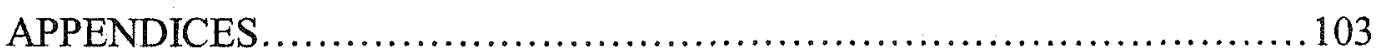




\section{LIST OF TABLES}

Table 1. Overview of the Domains, Areas, and Categories of the Life Space.

Table 2. Biological Domain: Factor-Based Scales and Preliminary

Analyses

Table 3. Situational Elements Domain: Factor-Based Scales and

Preliminary Analyses.

Table 4. Interactive Domain: Factor-Based Scales and Preliminary

Analyses

Table 5. Incorporative Domain: Factor-Based Scales and Preliminary

Analyses

Table 6. Global Life Space Dimensions: Factor-Based Scales and Preliminary Analyses.

Table 7. Correlations Among Global Life Space Dimensions (Males and Females)

Table 8. Statistically Significant Correlations Between Brackett's (2001)

Life Space Scales and Openness....................................... 88

Table 9. Preliminary Analyses on Openness Factor and Facet Scales.

Table 10. Relations Between Scales in the Biological Life Space Domain and Openness

Table 11. Relations Between Scales in the Situational Elements Domain And Openness.

Table 12. Relations Between Scales in the Interactive Domain and Openness

Table 13. Relations Between Scales in the Incorporative Domain and Openness. 95

Table 14. Relations Between Global Life Space Scales and Openness 97 


\section{LIST OF TABLES (Continued)}

Table 15. Comparison of Extreme Groups (High versus Low Openness) on Life Space Items for Males (Cross-Validation) ...................... 98

Table 16. Comparison of Extreme Groups (High versus Low Openness) on Life Space Items for Females (Cross-Validation). 99 


\section{LIST OF FIGURES}

Figure 1. Graphical Representation of the Life Space (after Mayer,

Carlsmith, and Chabot, 1998)............................................ 101

Figure 2. Graphical Representation of the College Student Life Space........ 102 


\title{
ABSTRACT \\ CONCEPTUALIZING AND MEASURING THE LIFE SPACE AND ITS RELATION TO OPENNESS TO EXPERIENCE
}

\author{
By \\ Marc A. Brackett \\ University of New Hampshire, September, 2003
}

The Life Space is divided into four domains that surround personality, which broadly encompass a person's biological foundations, owned possessions, interactions and daily activities, and group memberships. In Study 1, a revised measure of the Life Space (the College Student Life Space Scale) was developed. Factor analysis of the items within each domain resulted in 96 meaningful and reliable factor-based scales that provided a rich description of college students' personal surroundings and everyday behavior. A second-order (hierarchical) factor analysis of the first-order scales resulted in seven global Life Space dimensions. In Study 2, the first- and second-order Life Space scales were used as criterion measures to test the construct validity of Openness to Experience (Openness). Also in Study 2, cross-validated criterion-keyed Life Space scales were developed to compare individual Life Space items for high and low scoring individuals on Openness. The results of Study 1 replicated and expanded upon previous research on the structure of the Life Space. The results of Study 2 supported the construct validity or social significance of Openness. The value of a more detailed and comprehensive approach to studying personality within the context of the external systems that surround the person is discussed. 


\section{INTRODUCTION}

Definitions of personality almost always refer to the pattern or organization of a person's thoughts, emotions, and behavior (e.g., Allport, 1961; Funder, 2001; Pervin, 1996). Why, then, have personality psychologists primarily focused their attention on the internal, psychological structure and dynamics of the individual, while paying little attention to measuring the external environment or behavior?

A large part of last century, for instance, was spent investigating the structure of personality traits, in particular, the Five-Factor Model (FFM) of personality (Costa \& McCrae, 1992; Digman, 1990; Goldberg, 1990; John \& Srivastava, 1999; Wiggins, 1996). That model asserts that the most important and prominent dimensions of personality are composed of the traits: Neuroticism, Extraversion, Openness to Experience (Openness), Agreeableness, and Conscientiousness. There is a general consensus about the efficacy of the FFM (but not complete, see Block, 1995, McAdams, 1992; Pervin, 1994; Westen, 1996). Surprisingly, there is no comparable taxonomy of a person's Life Space or external situations in which personality is expressed. There is, in fact, a paucity of good external criteria in personality research (Frederiksen, 1972; Funder, 2001; Magnusson \& Torestad, 1992).

In Study 1, an omnibus measure of the Life Space for college students is conceptualized and developed, the College Student Life Space Scale (CSLSS). The Life Space is based on a systems framework (Mayer, 1998), which divides data from the external environment into four broad domains that surround and interact with internal personality: biological foundations, situational elements (or possessions), daily 
interactions and activities, and group memberships. First, factor-based scales are constructed to represent each domain of the Life Space. Then, the first-order scales are treated as items themselves in a second-order analysis to develop global Life Space dimensions. A pilot study is also presented in this study, which describes the methods that were used to develop the CSLSS. The primary objective of Study 1 is to replicate and expand upon previous work on the structure of the Life Space for college students (Brackett, 2001; Mayer, Carlsmith, \& Chabot, 1998) and to improve upon its measurement and description.

The purpose of Study 2 is to empirically test how Life Space scales can be employed as external criteria to demonstrate that personality traits can predict a wide range of behaviors. Here, the trait of Openness is explored in the Life Space. In the past, Openness has been correlated with conceptually related criteria, including divergent thinking, creativity, artistic preferences, and college grades. But no study as yet has tested the criterion validity of Openness in relation to an omnibus measure that systematically covers a wide range of important health behaviors, everyday activities, personal belongings, and group memberships. Thus, in this study, the first-order scales and global dimensions from Study 1 are used as criterion measures to show how Openness is related to different aspects of Life Space. Also in this study, criterion-keyed Life Space scales are developed, which compare individual Life Space items for high and low scoring individuals on Openness. Prior to the main study, a pilot study is presented to test for preliminary associations between Openness and earlier Life Space scales (Brackett, 2001). The primary objective of Study 2 is to replicate findings from the pilot study and to expand upon existing research on the social significance of Openness. 


\section{CHAPTER I}

\section{THE LIFE SPACE}

Various definitions of the Life Space exist (e.g., Lee, 1985; Lewin, 1936, 1951; Mayer et al., 19981; Richards \& Larson, 1989), but here the term is used to denote the comprehensive environment that surrounds the individual. Because the Life Space is very large, optimal study of the Life Space requires definition of its major domains and subdivisions. In this section conceptions and current research on the Life Space are reviewed and Life Space data are explained in detail.

\section{Initial Conception of the Life Space}

Lewin (1936) initially conceptualized personality within the context of the various systems surrounding the person. He employed the term "Life Space" - the totality of factors that influence a person at any one time. For Lewin, understanding the Life Space was the "first prerequisite" for understanding an individual's actions. According to Lewin, some parts of the Life Space were objectively real (i.e., part of the physical world), others were psychological (e.g., a person's motives, emotions, and feelings), and a few were imaginary (e.g., illusions of what might happen in the future). He also emphasized the "boundary zone" where things could move in and out of the periphery of the Life Space at different points in time.

According to Lewin (1951), the primary task of the psychologist was to represent the field "correctly" as it exists for the individual in question at that particular time (p. 240). Lewin believed there were two criteria that should be adhered to when examining 
the Life Space. First, it must be determined what should be part of the Life Space at a particular point in time. The second criterion for which he argued was an accurate representation of the various components of the Life Space with an emphasis on the interdependency of its various parts (i.e., the specific contents of each domain and the relation among the various domains). For example, the Life Space of a student in Seoul, Korea is plainly different from the Life Space of a student at a small rural campus in the United States. Lewin essentially viewed the Life Space as a Gestalt in which the different parts amalgamate to form a complete picture. Despite his pioneering work in the area, Lewin never provided guidelines for exactly what is part of the Life Space and what is not. He also never developed an empirical method to measure the principal components of the Life Space.

\section{Initial Measurement of the Life Space}

Mayer et al. (1998) borrowed the term "Life Space" from Lewin and redefined it so that it strictly pertained to the external environment. Guided by a systems framework (Mayer, 1998), these researchers created a theoretical model of the Life Space, which is comprised of the interaction of four domains (biological, situational elements, interactive, and incorporative) that surround personality. The four domains emerge as surrounding personality if one depicts personality in a two-dimensional space defined, first, by a vertical molecular-molar dimension (i.e., from biological systems to the individual's psychology to societal influences) and, second, by a horizontal, internal-external dimension (i.e., from internal personality to the outside environment) as can be seen in Figure 1. 
Below internal personality is the biological domain, which includes one's physical attributes (height, weight, strength), medical history such as psychiatric diagnoses, and general health habits, including diet and sleep. To the right of personality are two domains. At the more molecular level is the situational elements domain, which consists of settings and possessions with which the person interacts (e.g., owned philosophy books, pictures of family members displayed in home, and clothing). Above this domain is located the interactive domain, which refers to individuals and situations that interact with personality (e.g., displaying affection with parent, time spent reading and listening to music, and personal hygiene habits). Finally at the top of the molecularmolar continuum is the incorporative domain, which concerns itself with socio-cultural groups that interact with personality, including memberships in certain organizations (e.g., political affiliation and varsity sports team membership), the person's family situation (e.g., socioeconomic status and residency), and other demographic variables such as ethnicity and religion.

Mayer et al. (1998) sampled over 500 items from the four domains to empirically assess the Life Space. Factor analysis of the items within each domain resulted in 26 scales that described the external environment and behaviors of college students. Furthermore, a second-order (hierarchical) factor analysis of the 26 first-order scales yielded five global dimensions: (a) Caring Environment, related to health and appearance possessions and positive interactions with family and friends; (b) Socially Active Environment, characterized by high levels of interpersonal interactions and party-going; (c) Drug Culture Environment, typified by involvement with drug-related possessions and drug users; (d) Sports Environment, involving participation in team sports; and (e) 
Isolated Environment, describing a pronounced lack of interactions with others. Both the first-order scales and global dimensions provided meaningful descriptions of college students and many of the scales were related to internal personality variables. As would be expected, extraversion correlated with the Socially Active Environment (Mayer et al., 1998).

\section{College Student Life Space Scale}

Development of the College Student Life Space Scale (CSLSS; Brackett, 2001) followed Mayer et al.' s (1998) Life Space scales. The CSLSS included a more comprehensive item sample (over 900 items versus 500 items in the original scale). In particular, the CSLSS measured underrepresented areas within each domain of the original Life Space measure (e.g., health behaviors, leisure activities, group memberships).

Each Life Space domain (biological, situational elements, interactive, incorporative) was divided into well-defined narrower areas with subcategories (Brackett, 2001). For example, the situational elements domain was divided into conceptually distinct areas such as personal care, clothing and accessories, and media-related possessions. Subdividing the domains allowed for a clearer depiction of the Life Space and it helped to gather and organize items for statistical analyses (see Figure 2).

In keeping with Mayer et al. (1998), a multi-domain factor analytic approach was used to analyze the Life Space (Brackett, 2001). This resulted in 75 factor-based scales (compared to Mayer et al,'s 26 scales) to describe college students' everyday behaviors and personal belongings. Each scale was defined by multiple items and had fairly high reliability. Brackett now had 4 scales in the biological domain, 27 scales in the situational 
elements domain, 30 scales in the interactive domain, and 14 scales in the incorporative domain. Hierarchical factor analysis of the first-order scales resulted in 6 global dimensions, which, despite the inclusion of almost 400 new items, clearly replicated and expanded upon Mayer et al.’s global dimensions.

The "Caring Environment" accounted for the most amount of variance; the highest loading first-order scales on the dimension pertained to the care of one self and others. For example, the Appearance Maintenance scale (e.g., time spent grooming) represented a clear concern of college students who convey messages about their body image and personality through the ways they present themselves to others (Cash \& Wunderle, 1987). The "Sedentary Media Consumer" dimension was comprised of firstorder scales that described a person who engages in passive activities such as playing video games and watching television. The "Music \& Arts Achievement" dimension was comprised of scales pertaining to activities that involve both skill and concentration in the area of artistic expression (e.g., playing in a band, singing in a choir, or performing in a play). The "Drug-Culture Environment" dimension contained scales pertaining to drug use, alcohol consumption, and deviant behavior. Given the soaring statistics on drug and alcohol use among college students, this is a vital aspect of the Life Space to know about (Bell, Wechsler, \& Johnston, 1997). The fifth dimension, "Introspective Lifestyle" contained first-order scales pertaining to time spent reading and writing, and time listening to blues and jazz music. Finally, the "Sports Environment" was comprised of scales pertaining to organized and leisure sports.

This replication and extension of Mayer et al,'s (1998) work supported the notion that the above dimensions of the Life Space are central characteristics of college students, 
at least in the New England area. The dimensions provided a lucid, in-depth description of the daily contexts of college students lives: what they own, what they do, whom they associate with, and the groups to which they belong. They also provided criteria that can discriminate among different types of college students. For example, students with high scores on the Sedentary Media Consumer dimension probably look different from students with high scores on the Introspective Lifestyle or Music \& Arts Achievement dimensions.

To demonstrate the utility of the Life Space, Brackett (2001) and Brackett, Mayer, and Warner (in press) correlated selected scales from the CSLSS with an ability measure of emotional intelligence (EI; Mayer, Salovey, \& Caruso, 2002). Many of the scales provided rich information about EI. For example, lower EI predicted more fighting, illegal drug use, and gambling. Individuals with lower EI were also prone to negative interpersonal relations (e.g., arguments, criticizing others). On the other hand, individuals with higher EI reported more positive relations with others (e.g., laughing, displaying affection, seeking advice) and were more likely to keep sentimental items in their possession (e.g., pictures of loved ones, old love letters).

In sum, current research has demonstrated that Life Space scales not only provide a detailed description of college students' lives, but are useful as external criteria to show how aspects of personality such as extraversion and emotional intelligence are expressed in people's everyday lives. But what exactly are Life Space data? This is the topic of the next section. 


\section{$\underline{\text { Life Space Data }}$}

For decades, researchers have measured subsets of the Life Space. Cattell (1965, p. 61), for example, collected "L-data" (life record) to represent the "personality sphere." Buss and Craik (1983) used an act-frequency approach, which specifies particular acts that correspond to different dispositional categories. This approach presumes that people will perform more acts that are prototypical of traits that describe them well than other traits that describe them less well. There is also the time diary method (e.g., Moss \& Lawton, 1982) in which respondents record the sequence and duration of activities over a specified period. Similarly, the now widely used experience sampling method (e.g., Larson, 1989) monitors people during their everyday lives and has people report on the psychological states that accompany certain activities. Finally, Craik (2000) recently developed a "lived day analysis" method in which participants use video recorders to capture daily events, in addition to writing down images, scenes, and objects that are central to understanding their lives.

The above methods and others have led to many advances in personality research. A major contribution of some methods (e.g., experience sampling) is that information is recorded during or shortly after a behavior occurs, which may increase accuracy and decreases distortion. There are also some disadvantages such as high expenses (e.g., use of pagers or beepers, camcorders) or assumptions that the day or week being assessed is typical or representative. A more general concern is that they focus on either the data's source (e.g., self-report, act-frequency) or what the data pertain to (e.g., physical health and leisure activities), when what is needed is a focus on both (Mayer, in press). The Life 
Space supplements existing methods by providing a new, comprehensive model of the person's external environment and a method for its assessment.

Conceptually speaking, Life Space data fall into a different category than traditional self-report data. They are a report of the external qualities of one's world (Mayer, in press). The data are also organized according to a comprehensive systems framework (Mayer, 1998), are based on aggregated information about the person, and are focused on a specific population at a specific point in time.

\section{Life Space Data Focus on the Observable External Environment}

Most personality data pertain to people's self-reported projected behavioral tendencies (Fiske, 1973). For example, items on an extraversion survey ask "Do you enjoy going to parties?" or "Do you prefer to be alone or with crowds?" Even surveys that intend to assess behaviors, in many cases, still assess the propensity to behave in certain ways. For example, on the Behavioral Report Form (Paunonen, 1998) people are asked to respond how honest they are compared to their friends using a 9-point Likerttype scale.

Life Space data, similar to bio-data (e.g., Mael, 1991; Stokes, Mumford, \& Owens, 1994) strictly focus on the outside world of the individual (Mayer, in press). The items are based on external, observable, discrete aspects of the individual's environment. The items are also factual, require minimal interpretations on the part of the participant, and the answers are definite and potentially verifiable. For example, the question, "How many times in the last month have you gone to a party?" is quite different from a parallel self-report of a related internal sentiment such as, "Do you enjoy going to parties?" Such question formats minimize social desirability response bias (Mael \& Hirsch, 1993). The 
rationale is that when people report on concrete, verifiable acts they are less tempted to dissimulate. Job applicants, for instance, tend to fake less when responding to bio-data questions than when responding to scales on attitudes or preferences (Becker \& Colquit, 1992; Mael \& Hirsch, 1993). The scales also show predictive validity independent of self-report inventories (Mael \& Hirsch, 1993).

Life Space Data are Organized According to a Systems Framework

The totality of the Life Space has properties that cannot be derived by summing results from studies on single-item behaviors. Furthermore, employing a limited number of criteria provides an incomplete picture of the whole person and may even mask dispositional effects (Kenrick \& Funder, 1988). Thus, the Life Space includes a broad range of criteria, which are organized according to a well-defined framework that divides the external environment into four broad domains (biological, situational elements, interactive, incorporative) (Brackett, 2001; Mayer, 1998; Mayer et al., 1998). The framework is important because it guides the sampling of items.

Recall, the biological domain pertains to the person's physical body, health behaviors, and mental health. The situational elements domain pertains to a person's personal belongings and physical environment. The interactive domain pertains to daily activities such as studying, smoking, and interpersonal relationships. Finally, the incorporative pertains to group memberships such as political affiliation and organized group memberships such as belonging to a fraternity or sorority. Together, data from the four domains provide a wide range of criteria to which personality can be expressed and understood. 


\section{The Life Space Measures Aggregated Information about a Person's Life}

A measure of behavior may be very specific as, for example, a single item measure of regularity in coming on time to a class; or much broader, such as a multiple item assessment of broad behavioral aspects of conscientiousness (Mischel \& Peake, 1982). A large number of studies employ the former, single-item assessments of behavior as opposed to the latter. Paunonen and colleagues (Paunonen, 1998; Paunonen \& Ashton, 2001), for instance, have employed a number of single-item assessments of behavior (e.g., "Have you ever engaged in a long-term diet?") in their research on the predictive validity of personality traits. The rather low correlation coefficients they obtained between personality traits and the criteria may in part be due to the high measurement error of single-item behavioral assessments. Trait influences may be more readily identified when behavioral indices are aggregated over multiple situations (Epstein, 1979, 1983; Epstein \& O’Brien, 1985) or multiple aspects of the Life Space.

All Life Space scales are comprised of multiple interrelated items. For example, a Life Space scale on dieting behavior might include the aforementioned question, but it would also have least two other questions, such as "How many diet books have you read in the last year?" or "How many times have you gone to a weight loss center in the last year?' Having more items widens the range of possible responses and lessens measurement error, which can help to strengthen predictions.

\section{Life Space Scales Target a Specific Population During a Specified Time Frame.}

Neugarten (1979) noted that society imposes normative, age-related expectations concerning the situations to which people are exposed and their expected behavior in these situations. That is, situations are not open to all people of all ages in all locations. 
Nor can it be assumed that traits will be predictive of the same behaviors at different points in time or that a measure that performs well with one population will work as successfully in another.

There are aspects of the Life Space of college students, such as specific courses (e.g., band), memberships in certain societies (e.g., fraternity/sorority), and participation in particular activities (e.g., intercollegiate sports) that may manifest as correlates of personality for college students, but not for other groups of individuals. In college, for instance, having extraverted tendencies may lead to going to lots of parties, staying out late on the weekends, and dating frequently. At age 50, however, extraversion may take on a quite different form; it may manifest itself in hosting formal dinner parties and joining many community activities (cf. Piedmont, 1998). Thus, items that measure Life Space address relevant information for a targeted population. In turn, correlations between dispositional constructs and external criteria may be higher because both inventories are tapping relevant tendencies and life experiences of the participants being studied (Owens, 1976).

Finally, Life space scales obtain assessments of behaviors for precise time frames. For example, the question "How many days in the last month have you spent at least 2 hours studying?" is used in place of "Did you study for at least 2 hours yesterday?" The first question provides more information because it aggregates across time (see Epstein, 1979), whereas the second question may not reliably or validly assess the behavior because the day being assessed may be atypical or unrepresentative of the person's habits. 


\section{CHAPTER II}

\section{PILOT STUDY: DEVELOPMENT OF THE REVISED COLLEGE STUDENT LIFE SPACE SCALE}

Brackett's (2001) Life Space measure, the CSLSS contained just over 900 items that were divided among the biological (41 items), situational elements (330 items), interactive (362 items), and incorporative (194 items) domains. Brackett's factor analyses resulted in 75 scales, which reduced the overall measure by $30 \%$ to about 600 items. Each scale had a minimum of 3 items and reliabilities of $\alpha s>.60$.

Although Brackett's (2001) CSLSS enhanced initial measurement by Mayer et al. (1998), there was still a need to improve the interpretability and reliability of some scales and to gather new items for areas of the Life Space that were underrepresented. Thus, the first step in the process of developing the revised CSLSS was to examine Brackett's scales. First, only high-quality items were retained, which left adequate room for new, better-suited items. Specifically, superfluous and ambiguous items, and items for which there were no endorsements, were eliminated from the present scale. Furthermore, only the top 15 items from the larger scales were retained so long as the scale's meaning or reliability was not altered.

\section{Gathering of New Life Space Items}

In order to obtain new items for the revised CSLSS, open-ended questionnaires were administered to male and female college students $(N=90)$. Participants answered specific questions that were based on Brackett's (2001) 75 Life Space scales. The 
questions inquired about various health factors, possessions, interactions, and group memberships that pertain to college students. For example, to gain items for the less reliable Allergy, Sinus, and Cold scale in the biological domain, students were asked to list the over-the-counter drugs and prescription medications they had purchased and used over the last year. This procedure was repeated for scales in all four domains. For example, to acquire items for the Personal Care Products scale in the situational elements domain, students were asked to list important self care products they used and owned (e.g., moisturizer, hair gel). To gain items in the interactive domain, students were asked to describe ways in which they socialize with friends and family (e.g., e-mail, cell phone, post cards), the extracurricular activities they participate in (e.g., soccer, chess), and other, more general leisure pursuits (e.g., types of movies seen, kinds of books read, music recently purchased). Finally, to supplement the incorporative domain, students were asked to list the organized clubs to which they belonged (e.g., fraternity/ sorority, academic clubs) and other, general demographic questions.

Additional items for all domains were obtained from a variety of resources such as high school and college catalogs (e.g., organized clubs and courses), various internet sites, (e.g., lists of books and music), popular magazines (e.g., electronics equipment or accessories) department store catalogs (e.g., personal care products, sports equipment, clothing), theoretical books and scholarly articles (e.g., leisure activities and interests of college students), medical checklists, and communication with health services and the counseling center at our university. 


\section{The Final Life Space Scale}

The author wrote the final version of the revised CSLSS with the help of five Ph.D. level psychologists, a senior graduate student in personality psychology, and focus groups that were comprised of numerous research assistants from undergraduate personality psychology classes. The final scale had nearly 1100 items. The items were separated into conceptually distinct areas within each domain, and in certain cases, items were further divided into narrower subcategories. For example, in the interactive domain, there was an area for interactions with people, which was divided into subcategories such as relationships with mother, father, significant other, and best friend. An outline of the domains, areas, and subcategories of the revised CSLSS can be found in Table 1.

In sum, although a systematic approach to item sampling was used to develop the CSLSS, it was admittedly impossible to cover the entire Life Space of college students. A focus was instead placed on the diversity and full representation of important aspects of the Life Space for a college student population. When building the final version of the scale every attempt was made to adequately cover the most relevant information for the biological, situational elements, interactive, and incorporative domains. 


\section{CHAPTER III}

\section{STUDY 1: DEVELOPMENT OF FIRST-AND SECOND-ORDER LIFE SPACE SCALES}

\section{Methods}

\section{Participants and Procedure}

1021 college students participated in this research. After handling incomplete, missing, and invalid data, the final sample consisted of 936 students (326 males and 610 females). Ninety five percent of the students were heterosexual, $1.2 \%$ homosexual, $2.1 \%$ bisexual, and $1.6 \%$ were questioning their sexual orientation. Most students were between 17 and 22 years (96.7\%). Just 33 students (3.3\%) were over 23 years old. The sample was also predominately white $(94.9 \%)$. About half of the participants were from New Hampshire (46.5\%); 40.5\% were from other New England states, $11.7 \%$ were from other areas of the United States, and just 1.2\% were from outside the USA. Most of the participants came from middle to upper class families as $73.8 \%$ of students reported household incomes above $\$ 60,000$. About $50 \%$ of the participant's parents went to college; a bachelors degree or higher was held by $49.1 \%$ of the mothers and $54.5 \%$ of the fathers.

The majority of the participants (73.6\%) were recruited from introductory psychology courses; the remainder of the sample came from four sections of a personality psychology course. All participants received course credit. Because multiple sessions were necessary to collect the data, participants were given id code numbers so the data 
from each session could be matched. The participants' data were kept completely anonymous and confidential. Informed consents were obtained in the first testing session and debriefing forms were presented to respondents upon completion of the study.

Originally, all participants took the revised CSLSS and personality scales in three sessions, each lasting $11 / 2$ hours. Session 1 included a measure of the Big Five, the NEO PI-R (Costa \& McCrae, 1992), social desirability scales (Paulhus, 1998), and items from the biological domain of the CSLSS. Session 2 included items from the interactive domain and Session 3 included items from the situational elements and incorporative domains. All surveys were pre-tested to make certain that students could thoughtfully complete the surveys in the allotted time.

\section{College Student Life Space Scale}

Recall, after the Life Space items were written, they were divided into conceptually distinct areas and subcategories within the four domains (biological, situational elements, interactive, and incorporative). Participants recorded their responses using a 1 to 5 scale, with higher numbers representing response categories that involve greater amounts of a behavior or numbers of possessions. This method accommodated computer scoring, which was highly efficient for collecting such large amounts of data. One disadvantage was that the resulting Life Space criteria did not strictly have interval scale properties. However, this method was successfully employed in previous studies (Ashton, 1998; Brackett, 2001; Mayer et al., 1998) and any problems concerning the metric properties of the resulting criteria were not expected to inflate correlation coefficients (Ashton, 1998). 
Biological Domain. The biological domain contained 130 items that assessed three general biological characteristics: (a) Physical Health (e.g., number of headaches in the last month, number of doctor's visits for flu in the last year), (b) Psychological Health (e.g., psychiatric diagnoses, time spent in psychotherapy), and (c) Diet, Exercise, and Sleep (e.g., physical strength, hours of sleep, and days ate breakfast).

Situational Elements Domain. The situational elements domain contained 347 items that pertained to the possessions a person keeps in his or her environment. These items were divided into various merchandising categories similar to department store catalogs, such as personal care products, clothing, and electronics. The six areas of this domain are: (a) Personal Care Products (e.g., make up, disposable razors), (b) Clothing and Accessories, which is divided into two subcategories: Apparel (e.g., button down shirts, skirts, silver bracelets) and Body Adornments (e.g., number of tattoos, number of piercings in ear), (c) Illicit Drug Possessions (e.g., bong, marijuana joints), (d) MediaRelated Possessions, which is divided into two subcategories: Books and Videos (e.g., novels, action movies), and Music Recordings (e.g., pop, jazz), (e) Room Furnishings, which is divided into four subcategories: Religious and Spiritual Items (e.g., bibles, occult objects), Home Electronics (e.g., computer, stereo), Endorsements (e.g., prochoice emblem), and Personal Room Surroundings (e.g., photos of family displayed, posters of art), and, finally (f) Sports, Avocation, and Leisure Possessions, which is divided into three subcategories: General Sports Possessions (e.g., footballs, roller blades), Instruments (bass guitar, keyboard), and Games (e.g., number of board games).

Interactive Domain. The interactive domain was measured with 480 items that were organized according to 8 broad areas: (a) Personal Care (e.g., time spent grooming), 
(b) Recreational Drug Use (e.g., alcohol consumption, illicit drug use), (c) Social

Deviance (e.g., physical fights, verbal assaults), (d) School and Work (e.g., study habits, hours worked per week), (e) Leisure and Sports, which is divided into two subcategories: Arts (e.g., arts and crafts, attending plays), and Sports (e.g., kayaking, wrestling event), and (f) Media Consumption, which is divided into two subcategories: Daily Media Consumption (e.g., pleasure reading, watching television), Internet Activity (e.g., emails received, sent), (g) Social and Solitary Activities, which is divided into two subcategories: Sexual Activity (e.g., number of romantic partners), and Social Behavior (e.g., telephone use, church attendance), and, finally (h) Interactions with Others, which is divided into interactions with Mother and Father (e.g., having a meal with mother/father), Significant Other Relations (e.g., making love, going to movies), and Best Friend Relations (e.g., attending a party, watching television together).

Incorporative Domain. The incorporative domain was measured with 133 items pertaining to socio-cultural groups that interact with personality. Incorporative memberships include general demographics and vocational (school) pursuits. Grouping of items in this domain resulted in two areas: (a) Family Demographics, which is divided into Family Social Status (e.g., parent's income, family size) and Family Biological Characteristics (e.g., depression diagnosis, heart attacks), and (b) Academic and Professional Training (e.g., physics or calculus courses and sports team memberships).

\section{Personality Measures (for Study 2)}

NEO PI-R. Big Five personality traits were assessed with the 240-item NEO-PI-R (Costa \& McCrae, 1992). This scale measures five global dimensions of personality: Neuroticism, Extraversion, Openness to Experience (Openness), Agreeableness, and 
Conscientiousness. Each dimension is a composite of 6 primary (facet) scales.

Participants complete the scale using a 1 (strongly disagree) to 5 (strongly agree) response format.

Social Desirability. Social desirability was assessed with the Paulhus Deception Scales (PDS; 1998). This 40-item questionnaire has two subscales. The first is SelfDeceptive Enhancement, the tendency to give honest but inflated self-descriptions that show a pervasive lack of insight or an unconscious bias related to narcissism. The second is Impression Management, the tendency to give inflated self-descriptions because of contextual factors (i.e., faking or lying). Participants rate the degree to which they typically perform these desirable, but uncommon behaviors using a 1 (not true) to 5 (very true) response format. Both subscales have extensive empirical confirmation of reliability and validity.

\section{$\underline{\text { Results }}$}

Results are divided into two sections. First, the development of the first-order factor-based scales for the biological, situational elements, interactive, and incorporative domains of the Life Space are presented. Then, the findings from the second-order factor analysis are presented. Prior to the results, the handling of missing and invalid data and an overview of the analyses are presented.

\section{Handling of Missing and Invalid Data}

Given the size of the CSLSS, it was expected that some participants would not take the research seriously. Thus, participants' responses were checked for missing, invalid, and inconsistent data. First, 30 of the original 1021 participants were removed because they did not complete all three testing sessions. Another 26 participants were 
removed because more than $5 \%$ of their overall data were missing. Finally, 31

participants were removed due to invalid data. These were students who provided either inconsistent or random responses to the questions. For example, if a participant had more than three questions with invalid responses (i.e., the question was restricted to a response of either 1 or 2 and the participant filled in 4) he or she was removed. Inconsistent data were checked by comparing responses on two separate but related questions. For example, the responses to the questions "How long has your longest lasting monogamous relationship lasted?" and "If you are in a monogamous relationship, how long have you been together?" were checked for response consistency. If a subject answered "one month" to the first question and " 3 years" to the second question, he or she was eliminated. After thoroughly screening the data, 936 participants were retained for the main analyses. Of note, some analyses (e.g., romantic partner relations) are based on a smaller sample because data were only available for students who reported such relationships.

\section{Overview of the Analyses}

To analyze the Life Space, multi-domain principal components analyses were performed with oblique rotations. Specifically, each domain of the Life Space was treated independently and factor analysis took place at the level of area or narrower subcategory depending on the conceptual divisions and number of items in each domain. Given the large number of Life Space items in each domain this approach was ideal because it tailored the analyses to a manageable set of items with similar qualities (cf. Mayer et al., 1998; Mayer, Salovey, Gomberg-Kaufman, \& Blainey, 1991). A clear drawback is that factors across domains may correlate. This concern, however, was addressed in the 
subsequent second-order factor analysis in which the first-order scales from each domain were treated as items themselves in a single factor analysis to develop global Life Space dimensions.

For both the first- and second-order analyses, the number of factors extracted and rotated for the final solution was decided on the basis of a joint scree/meaningfulness criterion. As recommended by Tabachnick and Fidell (2001), factor-based scales were created using the pattern matrix coefficients (after oblique rotation) because the factor loadings do not include the overlapping variance of the other factors. An item was included on a scale if its loading was above the absolute value of .30 . Complex items, that is, items with loadings on more than one factor (less than $1 \%$ ) were placed on the factor with the largest (absolute value) loading. A few complex items (less than .05\%), however, were placed on a secondary factor (based on conceptual issues) to improve the interpretation or reliability of a scale. To create the scales, all raw items were $z$-scored and then averaged. Most scales had at least 4 items and reliabilities greater than $\alpha=.60$. Finally, on a few occasions a scale with 3 items or a scale with lower reliability was retained because its conceptual importance in understanding the Life Space of college students.

\section{Development of First-Order Life Space Scales}

Biological Domain. Three factor analyses were performed to cover the 117 items in the biological domain. The items were divided into three areas: Physical Health, Psychological Health, and Diet, Exercise, and Sleep. The factor analyses resulted in 7 meaningful and reliable factor-based scales, which are displayed in Appendix A. The 
scales had between 8 and 15 items and reliability coefficients ranging from $\alpha \mathrm{s}=.60$ to .82.

Two factors were extracted from the Physical Health area, "Somatic Complaints" (e.g., stomach ache, nausea, headache) and "Allergy, Sinus, and Cold" (e.g., allergy medications, inhalers, diagnosed with asthma). Two factors were also extracted from the Psychological Health area, "Psychopathology" (e.g., prescriptions for psychotropic drugs, depression diagnosis) and "Nervous Behavior" (e.g., feelings of restlessness, chewing on pen, tap feet). Finally, three factors were extracted from the Diet, Exercise, and Sleep area, "Physical Fitness" (e.g., pounds can bench press, number of pushups can do), "Healthy Diet" (e.g., keeps bottle of water around, vegetables per day), and "Unhealthy Lifestyle" (e.g., sleeps less than 5 hours, skips dinner).

Table 2 displays the results of the independent samples $t$ tests, which examined whether there were gender differences on the scales. Significant gender differences were found for six of the seven scales. The two largest differences were found on the Physical Fitness scale, with men scoring significantly higher than women $\left(\eta^{2}=.21\right)$, and on the Healthy Diet scale, with women having significantly higher scores than men $\left(\eta^{2}=.10\right)$. There were no gender differences on the Unhealthy Lifestyle scale.

Situational Elements Domain. Fourteen factor analyses were performed on the 347 items in the situational elements domain. The analyses were broken-down by the six areas and their narrower categories described in the methods section. For two areas (Personal Care and Clothing and Accessories) factor analyses were performed separately for male and female participants due to gender specific content. For example, only female participants owned lingerie or feminine hygiene products, whereas only men owned 
aftershave or a jock strap. The factor analyses resulted in 35 meaningful and reliable scales, which are displayed in Appendix B. The scales had between 4 and 15 items and reliability coefficients ranging from $\alpha=.57$ to .86 . Due to the large number of scales, only one or two from each area are presented here.

Among numerous factors extracted from the Personal Care area, there were two scales labeled "Attention to Appearance" (one each for males and females). The items with the highest loadings on the factor for males included aftershave, shaving cream, and lip balm, whereas for females the top items included facial makeup, eye makeup, and lipstick. Three scales were extracted from the Drug Possessions area, of which one was labeled "Hard Drugs" (e.g., owns cocaine, designer drugs). Six factors were extracted from the Sports, Avocation, and Leisure area. For example, in the General Sports subcategory, there was a "Popular Masculine Sports" factor (e.g., owns footballs, basketballs, and posters of sports professionals). Six factors were also extracted from the Media Related Possessions area. In the Music subcategory, for example, there was a "Nonconforming Music" factor (e.g., owns blues, jazz, folk music). In the Books and Videos subcategory, there was a "Self-Help Books" factor (e.g., owns relationship, selfhelp, and mind/body books). Eight factors were extracted from the General Room Furnishings area. In the Religious and Spiritual subcategory, there was a "New Age" possessions factor (e.g., owns occult objects, pagan writings, and crystals). In the Personal Room Surroundings subcategory, there was a "Sentimental Objects" factor (e.g., owns photographs of friends, photo albums, photographs of family) and an "Artistic Objects" factor (e.g., owns old journals, drawing or sketches, paintings). Finally, eight factors were extracted from the Clothing and Accessories area. In the Apparel 
subcategory, for example, there were two factors, one each for females and males, labeled "Sophisticated Wear". The items that had loadings on this factor for females included: gold rings, high-heeled shoes, and lingerie, whereas for men the items included blazers, suits, and dress shoes.

Table 3 displays the results of the independent samples $t$ tests, which examined whether there were gender differences on the scales. Significant gender differences were found on 18 of the scales. The two largest differences were found on the Sentimental Objects scale, with women having significantly higher scores than men $\left(\eta^{2}=.50\right)$, and on the Hunting Equipment scale (e.g., hunting knives, hand guns) with men having significantly higher scores than females $\left(\eta^{2}=.21\right)$.

Interactive Domain. Thirteen factor analyses were performed on the 480 items in the interactive domain. Similar to the situational elements domain, factor analyses were performed on the items from within the eight areas (and subcategories) that were described in the methods section. The analyses resulted in 45 meaningful and reliable factor-based scales, which are displayed in Appendix C. The scales had between 5 and 15 items and reliability coefficients ranging from $\alpha=.48$ to .89 . Again, due to the large number of scales, only a few are described here.

Two factors were extracted from the Personal Care area, of which one was labeled, "Physical Appearance" (e.g., time spent looking in mirror, wearing jewelry, time spent choosing clothes). Four factors were extracted from the Recreational Drug Use area, including an "Alcohol Abuse" factor (e.g., greatest amount of alcohol consumed in one day, loss of memory while drinking). Four factors were extracted from the Social Deviance area, including an "Physical Aggression" factor (e.g., number of fights in the 
last two years, times threw something in a fight), and a "Verbal Aggression" factor (e.g., made fun of someone's looks, made fun of gay person). Three factors were extracted from the School and Work area, including a "Studious Lifestyle" factor (e.g., studied alone for three hours, emailed or met with a professor). Seven factors were extracted from the Sports and Leisure Activity area. For example, in the Arts subcategory, there was a "Music Achievement" factor (e.g., composed music, wrote a song), whereas in the Sports subcategory, there was a "Sports Events" factor (e.g., sports with friends, sports events attended). Six factors were extracted from the Media Consumption area, including a "Television Consumer" factor (e.g., number of different "must" watch television shows, hours of television watched per day) and an "Internet Enthusiast" factor (e.g., time spent online, times checked email). Eight factors were extracted from the Social and Solitary Activity area, including a "Promiscuous Lifestyle" factor (e.g., number of different sexual partners, number of one night stands) and a "Solitary Lifestyle" factor (e.g., spent a day entirely alone, had dinner alone). Finally, 10 factors were extracted from the Interactions with Others area. In the Parents, Significant Other, and Best Friend subcategories, there was a "Positive Relations with Mother" factor (e.g., discuss personal issues, said I love you), a "Relationship Conflict with Partner" factor (e.g., verbal arguments, talked badly about), and a "Social Activity with Best Friend" factor (e.g., went to party, drank alcohol, hanged out with).

Table 4 displays the results of the independent samples $t$ tests, which examined whether there were gender differences on the scales. Significant gender differences were found on 35 of the 45 scales. The two largest gender differences were on the Masturbation factor (e.g., times masturbated in the last week, pornography magazines), 
with men having significantly higher scores than women $\left(\eta^{2}=.36\right)$, and on the Appearance Maintenance factor, with women having significantly higher scores than men $\left(\eta^{2}=.28\right)$

Incorporative Domain. Three factor analyses were performed on the 129 items in the incorporative domain. The analyses, which took place within two broad areas: Family Demographics and Academic Setting and Group Memberships. Nine meaningful and reliable factor-based scales were extracted, which are displayed in Appendix D. The scales had between 7 and 12 items and reliability coefficients ranging from $\alpha=.53$ to .71 . Below is a brief description of a few scales.

In the Family Demographics area, two factors were extracted from the Parent's Health subcategory, including a "Parent Psychopathology" factor (e.g., mother diagnosed with depression, father diagnosed with anxiety disorder). In the Family Financial Situation subcategory there was a "Family Wealth" factor (e.g., family income, mother's education). Six factors were extracted from the Academic Setting and Group Membership area. These include a "Political Action" factor (e.g., membership in political action group, student government) and an "Academic Achievement” factor (e.g., receives academic scholarship, member of national honor society).

Table 5 displays the results of the independent samples $t$ tests, which examined whether there were gender differences on the scales. Significant gender differences were found on 6 of the 9 scales. The two largest gender differences were on the Sports Groups scale (e.g., sports awards, intercollegiate sports), with men having significantly higher scores than females $\left(\eta^{2}=.11\right)$, and on the Academic Achievement scale, with women having significantly higher scores than men factor $\left(\eta^{2}=.03\right)$. 


\section{Hierarchical Factor Analysis and Development of Global Dimensions}

The goal of this part of the study was to move to a more abstract level of analysis and synthesize the findings from the biological, situational elements, interactive, and incorporative domains of the Life Space. In previous analyses observations were limited to data that measured restricted aspects of the Life Space such as physical strength (biological domain) or positive relationship qualities (interactive domain) because factor analyses were conducted within each domain. However, it was likely that a number of first-order scales from different domains would intercorrelate to potentially form aggregated global Life Space dimensions. A second-order analysis, therefore, would reduce the first-order scales into a more manageable set of criterion measures. Moreover, larger, more comprehensive dimensions may increase predictive validity of some traits.

Both Brackett (2001) and Mayer et al. (1998) successfully employed hierarchical factor analyses in their work on the Life Space. Recall, Brackett reduced the first-order Life Space scales to 6 global dimensions, which were labeled: Caring Environment, Sedentary Media Consumer, Introspective Lifestyle, Music Achievement Environment, Sports Environment, and Drug-Culture Environment. The Music Achievement Environment, for instance, was comprised of interrelated scales from the situational elements domain (e.g., owns musical instruments), interactive domain (e.g., practices with instrument), and the incorporative domain (e.g., belongs to a band).

Hierarchical Analyses. For the hierarchical analyses employed here, 82 of the 95 first-order scales were subjected to a single second-order factor analysis. Thirteen scales were excluded because data were not available for the full sample. These were first-order 
scales that pertained to romantic partnerships (data were only available for half the sample) or scales for which information was only available for females or males. A primary objective of this part of the study was to replicate and expand upon the global dimensions developed by Brackett (2001), with an increased item-pool and a new, larger group of participants.

A single principal components factor analysis with oblique rotation was used, and the final number of higher-order factors was extracted using the same joint scree/ meaningfulness criterion. The eigenvalues for the first 10 factors were $7.61,5.82,4.40$, $3.74,2.74,2.28,2.01,1.71,1.63$, and 1.54 . Based on the previously mentioned criteria, eight global dimensions were extracted, which collectively accounted for $37 \%$ of the variance in the initial solution of first-order factors. The eighth factor was difficult to interpret; it also contained the fewest scales and was less reliable than the other dimensions. This factor was dropped from subsequent analyses.

The seven remaining global dimensions were labeled: Positive and Social Orientation, Sports Orientation, Drug Culture Environment, Music \& Arts Achievement, Media Consumer, Negative and Unhealthy Lifestyle, and Intellectual Pursuits. All of the global dimensions were comprised of at least 7 first-order scales, and most brought together aspects of biological, situational elements, interactive, and incorporative domains. The dimensions were both reliable $(\alpha=.65$ to .79$)$ and content valid. Appendix E displays the first-order scales that loaded on the global dimensions. Recall, the primary scales that comprised the global dimensions can be viewed in Appendices A-D.

Table 6 displays the results of the independent samples $t$ tests, which examined whether there were gender differences on the global dimensions. Significant gender 
differences were found on 6 of the 7 dimensions. Consistent with previous work, the largest gender differences were on the Positive and Social Orientation factor, with females having significantly higher scores than males $\left(\eta^{2}=.22\right)$, and on the Sports Orientation factor, with males having higher mean scores than females $\left(\eta^{2}=.19\right)$. The pattern of correlations among the dimensions, which can be seen in Table 7 , was similar for both males and females, and ranged between $r s=.04$ to .47 for males and $r s=.01$ to .37 for females.

The "Positive and Social Orientation" dimension accounted for the most amount of variance and was comprised of 8 first-order scales from the interactive domain. The scales with the highest loadings were: Positive Relations with Mother (e.g., discusses personal issues, says, "I love you", converses with often), Positive Relations with Father (e.g., Converses with, laughs with, seeks advice from), Social Activity with Parents (e.g., Went to concert or cultural event with mother and/or father), and Positive Relations with Best Friend (e.g., Seeks advice from, had long conversation, laughed with). The dimension was also comprised of scales pertaining to other social behaviors. For example, the Telephone Enthusiast (e.g., different people talked to each day, time of longest phone conversation), Social and Party Orientation (e.g., number of good friends, number of parties has gone to), and Appearance Maintenance scales (e.g., time spent looking in mirror, time spent choosing clothes to wear) were also on this dimension. It is worth mentioning that four first-order scales (Positive Relations with Partner, Social Activity with Partner, Attention to Appearance, for both males and females) that were not included in the hierarchical analyses correlated in expected directions ( $r \mathrm{~s}=.17$ to .42$)$ with this global dimension. 
The second dimension "Sports Environment," consisted of 8 primary scales, and combined first-order scales from all four Life Space domains. The scales with the highest loadings were: Physical Fitness (e.g., pounds able to bench press, times exercised), Sports Groups (e.g., sports awards, participates in intercollegiate sports), Sports Consumption (e.g., plays sports with friends, sports events attended), and Masculine Sports Orientation (e.g., owns footballs, posters of sports professionals). Finally, to a lesser degree, this dimension was comprised of Hunting activity (e.g., hunting, gun shooting), and Hunting equipment (e.g., hunting knives, hand guns, fishing rod).

The third global dimension, "Drug Culture Environment," was comprised of 9 first-order scales from the interactive and situational elements domains. The scales with the highest loadings were: Illicit Drug Abuse (e.g., times smoked marijuana, has sold illegal drugs), Smoking Possessions (e.g., owns bong or pipe, cigarette lighter, marijuana joints), Smoking Addiction (e.g., packs of cigarettes owns, smokes before breakfast), and Alcohol Abuse (e.g., greatest amount of alcohol consumed in one day, times vomited because of drinking). In addition, the Promiscuous Lifestyle (e.g., different sexual partners, cheated on current partner) and Delinquent Student (e.g., arrived to class late, intentionally skipped class) scales were part of this dimension.

The fourth global dimension, "Music \& Arts Achievement," was comprised of 7 first-order scales, and brought together aspects of the situational, interactive, and incorporative domains. The first-order scales with the highest loadings on this dimension were: Music Ability and Achievement (e.g., composed music, wrote a song, played in band), Musical Instrument Ownership (e.g., owns bass guitar, acoustic guitar), Artistic Expression and Appreciation (e.g., has gone to plays, acted on stage, gone to see local 
band gig), and Music \& arts Groups (e.g., music courses taken, belonged to band or orchestra, music theatre).

The fifth global dimension, "Media Consumer," consisted of 8 primary scales, all from the situational elements domain. Together these scales depicted a person who surrounds him or herself with media-related materials. The scales with the highest loadings were: General Media (e.g., owns television, stereo), Challenging Games (e.g., owns board games, chess set), Video Game Possession (e.g., has video cartridges, video game machine), and Movie Orientation (e.g., owns comedy, drama, action tapes). This dimension was also comprised of scales pertaining to larger music collections, including: Popular Music (e.g., R\&B, pop, hip hop recordings) and Alternative Rock Music (e.g., hardcore, hard rock, and punk music).

The sixth global dimension, "Negative and Unhealthy Behavior", consisted of 9 primary scales from the interactive and biological domains. The primary scales on this dimension with the highest loadings were: Nervous Behavior (e.g., feelings of restlessness, chews on pen, taps feet), Somatic Complaints (e.g., has had stomach ache, felt dizzy, had headache), and Relationship Conflict with Parents (e.g., dad screamed at, did not speak to father). This dimension was also comprised of scales such as: Verbal Aggression (e.g., made fun of someone's appearance, hurt someone's feelings), Physical Aggression (e.g., number of fights in the last two years, has been knocked unconscious in a fight), and Stealing (e.g., has stolen something small, switched tags, sneaked in theatre). In addition, this dimension contained scales pertaining to poor health issues as seen in the Unhealthy Lifestyle (e.g., sleeps less than 5 hours, skips meals). Finally, it is worth 
noting that the Relationship Conflict with Partner scale that was not included in the hierarchical analysis correlated in the expected direction with this dimension $(r=.42)$.

The seventh, and final global dimension, "Intellectual Pursuits" brought together 11 first-order scales from all four Life Space domains. The scales with the highest loadings were: Book Consumer (e.g., reads for pleasure, number of novels read), Conversationalist (e.g., has had conversations about politics, books, philosophy), and Reading Orientation (e.g., owns large numbers of science fiction, comic/joke, philosophy books, etc.). Also on this dimension were the Studious Lifestyle (e.g., studied for 3 hours, read over class notes) and Liberal Political Endorsements (e.g., owns emblems of environmental issues, world peace) scales. Artistic Objects (e.g., has old diaries, drawings and sketches, posters of art) and Psychopathology (e.g., depression diagnosis, time spent in therapy) also had relatively high loadings on this dimension.

\section{Discussion}

Guided by a systems framework (Mayer, 1998) the biological, situational elements, interactive, and incorporative domains of the Life Space were examined for college students. Each domain was conceptually subdivided and 96 factor-based scales were developed that described college students' external surroundings and everyday behavior. There were now 7 scales in the biological domain, 35 scales in the situational elements domain, 45 scales in the interactive domain, and 9 scales in the incorporative domain. Each scale was defined by a minimum of three items and most scales had fairly high reliability.

A second-order factor analysis reduced the primary scales to a more manageable set of 7 global dimensions. The global dimensions were labeled: Positive and Social 
Orientation, Sports Orientation, Drug Culture Environment, Music \& Arts Achievement, Media Consumer, Unhealthy and Negative Lifestyle, and Intellectual Pursuits. Each of the global dimensions was comprised of at least 7 first-order scales, and in many cases brought together first-order scales from multiple domains. The global dimensions were reliable and content valid.

\section{Improvements in the First-Order Scales}

This study broadened the scope of the college student's Life Space. Considerably more primary factors ( $N=96$ scales) were developed here compared to the 75 scales developed in prior research (Brackett, 2001) and the 26 scales first developed by Mayer et al. (1998). More factors with higher reliabilities were found in each domain (i.e., biological, situational elements, interactive, and incorporative). Due to the large number of primary factors, only a few highlights from each domain will be discussed here.

In the biological domain, two new meaningful scales were extracted: Somatic Complaints (e.g., stomach ache, nausea, dizziness, indigestion, constipation) and Healthy Diet (e.g., drinking water, eating vegetables and fruit, not eating fried foods, taking vitamins). Other scales in this domain were improved replications of earlier scales. The Physical Fitness scale, for instance, became more reliable (e.g., pounds can bench press, number of pushups, outside sports activity per week, gym exercise, and eating strength building foods such as milk and red meat).

Most scales in the situational elements domain replicated and expanded upon Brackett's (2001) scales. Some scales became differentiated into two more distinct and meaningful scales. For example, in place of Brackett's single measure of religious and spiritual possessions, two factors were extracted here: Religious Possessions (owning 
crucifixes, rosary beads, and a bible) and New Age possessions (e.g., occult objects, pagan writings, and crystals). This distinction provided a clearer picture of varied religious and spiritual beliefs held by students.

Similar to the situational elements domain, many of the scales in the interactive domain replicated and extended Brackett's (2001) scales. However, a number of new scales also emerged in this domain. For example, instead of a single social deviance factor, two separate scales were extracted here. The first was Verbal Aggression (e.g., making fun of someone's appearance) and the other was Physical Aggression (e.g., physical fights). This distinction was important because there was a restriction of range in scores for females on the social deviance scale, which was mostly comprised of physical and aggressive behaviors. The scale lacked verbal aggressive tactics (e.g., gossiping) that are commonly used by women (White, 2001). Also in this domain, two behavioral measures for school-related study habits were developed. The Studious lifestyle (e.g., times studied alone for 3 hours, times emailed or met with a professor) measured good habits, whereas the Delinquent Student (e.g., times arrived late to class, times skipped class) measured negligent behavior. Finally, the Conversationalist (e.g., times talked about news, politics, philosophy) was an altogether new and interesting scale.

Scales in the incorporative domain were also improved upon in this study. For example, the Political Action (e.g., belongs to political action, campus concerns, student government) and Family Wealth (e.g., parents income, financial aid received (reversed), mom's and dad's education, size of primary residence) scales both had more items and were more reliable than Brackett's (2001) scales. Also in this domain, a new and highly 
informative Academic Achievement scale (e.g., received academic scholarship, member of national honor society, number of AP exams passed) was developed.

The success of the development of the first-order scales was probably due to a number of improvements over previous studies, including the removal of poor items, the addition of new items from the pilot study, and the superior factor analytic strategy employed in this study. A major innovation relative to previous studies was that factor analyses were organized according to clearly defined areas (and subcategories) within each Life Space domain, which permitted items in each domain to cluster and form. distinct sets of meaningful factors.

\section{Improvements in the Global Dimensions}

A central finding in this study was the similarity between the 7 global dimensions developed here, the 6 global dimensions found by Brackett (2001) and the 5 global dimensions originally found by Mayer et al. (1998). For example, across all three studies a Sports Environment and a Drug-Culture Environment emerged. Something similar to the present Positive and Social Orientation also emerged in the earlier studies. Moreover, two of Brackett's global dimensions, Music \& Arts Achievement and Media Consumer were almost perfectly replicated in this study.

The global dimensions also became more clearly defined in the present work. For example, the Drug-Culture Environment found by Brackett (2001) and Mayer et al. (1998) was now separated into two distinct dimensions. In earlier studies the DrugCulture Environment was comprised of scales that broadly assessed relationship conflict, alcohol consumption, drug use, and promiscuity. Here, a clearer Drug-Culture Environment was extracted, which included scales addressing drug-related possessions 
and activities, but an altogether new dimension emerged, the Unhealthy and Negative Lifestyle. This last dimension brought together scales pertaining to adverse life conditions, including poor health, nervous behavior, relationship conflict, and aggressive behavior. Finally, the Intellectual Pursuits dimension (e.g., Book Consumer, Self-Help Books, Political Action, Conversationalist) that emerged in this study resembled Brackett's (2001) Introspective Lifestyle. But here, Intellectual Pursuits was more clearly defined by first-order scales that reflect liberal politics, philosophical interests, and introspection. Moreover, the music-related scales that were part of Brackett's Introspective Lifestyle dimension were now more clearly and appropriately placed on the Music and Arts Achievement dimension.

The substantial overlap between earlier dimensions and the 7 dimensions developed in this study supports the notion that the Life Space brings together central features of college students' lives. The present findings also converge with research that has developed typologies of college students (e.g., Astin, 1993; Kuh, Hu, \& Vesper, 2001). For example, Kuh et al.'s typology of college students was comprised of groups, which were termed: “Artist," "Intellectual," "Recreational," and "Socializer". These groups imply something like the existence of the Music and Arts Achievement, Intellectual Pursuits, Sports Orientation, and Positive and Social Orientation dimensions. One noteworthy difference between Kuh et al.'s typology and these global dimensions is that the former are comprised of strictly campus-related activities, whereas the Life Space assesses other important aspects of students' lives, including possessions, personal habits, and non school-related activities such as illegal drug use and sexual behavior. 
The global dimensions also describe overarching elements of college students' lives. For example, the Positive and Social Orientation is likely a stable dimension in a college student sample; it explained the largest amount of variance in this study and in earlier studies. Together, the first-order scales that comprised this dimension (e.g., positive relationships their mother, father, and friends, active social life) seem like an environment created by people who are higher than the norm in both extraversion and well-being. The dimension is important to know about given findings, which show that social support, networks and activities performed with others are linked to psychological well-being in college students (Cooper, Okamura, \& Gurka, 1992; Monroe \& Steiner, 1986; Watson, Clark, McIntyre, \& Hamaker, 1992). Because the Appearance Maintenance and Sentimental Objects scales both reflect self care and care for others, it is not surprising that they were also part of this dimension.

The Sports Orientation Environment, which is comprised of organized and leisure sports activities, plays a large role in many college students' Life Space. Abundant research shows that interest or involvement in certain sports may constitute a symbol system that communicates something about a person's personality and identity (Franken, Hill, \& Kierstead, 1994; Sadalla, Linder, \& Jenkins, 1988). For example, Owens \& Schoenfeldt (1979) extracted a "Conservative Athlete" in their typology of students. The number of sports a student participates in has also been associated with motivational traits for physical exercise and social contact (Reiss, Wiltz, \& Sherman, 2001). For females, in particular, participating in sports may promote self-worth by fostering physical competencies, favorable body images, and gender flexibility (Richman \& 
Shaffer, 2000). Finally, participation in sports may be a protective agent against suicidal behavior for both male and female college students (Brown \& Blanton, 2002).

The Drug-Culture Environment is yet another vital part of the college student's Life Space. Given the soaring statistics on drug and alcohol use among college students, it is no wonder that this defined its own area of the Life Space (e.g., O’Malley \& Johnson, 2002). For example, at the University of New Hampshire, where this study was conducted, a separate study using a representative sample of first year students revealed that in the month of February $2001,83 \%$ of the students had drank alcohol, $40 \%$ had smoked marijuana, and between 5 and 10\% had used amphetamines, sedatives, or other designer drugs such as ecstasy. Students in this second study also reported having had at least one hangover $(69 \%)$, argument or fight $(32 \%)$, or unprotected sexual act $(19 \%)$, while drinking alcohol or using drugs (University of New Hampshire, 2001). Further investigations in this area may be of considerable use in identifying students who have a propensity toward drug addiction (cf. Bentler \& Newcomb, 1986) or students who are susceptible to stress, which may underlie drug abuse (Shedler \& Block, 1990). Finally, the links between drugs and other problem behavior supports the inclusion of the Delinquent Student and Promiscuous Lifestyle scales on this dimension (Bell et al., 1997).

The Music and Arts Achievement scale represents another major dimension of the Life Space for college students. This is supported by a study in which over $50 \%$ of 2,645 participants reported they were currently playing an instrument or had played regularly one in the past (North, Hargreaves, \& O'Neill, 2000). The students in that study also listened to music for an average of 2.45 hours per day and reported a preference for 
listening to music over other indoor activities. This dimension is probably central to college students because music plays multiple roles in one's life; it can be recreational, educational, social, emotional, therapeutic, and spiritual (Hay, Bright, Minichello, 2002). Finally, this dimension is a strong candidate as a criterion for personality characteristic such as flow and Openness. Most of the activities that comprise this dimension, including artistic activity, playing in band, and acting on stage have been associated with Openness and people's reports of flow experiences (Csikszentmihalyi, 1992; Cost \& McCrae, 1992).

The Media Consumer (i.e., owned possessions such as such as electronics equipment, video games, movies, and computers) has theoretical resonance to past and contemporary research in psychology. William James (1890, pp. 291-292) cited in Belk (1998), for instance, held that: "a man's Self is the sum total of all that he CAN call his, not only his body and his psychic powers, but his clothes and his house...his lands, and yacht and bank account..." The possessions that comprise the Media Consumer such as large popular music collections and other collectibles (e.g., posters, beer bottles) may be a major contributor to and reflection of college students' identities (Belk, 1988; Csikszentmihalyi \& Rochberg-Halton, 1981; Wallendorf \& Arnould, 1988). This dimension is also relevant given that contemporary society is often characterized as a "culture of consumption," which comes with ideologies that suggests to students that they are worthy members of society to the extent that they can afford and own consumer goods (Kasser \& Sheldon, 2000).

The Unhealthy and Negative Lifestyle, forms an interesting contrast to the first dimension, Positive and Social Orientation dimension. This dimension was comprised of 
reports of nervous behaviors such as chewing on pens, somatic complaints, problematic relationships, and aggressive behavior. This dimension may characterize an environment created by people who are higher than the norm on neuroticism and lower than the norm on agreeableness. The Unhealthy and Negative Lifestyle is important to consider given the substantial literature linking Nervous Behavior, highest loading first-order scale on the this dimension, to poor academic achievement (see Zeidner, 1998 for a review). The dimension also seems an urgently important aspect of the Life Space to know about based on the concerns about violence as a serious problem plaguing our nation and its schools. For example, in one study of college students $(N=385), 63 \%$ of the participants were able to describe a physical altercation that they recently had, with almost $10 \%$ reporting suffering injuries that required medical attention (Marcus \& Reio, 2002).

The seventh and final dimension, Intellectual Pursuits, depicts, more than any other dimension, an aspect of the Life Space characterized by an academic subculture of students who seek to broaden their knowledge and engage in more intellectual activities. The person with high scores on this dimension may be characterized as having a "scholastic motive," or driven by intellectual stimulation for purely academic reasons (Bogler \& Somech, 2002, p. 234). The Intellectual Pursuits dimension appears to reflect an outward expression of three facets of Openness (Costa \& McCrae, 1992): feelings, ideas, and values. This is evidenced from the first-order scales with high loadings on this dimension (e.g., Book Consumer, Self-Help Books, Political Action, Conversationalist). The relevance of this dimension is supported by research, which shows that political efficacy has increased in college student samples, whereas apathetic and cynical attitudes about politics have decreased (Blackhurst, 2002). 


\section{CHAPTER IV}

\section{OPENNESS TO EXPERIENCE}

Openness (or Intellect/Culture) is the fifth dimension of the Five-Factor Model of personality. It is referred to as the fifth dimension because in lexical studies the fewest adjectives represent it. In general, people who are Open to Experience perceive themselves as having a broad and deep scope of awareness and a general need to broaden and examine life. They characterize themselves as imaginative, aesthetically responsive, empathic, exploring, curious, and unconventional (McCrae, 1994, 1996; McCrae \& Costa, 1997). High scoring individuals on this dimension are curious about both their inner and outer worlds, and their lives are experientially richer than those who are closed to experience.

Of all the Big Five factors, Openness is the most controversial and the least developed and explored (see McCrae, 1994; Trapnell, 1994; Saucier, 1992). For example, there have been debates as to whether this dimension should be labeled Openness or Intellect or whether these traits should be measured with trait words or short descriptive statements. McCrae (1994) prefers the term Openness and asserts that the terms Intellect and Openness have different evaluative connotations. For example, using the term Openness as opposed to Intellect clarifies that this factor is not equivalent to general intelligence. People with high scores on Openness are only slightly more intelligent than 
closed people, and when both constructs are placed in a joint factor analysis two separate factors are formed (McCrae and Costa, 1985).

\section{Openness on the NEO PI-R}

Openness (or Intellect) can be measured with adjective checklists (e.g., Goldberg, 1990 or short self-descriptive statements (e.g., Costa \& McCrae, 1992). To date, the most comprehensive, and best-validated measure of Openness is on the revised NEO Personality inventory (NEO PI-R, Costa \& McCrae, 1992). Because descriptive sentences are used, the NEO PI-R permits differentiated measurement of specific facets or narrower traits of Openness, which allows for more detailed articulations of the qualities subsumed by each factor. The facets were selected on the basis of their psychological relevance and descriptive diversity (see Costa \& McCrae, 1995 for more details).

On the NEO PI-R Openness is a composite of six facets: fantasy, aesthetics, feelings, actions, ideas, and values. The fantasy, feelings, and ideas facets focus on a person's inner world, whereas the aesthetics, actions, and values facets focus on the person's outer world. Specifically, individuals who are open to fantasy have vivid imaginations and fantasies. Low scoring individuals are more ordinary and prefer to keep their minds on the task at hand. Individuals who are open to aesthetics have a deep appreciation for art and beauty and are also moved by poetry, music, and art. These individuals do not necessarily have artistic talent, but they do have a deep understanding of and appreciation for it. Low scoring individuals are relatively insensitive to and uninterested in art and beauty. Individuals who are open to feelings are receptive to their own and others feelings, experience deeper and differentiated emotional states, and report 
more intense feelings. Low scoring individuals are somewhat less excitable and do not believe that feeling states are of much importance. Individuals who are open to actions are adventurous and are willing to try different things such as new activities and foreign foods; they also prefer variety to routine. Low scoring individuals find change difficult, and prefer to stick with the tried and true. Individuals who are open to ideas are curious, inventive, and may have unconventional ideas. Low scoring individuals have limited curiosity and are unappreciative of intellectual challenges. Finally, individuals who are open to values have a readiness to reexamine social, political, and religious values and are more broad-minded and non-conforming types. Low scoring individuals honor tradition, and are generally more dogmatic and conservative. More complete descriptions of Openness and its facets can be found elsewhere (Costa \& McCrae, 1992; Piedmont, 1998)

\section{Correlates of Openness}

There is an abundant literature relating Openness to other personality variables. For example, Open people are known to have artistic and imaginative interests (Costa, McCrae, \& Holland, 1984), to score higher on measures of Gough's (1979) measure of creativity personality (Costa \& McCrae, 1992), and to be more to be more individualistic (Dollinger, Ross, \& Preston, 2002). Closed people on the other hand have a hard time understanding and adapting to other's perspectives (Gurtman, 1995) and have higher scores on measures of homophobia (Cullen, Wright, \& Alessandri, 2002). More detailed reviews of the internal personality correlates of Openness can be found elsewhere (e.g., McCrae, 1994, 1996; McCrae \& Costa, 1997). 
Part of making sense of personality traits, however, requires putting them into a broader context and showing how they form the context for specific behaviors (McCrae \& Costa, 1995). There is a surprising lack of research on the external behavioral correlates of Openness. That is, relatively few studies have examined important social outcomes of Openness. A brief overview of the external correlates of Openness is reviewed.

McCrae and Costa (1997) emphasize the relations between Openness and aesthetic preferences, asserting that artists can be seen as exemplars of Openness. It is no surprise, therefore, that studies report correlations between Openness and creative performance and divergent thinking (Costa \& McCrae, 1992; McCrae, 1996). Moreover, Openness correlates with specific behaviors, including self-reported creative acts in visual, performing, literary, and domestic arts (Griffin \& McDermott, 1998). Openness is also linked to playing musical instruments (Paunonen, 2003) and preferences for musical and art forms outside the mainstream (Dollinger, 1993).

Openness has also been related to a number of mental health outcomes such as depression (Wolfenstein \& Trull, 1997). It appears that two of its facets (aesthetics and feelings) have the highest correlations with depression. Other studies have found interaction effects between Openness and depression; in one study, for example, women who scored higher in fantasy were more susceptible to depression than men (Carrillo, Rojo, Sanchez-Bernardos, \& Avia, 2001). Finally, to a smaller extent, Openness correlates with both positive and negative affect (McCrae \& Costa, 1991). Although this finding seems paradoxical, it is consistent with the notion that Open people tend to experience emotions, both positive and negative, more intensely than others. 
In a few studies, the relation between Openness and political ideology, religiosity, and prejudice attitudes was examined. Because Open individuals perceive themselves as broad-minded, it is not surprising that it is positively correlated with liberal political and social values, and negatively correlated with right-wing political ideology (Griffin \& McDermott, 1998; McCrae, 1996; Trapnell, 1994). In one study the correlation between Openness and right-wing authoritarianism was $(r=-.57$; Trapnell, 1994). Paunonen also reported a positive association between Openness and self-reported religiosity (Paunonen, 1998).

Finally, Openness may have an impact on interpersonal relations. For example, McCrae (1996) reviewed research that showed high cross-spouse correlations between Openness-related traits $(r s=.19$ to .69$)$, and among the Big Five, assortment effects are the strongest for Openness.

Beyond the above findings, it would be valuable to relate Openness to an omnibus measure of a person's Life Space. This would provide a complete illustration of the Open person's health habits, personal belongings, daily behavior, and group memberships.

Given the breadth of the Life Space, failure to find evidence for the criterion or external validity of Openness with the Life Space would be noteworthy; such a result could mean that the construct cannot be usefully applied, at least for college students in the United States. 


\section{CHAPTER V}

\section{PILOT STUDY: EXPLORING OPENNESS AND ITS CORRELATES IN THE LIFE SPACE}

A pilot study ( $N=330 ; 89$ males, 241 females) was conducted in which Brackett's (2001) Life Space scales were correlated with a 10-item measure of Openness (or Intellect; Goldberg, in press). Here, the term Openness is used for purposes of consistency. Research has shown that measures of Intellect and Openness load on a single factor when combined in a factor analysis (Saucier, 1992). The goal was to provide a first look at the relations between Openness and the Life Space. The pilot study also helped to develop hypotheses for the main study, to assess whether there are gender differences in the correlations between Openness and the Life Space, and finally, to offer insight as to the most appropriate analyses for the main study.

\section{Gender Differences in Openness and the Life Space}

In order to assess whether there were significance differences between male and female mean scores on Openness, an independent samples $t$ test was conducted. No significant gender differences were found. Subsequently, independent samples $t$ tests were performed to assess whether there were significant gender differences on the Life Space scales. Significant differences were found on 35 of the 75 scales, indicating that men and women differed in many aspects of their respective Life Spaces. Most of the significant differences were small. Men, for example had slightly larger rock and roll CD collections than women, whereas women had somewhat larger collections of popular 
books and novels than men $\left(\eta^{2}=.09\right.$ and .06 , respectively). Other differences, however, were moderate to strong. Women, for example, had larger collections of pictures and sentimental memorabilia than men, whereas men were more likely to engage in delinquent behavior than women $\left(\eta^{2}=.25\right.$ and .40 , respectively). Therefore, there are clear gender differences in what men and women purchase (e.g., music selection), what activities or behaviors they become involved in (e.g., delinquent conduct), and even the groups to which they belong.

\section{Correlations Between Openness and the Life Space}

Correlations between Openness and the Life Space scales were conducted separately for males and females, and also for the full sample. The goal was to assess whether gender interacts with Openness in the prediction of the criteria, or more generally, whether Openness is correlated with the same or different aspects of the Life Space for males and females.

As seen in Table 7, Openness significantly correlated with 23 scales from all domains of the Life Space. More specifically, Openness correlated with 2 scales in the Biological Domain, 10 scales in the Situational Elements Domain, 7 scales in the Interactive Domain, and 4 scales in the Incorporative Domain.

Most of the findings were consistent with the general prediction that Openness would be related to aspects of people's personal surroundings, activities, and group memberships that reflect a person's broad and deep scope of awareness, general tendency to appreciate aesthetics, and need to enlarge and examine life. For example, Openness correlated positively with the following factor-based scales: Pictures and Sentimental Objects (e.g., keeping pictures of loved ones in one's surroundings), Arts and Philosophy 
Books, Blues and Jazz Recordings, Self-Reflection (e.g., going to a place to relax by oneself, meditation), Music and Reading Enthusiast (e.g., time spent listening to music, number of books read), Artistic Creativity (time spent pursuing arts and crafts, drawing or sketching), Artistic Expression and Appreciation (e.g., practicing a musical instrument, going to a concert), Music and Arts Courses (e.g., band), and Music and Arts Groups (e.g., drama club). Finally, Openness was strongly associated with the Music and Arts Achievement global dimension $(r=.44$; Brackett, 2001). The magnitude of this correlation is not surprising because this dimension an aggregate of many first-order scales that correlated with Openness.

Some of the correlations suggested an interaction between gender and Openness as predictors of the Life Space criteria. That is, the size of the correlation between Openness and the Life Space scales was different for men versus women. For example, the correlation with Solitary Lifestyle (e.g., lack of new friends and eating dinner alone) was $(r=.23)$ for males, whereas for females it was $(r=-.09)$. The difference in this correlation for males and females was statistically significant, suggesting that the relations between these two variables may be different for each gender. Openness was also positively correlated with a Hunting Equipment scale (e.g., owns fishing rod, bb gun) for female participants, but not for male participants. Larger gender differences were found, for example, on the Physical Fitness (e.g., pounds able to bench press) scale, which was negatively correlated with Openness for males $(r=-.25)$, but positively correlated with Openness for females $(r=.18)$.

In sum, the results of the pilot study broaden the small body of research on the correlations between Openness and external criteria. Admittedly, a large number of 
correlations between Openness and the Life Space were examined and at least some of the correlations may have reflected Type I error. For example, it is unclear why Openness was correlated with the Casual Clothing scale. On the other hand, the large number of significant findings and the agreement between the results of the pilot study and prior research on the correlates of Openness give credibility to the findings.

Now that there is a basis from which to conduct research of this sort, in the main study it will be possible to run a more limited set of predicted correlations to see whether the relations among these variables can be replicated and confirmed. Also in the main study, the following questions can be addressed: Will a more robust and reliable measure of Openness have higher validities with Life Space criteria? Will improvements in measurement of the Life Space increase the criterion validity of Openness? What else might Openness correlate with? To answer these questions, the main study will focus on relations between a new, robust measure of Openness, and a new, more powerful measure of the Life Space. 


\section{CHAPTER VI}

\section{STUDY 2: OPENNESS EXPRESSED IN THE LIFE SPACE}

One central concern of personality psychology is to understand traits in terms of their external correlates (Funder, 2001). Thus, the purpose of this study is to relate Openness to the first- and second-order Life Space scales developed in Study 1. All predictions are based on the results of the pilot study and a review the literature on Openness. Also in this study, criterion-keyed scales were developed to compare Life Space items for extreme groups of high and low scoring individuals on Openness.

Methods

\section{Participants}

Participants were the same 936 male and female college students described in Study 1.

$\underline{\text { Measures }}$

Recall, all measures (Life Space and personality) were presented in Study 1 and were originally administered in three testing sessions.

In this study the predictor variable was Openness from the NEO PI-R (Costa \& McCrae, 1992). The criterion variables were the 7 Life Space scales from the biological domain, 35 scales from the situational elements domain, 45 scales from the interactive domain, 9 scales from the incorporative domain, and the 7 global dimensions that were constructed in Study 1. 


\section{Results}

Results are divided into three sections. In the first section, an overview of the analyses is presented and preliminary analyses are conducted on Openness. The second section presents both predicted and exploratory relations between Openness and the firstscales and the global dimensions of Life Space. Finally, the third section presents the criterion-keyed Life Space scales, which were based on extreme groups of individuals on Openness.

\section{Overview of the Analyses}

Previous research on the predictive validity of the Big Five has controlled for participant sex to assess the extent to which personality traits add to the prediction of a criterion beyond what is predicted by sex (e.g., Paunonen, 1998; Paunonen \& Ashton, 2001). In the present study, participant sex was also statistically controlled because there was interest in whether personality variables predicted various behaviors independently of sex differences that may have been common to the predictor and criterion.

The goal of this study, however, was to use a more thorough approach to studying the effects of gender. There were two general ways to address this concern. The first was to use multiple regressions, entering Openness, sex, and the interaction terms between sex and Openness as predictors of the criteria. This would show whether the regression slopes are significantly different for males and females on Openness when predicting the criteria.

A second way to address gender is to conduct analyses separately for males and females. This approach would assess whether Openness predicts different amounts of variance in the criteria for men and women. Because the central goal of this study is to 
understand personality in terms of its expression in the Life Space, this latter approach was employed. This allowed for a clearer story to be told because the results could be presented in a way that shows, for example, that Openness has a strong, positive and significant relation to an aspect of the Life Space for women but not for men and vice versa.

\section{Preliminary Analyses}

Table 9 shows the reliabilities, descriptive statistics, and results of the independent samples $t$ tests to assess whether there were gender differences on Openness and its facets. The total Openness scale was highly reliable $(\alpha=.88,48$ items), whereas the facets were slightly less reliable ( $\alpha s=.52$ to $.77,8$ items in each scale). Significant gender differences were found on total Openness and on all six facets. The largest gender differences were on Openness to Feelings $\left(\eta^{2}=.09\right)$, with females scoring significantly higher than males, and on Openness to Ideas, with men scoring significantly higher than females $\left(\eta^{2}=.03\right)$. These findings mirror the results of a recent review of studies on Openness (Costa, Terracciano, \& McCrae, 2001). Finally, Openness was mostly uncorrelated with the social desirability scales; the correlation with self-deception enhancement was $r=.08, p=.02$, and with impression management it was $r=.05, p=$ .13. The social desirability scales were therefore dropped from later analyses Relating Openness to the first-order scales and global dimension of the Life Space

Predictions between Openness and the Life Space were based on the results of the pilot study and a thorough review of the literature on the criterion validity of Openness. Predicted correlations for each set of analyses are presented in boldface. 
Openness and the Biological Domain. Table 10 displays the correlations between Openness and the scales from the biological domain. As can be seen, all of the predicted correlations (Allergy, Sinus, \& Cold, Psychopathology, and Physical Fitness) were statistically significant. Openness also correlated significantly with three additional scales. The highest correlations were with the Somatic Complaints and Psychopathology scales $(r s=.12$ to .16$)$.

Some of the results suggested an interaction between Openness and gender in the prediction of the criteria. For example, for males, but not females, Openness was negatively correlated with the Physical Fitness scale $(r s=-.14, .03$, respectively). However, for females, but not males, Openness was positively correlated with the Healthy Diet scale ( $r s=.13,-.07$, respectively).

Openness and the Situational Elements Domain. Table 11 presents the correlations between Openness and the 35 scales in the situational elements domain. As can be seen, Openness correlated significantly with 22 of the 35 scales in this domain. Remarkably, 16 of the 18 predicted correlations were statistically significant and replicated findings from the pilot study and previous research. Due to the large number of correlations, only a few of the more interesting associations are presented here.

Some of the strongest correlations for Openness were with a person's ownership of music-related possessions. For example, Openness correlated with these scales: Musical Instruments, Nonconforming Music, Popular Music, and Alternative Rock Music $(r \mathrm{~s}=.11$ to .30$)$. The pattern of correlations for these scales was the same for males and females. As expected, Openness also correlated with the Reading Orientation and SelfHelp Books scales ( $r \mathrm{~s}=.24, .33$, respectively). Similar to the pilot study, Openness was 
related to the New Age possessions and Liberal Politics (endorsements) scales. Expected associations between Openness and Sentimental Objects, Artistic Objects, and Collectibles were also significant $(r \mathrm{~s}=.09$ to .42$)$. An interesting replication was the small negative correlation between Openness and Casual Clothing, which suggests that Open people tend to dress in distinct or non-conforming ways. Finally, an altogether new relationship (negative) emerged between Openness and Popular Masculine Sports products, for male students only.

Openness and the Interactive Domain. Table 12 presents the correlations between Openness and the 44 scales in the interactive domain. As can be seen, Openness was significantly related to 26 of the 44 scales. Fifteen of the 16 predicted correlations were statistically significant. Due to the large number of scales in this domain, only a few of the more interesting associations are presented here.

The strongest pattern of replicated correlations was between Openness and Artrelated activities, including: Artistic Activity, Musical Ability \& Achievement, and Artistic Expression and Appreciation ( $r \mathrm{~s}=.16$ to .39 ). A second, strong pattern of replicated associations was between Openness and Life Space scales pertaining to media consumption. Openness also covaried with the Book Consumer, Movie Consumer, and Music Consume $(r \mathrm{~s}=.15$ to .32$)$, and negatively with the Television Consumer $(r=-.17)$. Finally, as predicted, Openness was significantly related to the Conversationalist and Solitary Lifestyle ( $r \mathrm{~s}=.29, .33$, respectively).

A number of other interesting links emerged between Openness and scales in the interactive domain (exploratory analyses). For example, similar to the negative correlation with Sports Possessions in the situational elements domain, Openness was 
negatively correlated with Sports Consumption $(r=-.14)$. Interestingly, Openness was positively correlated with the Outdoor Sports scale $(r=.14)$. Other new findings with Openness include: negative associations with Relationship Conflict with Partner $(r=-.20$, males) and Verbal Aggression $(r=-.16)$. Finally, small but significant associations $(r \mathrm{~s}=$ .07 to .14) were found between Openness and Socializing with Parents, Masturbation (females only), Smoking Addiction, Illicit drug Use, and both the Studious Lifestyle and Delinquent Lifestyle.

Openness and the Incorporative Domain. Table 14 presents the correlations between Openness and the 9 scales in the incorporative domain. As can be seen, Openness was related to 7 of the 9 scales; all four of the predicted associations were statistically significant.

As expected, Openness correlated with scales pertaining to membership in the following groups: Political Action, Music and Arts Groups, Academic Achievement, Self and Other Groups ( $r \mathrm{~s}=.08$ to .22 ). Some of the correlations suggested interaction between Openness and gender in predicting the criteria. For example, Openness was positively correlated with Political Action for females, but not for males $(r \mathrm{~s}=.18,-.03$, respectively). Similarly, Openness was negatively correlated with Sports Groups for males, but not for females ( $r \mathrm{~s}=-.13, .02$, respectively), and positively correlated with Family Wealth for males, but not for females ( $r \mathrm{~s}=.19, .03$, respectively).

Openness and the Global Life Space Dimensions. The correlations between Openness and the global dimension are presented in Table 15. Based on the pattern of correlations found between Openness and the first-order scales in the biological, situational elements, interactive, and incorporative domains, the results of the pilot study, 
and reviews of prior research, it was predicted that Openness would be positively correlated with two global dimensions: Music and Arts Achievement, and Intellectual Pursuits. Because these dimensions were comprised of numerous first-order scales that individually correlated with Openness, it was also predicted that the size of correlations with the global dimensions would be higher than the correlations with the first-order scales. It was believed that associations with the two global dimensions would be higher because they contain aggregated variance that their component first-order scales may lack.

As expected, Openness was highly predictive of the Music and Achievement and the Intellectual Pursuits dimensions $(r s=.41, .45$, respectively). There were no significant differences in these correlations for males and females. A multiple regression was then performed to assess how much variance Openness accounted for in the prediction of both dimensions. The overall multiple $R$ was statistically significant, $R=$ $.53, F(2,934)=178.50, p<.001$, and Openness accounted for nearly $30 \%$ of the variance in both dimensions (adj $R^{2}=.28$ ). Finally, two other smaller correlations were found, both for males only, between Openness and the Positive and Social Orientation dimension and the Media Consumer dimension $(r s=.12, .14$, respectively).

\section{Criterion-Keying Approach to Understanding Openness}

In this part of the research, a criterion-keying approach (CKA) was used to assess relations between Openness and the Life Space. That is, instead of examining relations between Openness and the first- and second-order scales from the Life Space, empirically derived scales were developed, which were solely based on statistical relations between individual Life Space items and Openness. With CKA, the degree to which Life Space 
items intercorrelate is not emphasized as it was in previous sections. The main assumption with CKA is that high and low scoring individuals on Openness will have significantly different mean scores on items that comprise the Life Space. A number of scales in the past have been developed using this approach, including the CPI (Gough, 1987) and MMPI-2 (Butcher, Dahlstrom, Graham, Tellegen, \& Kraemer, 1989).

Because little importance is placed on homogeneity of items, CKA can result in an unwieldy set of items and interpretation of any underlying latent variable is speculative. On the other hand, its strengths include the discovery of: (a) new items related to the Life Space that were not apparent from the analyses between Openness and the first-order and global dimensions and (b) higher correlations between Openness and individual items (Gough \& Bradley, 1992; Meehl, 1945).

The exploratory nature of CKA requires cross-validation to estimate the accuracy of differentiation among people on the criterion. This is crucial because there is an increased chance that sample specific variance will artificially inflate the relationship between variables when the scale is based on a single sample. More specifically, the cross-validation narrows the number of significant findings that may reflect Type I error.

Development of Criterion-Keyed Scales. Because there were significant differences in mean scores on Openness for males and females, and earlier analyses showed Openness is at times expressed differently for each gender, separate scales were developed for males and females.

To examine differences at the individual item level independent samples $t$ tests were computed between high and low scoring groups of individuals on Openness. First, 
male and female participants were separately divided into thirds. Then, the top and bottom thirds ( $N=114$ males, 216 females) were randomly divided in half. This created four sets of extreme groups, with two sets of low scoring individuals (Groups A and B) and two sets of high scoring individuals (Groups C and D) for each gender. For males, there were between 53 and 57 individuals in each group, and for females, there were between 99 and 108 individuals in each group for all the $t$ tests that were performed. The sample sizes were not equivalent for all $t$ tests due to missing data on some of the individual Life Space items. The size of the smallest groups, however, were large enough to detect a small effect $\left(\eta^{2}=.10\right)$

The cross-validation procedure went as follows. First, $t$ tests were computed between the $\mathrm{A}$ and $\mathrm{C}$ groups for each gender and only items that significantly differentiated high and low scoring individuals on Openness were retained. Then, a second set of $t$ tests was performed between groups B and D (cross-validation), but only on the items that significantly differentiated the extreme groups from the first set of analyses. The final scales were comprised of only those items that were significant in the cross-validation.

As can be seen in Tables 15 and 16, 64 items passed the cross-validation procedure for males and 87 items passed the procedure for females. Both tables present three sets of $t$ tests, one for each group in the cross-validation, and a total $t$ value from analyses with the extreme groups combined. Items in both tables are arranged from highest to lowest $t$ value on the combined test.

Although this part of the research was highly exploratory, almost every item that differentiated open versus closed individuals had both face and content validity. Thirty- 
five items that differentiated open versus closed individuals were the same for male and female participants. These items are typed in boldface on both tables. The strongest effects were found for the following items: creating books of poems, owning poetry books, writing poetry, having philosophical conversations, owning philosophy books and owning art and architecture books. Owning poetry books was the item with the strongest effect size $\left(\eta^{2}=.19, .21\right.$, males and females respectively).

As might be expected, open versus closed people also differed in their reports of involvement in arts and crafts and drawing or sketching, watching foreign movies, belonging to an acting or drama group, owning jazz music, reading for pleasure, and having conversations about books or philosophy. It was also not surprising that closed people were more likely to make fun of gay people, whereas open people were more likely to report having a gay friend. One final interesting point to note is a qualitative difference among many items that differentiated open women versus men. Consistent with research on identity formation (e.g., Cramer, 2000), which shows that women have a more communal orientation then men, a number of items related to Openness for women, but not men, were expressed in interpersonal contexts (e.g., discussing politics with friends, family, and significant other, and writing to people).

In general, the findings from the CKA matched the results from previous analyses. One benefit of the CKA, however, was that differences between high and low scoring individuals at the item level provided a more detailed description of how Openness is expressed in people's everyday lives. For example, in previous analyses Openness was negatively correlated with the Verbal Aggression scale, but here it was shown that low Openness was related to one specific item on that scale (i.e., making fun 
of a gay person). Similarly, analyses using the first-order scales showed that Openness was positively correlated with the Psychopathology scale, but here it was revealed that Openness was specifically related to a diagnosis of depression for both males and females.

\section{Discussion}

The broad goal of Study 2 was to assess whether Openness was related to the biological, situational elements, interactive, and incorporative domains of the Life Space. Both predicted and exploratory analyses were conducted between Openness and the firstand second-order scales. Criterion-keyed scales were also developed to examine individual items that potentially differentiate open versus closed college students.

Based on the results of the pilot study and prior research in the area, it was predicted that Openness would correlate with 41 of the 96 scales in the Life Space. A remarkable 38 of the 41 predicted associations were statistically significant, which gave great confidence in the findings. Exploratory analyses resulted in an additional 17 significant correlations between Openness and the Life Space. Moreover, the CKA approach revealed dozens of items that differentiated open versus closed individuals.

Almost all of the findings (both predicted and exploratory) showed that Openness was predictive of important and socially significant criteria in all four domains of the Life Space. The findings were also consistent with theory - that Openness would correlate with personal belongings, daily activities, and group memberships that reflect a person's appreciation for aesthetics, openness to feelings, intellectual curiosity, willingness to try different activities, and inclination to examine political and cultural values. Analyses in the situational elements and interactive domains provided the richest and most interesting 
correlations with Openness. This may be due in part to the breadth and scope of personal belongings and activities that are covered in these domains.

Consistent with prior research (e.g., Dollinger, 1993; Paunonen, 2003; Rawlings, Barrante, \& Furnham, 2000), some of the strongest external correlates of Openness were with possessions, activities, and group memberships associated with a person's participation in music-related activities. This was evidenced in replicated correlations between Openness and scales in three domains (situational elements, interactive, and incorporative) of the Life Space. Openness was related to owning music (non-conforming music, in particular), writing lyrics, owning and playing a musical instrument, taking music classes and belonging to groups that involve music (e.g., band, choir). As expected, the highest correlation with was with the Music and Arts Achievement global dimension, which brought together many of the previously mentioned first-order scales.

A large number of the findings expanded upon research which suggests that Open people not only report an appreciation for art and beauty, but also create personal environments and engage in activities that reflect an outward expression of Openness (e.g., McCrae, 1996; Griffin \& McDermott, 1998). For example, the open college students in this study were more likely than closed students to keep sentimental objects in their surroundings, collect memorabilia, read and write poetry, create drawings or sketches, and create sculptures in their spare time. They were also more likely to have artistic objects displayed in their rooms such as posters of landscapes and art, and to visit museums. Aesthetics also appeared to be important for these open students because they reported owning less casual clothing and more sophistic apparel. 
Similar to previous studies, Openness was associated with students' reports of owning possessions and pursuing activities that convey intellectual curiosity, broadmindedness, and tolerant attitudes (e.g., Cullen, Wright, \& Alessandri, 2002; Griffin \& McDermott, 1998; McCrae, 1996; Trapnell, 1994). For example, Openness correlated with reports of liberal political views, a proclivity towards conversations around politics and culture, better study habits, owning and reading more books, watching foreign movies, spending time in self-reflection, and writing in a private journal. These students also had a tendency to keep New Age Products in their rooms and, interestingly, they made significantly fewer denigrating remarks about gay people than closed people. As expected, the global dimension, Intellectual Pursuits, which brought together many of the above items, had the strongest association with Openness.

A somewhat weak link between mental health outcomes and Openness that has been found elsewhere was also replicated here (Wolfenstein \& Trull, 1997; McCrae \& Costa, 1991). Openness correlated with the Psychopathology scale (diagnosis of depression and anxiety, seeking treatment) and the Somatic Complaints scale (reports of feeling dizzy, fatigue, sleeping problems). At the item level, Openness was specifically related to a diagnosis of depression for both males and females. This finding may suggest that Open people are more likely to recognize when they have emotional problems and, perhaps they are more likely to seek appropriate interventions.

Finally, a few unexpected findings emerged from the exploratory analyses. For example, open students reported having less conflict with their romantic partners, and slightly more positive relations with their friends. Moreover, to the extent that open people are non-conformers, some findings showed relations between Openness and less 
gender stereotypical behavior. For example, scores on the Masturbation scale were positively correlated with Openness for females; thus females who are open may break out of the norm and be willing to report this behavior. Similarly, for males, Openness was negatively correlated with sports-related aspects of the Life Space. A string of negative correlations was found between Openness and Physical Fitness (lifting weights), Popular Masculine Sports Possessions (e.g., owning hockey sticks, footballs), Sports Consumption (e.g., sports with friends, going to sports events), and Sports Groups (e.g., intercollegiate sports, basketball team). In sum, only future theoretical and empirical work will show the extent to which these associations are "real" or just instances of Type I error. 


\section{CHAPTER VII}

\section{GENERAL DISCUSSION AND CONCLUSION}

Until recently, little effort was placed on developing taxonomies of the Life Space or external situation to which personality is expressed (Brackett, 2001; Mayer et al., 1998). This delay may be related to imprecise definitions of the term "situation" (Pettigrew, 1997) and infinite ways to code or categorize a person's external environment and behavior (e.g., Colett, 1980). After all, a person's Life Space is comprised of a montage of potentially interdependent life settings, activities, and relationships.

The primary goal of this research was to advance descriptions of the Life Space by developing scales based on a comprehensive model of college students' external environment and behavior. The second goal was to demonstrate the utility of the Life Space as criterion for personality traits such as Openness.

Guided by a systems framework (Mayer, 1998) 96 reliable and meaningful primary factor-based scales were developed to describe the situational elements, interactive, and incorporative domains of the college student's external Life Space. The primary scales were then reduced to 7 global dimensions, which were labeled: Positive and Social Orientation, Sports Orientation, Drug Culture Environment, Music and Arts Achievement, Media Consumer, Negative and Unhealthy Lifestyle, and Intellectual Pursuits. The 7 dimensions replicated and extended prior work on the Life Space (Brackett, 2001; Mayer et al., 1998). As predicted, about half of the primary scales conveyed important information about Openness, with the interactive and situational 
elements domains providing the most evocative associations. Openness was also highly correlated with two global dimensions: Music and Arts Achievement and Intellectual Pursuits.

\section{What have we learned about Openness}

Psychologists, business people and the lay public are interested in personality because they want to understand its implications for their own and others' lives. The term Openness, for instance, carries with it specifiable properties that infer a certain lifestyle (e.g., creative thinking, a unique wardrobe, dining at exotic restaurants, traveling to exotic places, and frequenting museums) that are supposed to manifest this disposition. Of course, a number of studies have related Openness to predictable outcomes such as creativity, divergent thinking, and artistic expression. But no study as yet has painted a detailed picture of how Openness is fully expressed in a person's life.

Here, Openness was related to the Life Space, a comprehensive set of external criteria, which measured health habits, personal belongings, everyday behaviors, and group memberships. Both predicted and exploratory analyses demonstrated that Openness was related to dozens of external criteria that reflect students' appreciation for aesthetics, openness to feelings, intellectual inquisitiveness, readiness to try diverse activities, and penchant for examining political and cultural values.

\section{Limitations and Future Directions}

As described, the Life Space scales developed here were based on people's selfreports of potentially verifiable behaviors and personal belongings. Therefore, one might argue that the data may not match with more objective assessments. Paunonen (2003), however, has recently shown that validity coefficients between self and peer ratings on 
Life Space type data, in most instances, are high. For example, the agreement between self and peer ratings on smoking behavior and alcohol consumption was remarkably high $(r \mathrm{~s}=.92, .64$, respectively). This high agreement may be attributed to the innocuous nature of certain questions such as whether the person owns certain music, watches television, or belongs to a particular sports team. Other behaviors (e.g., sexual activity, drug use, private hygiene habits) may be less trustworthy and more prone to desirability biases. However, because anonymity was guaranteed to the participants and the Life Space scales were both reliable and predictable by Openness in expected ways, there is confidence in the obtained results. Nevertheless, future research is needed to examine additional ways of validating Life Space data. For example, it would be interesting to compare people's self-reports to their actual home environments or to informant reports from parents, best friends, and significant others. It would also be interesting to see whether informant reports of Openness correlate with the Life Space scales.

It is important to note several additional limitations to these studies. First, the use of a student sample and student specific criteria limits the generalizability of the results to other groups. The goal, however, was not to develop a universal criterion, but a criterion that will maximize our understanding of how Openness and other traits and mental abilities are expressed in a college student sample. In fact, by having both the predictor and criterion tap relevant tendencies and life expectancies of college students, it was expected that validity coefficients would be higher. Nonetheless, it will be important to develop additional criteria for both older and younger age groups. Then researchers will not only be able to examine the extent to which personality traits remain stable or change throughout the lifespan, but also test how internal personality characteristics are 
expressed at different ages. It would also be possible to assess how behaviors transform throughout the lifespan.

A second limitation of this research is that the facets of Openness, which were not examined, may predict some of the criteria better than overall Openness. This is because aggregating the facets into their underlying factor may result in decreased predictive accuracy due to the loss of trait-specific but criterion-related variance for some Life Space scales (e.g., Paunonen \& Ashton, 2001). For example, it is possible that the Liberal Politics scale will be more strongly related to the openness to ideas facet than to overall Openness. In other words, there may be an inverse relation between one or more facets of Openness and the Liberal Politics scale that attenuates the correlation with overall Openness. Therefore, carefully designed research should assess the extent to which the narrow facets of Openness will surpass the broad factor in the prediction of the criteria.

Finally, the mere fact of multiple influences on behavior places limitations on the size of the correlation coefficients between Openness and the Life Space. Higher validity coefficients would surely surface from carefully designed investigations in which a multivariate combination of traits, mental abilities, genetic predispositions, hormonal influences, and environmental determinants are used to predict the criteria.

\section{$\underline{\text { Conclusion }}$}

The broad goal of this research was to develop a measure of the Life Space and to relate it to Openness. In Study 1 an omnibus measure of the Life Space was developed, which looked at clusters of health behaviors, personal belongings, daily interactions, and group memberships as a starting point to understand how personality is expressed in an individual's external surroundings. In Study 2, Openness was related to the Life Space 
criteria in order to yield a full picture of how it is expressed in the real world. Study 2 also served as an example of an approach to studying other personality-Life Space relations.

Instead of relating Openness to one or two criterion variables such as college grades or creativity, or a limited set of behaviors or possessions, the present research related Openness to a comprehensive and theoretically driven measure of the Life Space. This offered a full picture of how Openness is expressed in multiple domains of person's life. Specifically, it was shown that Openness correlated with a wide range of health behaviors (e.g., depression, exercise habits), personal possessions (e.g., nonconforming music, posters of art displayed), daily interactions (e.g., discussions about politics), pastime activities (e.g., arts and crafts, singing in a band) and group memberships (acting troupe, political action). More research is needed to assess the extent to which college students actively structure their life experiences and create social environments to match and reinforce their personality dispositions such as Openness. 


\section{LIST OF REFERENCES}

Allport, G. W. (1961). Pattern and growth in personality. New York: Holt, Rinehart, and Winston.

Ashton, M. C. (1998). Personality and job performance: The importance of narrow traits. Journal of Organizational Behavior, 19, 289-303.

Astin, A. W. (1993). An empirical typology of college students. Journal of College Student Development, 34, 36-46.

Becker, T. E., \& Colquitt, A.L. (1992). Potential versus actual faking of a biodata form: An analysis along several dimensions of item type. Personnel Psychology, 45, 389-406.

Belk, R. W. (1988). Possessions and the extended self. Journal of Consumer Research, $15,139-168$.

Bell, R., Wechler, H., \& Johnston, L. D. (1997). Correlates of college student marijuana use: Results of a US national survey. Addiction, 92, 571-581.

Bentler, P. M., \& Newcomb, M. D. (1986). Personality, sexual behavior, and drug use revealed through latent variable methods. Clinical Psychology Review, 6, 363385.

Blackhurst, A. (2002). A comparison of college students' political attitudes and participation rates in 1996 and 2000. Journal of College Student Development, 32, 740-750.

Block, J. (1995). A contrarian view of the five-factor approach to personality description. Psychological Bulletin, 117, 187-215.

Bogler, R., \& Somech, A. (2002). Motives to study and socialization tactics among university students. Journal of Social Psychology, 142, 233-248.

Brackett, M. A. (2001). Emotional intelligence and its expression in the life space. Unpublished master's thesis, University of New Hampshire.

Brackett, M. A., Mayer, J. D., \& Warner, R. M. (in press). Emotional intelligence and its relation to everyday behaviour. Personality and Individual Differences.

Brown, D. R., \& Blanton, C. J. (2002). Physical activity, sports participation, and suicidal behavior among college students. Medicine and Sciences in Sports and Exercise, 34, 1087-1096. 
Buss, D. M., \& Craik, K. H. (1983). The act frequency approach to personality.

Psychological Review, 90, 105-126.

Butcher, J. N., Dahlstrom, W. G., Graham, J. R., Tellegen, A., \& Kaemmer, B. (1989). Manual for the restandardized Minnesota Multiphasic Personality Inventory: MMPI2. An administrative and interpretive guide. Minneapolis: University of Minnesota Press.

Carrillo, J. M., Rojo, N., Sanchez-Bernardos, J. S., and Avia, M.D. (2001). Openness to experience and Depression. European Journal of Psychological Assessment, 17, 130-136.

Cash, T. F. \& Wunderle, J. M. (1987). Self-monitoring and cosmetics use among college women. Journal of Social Behavior and Personality, 2, 563-566

Cattell, R. B. (1965). The scientific analysis of personality. Chicago: Aldine.

Collett, P. (1980). Segmenting the behavior stream. In M. Brenner (Ed.), The structure of action (pp. 150-167). New York: St. Martin's Press.

Cooper, H., Okamura, L., \& Gurka, V. (1992). Social activity and subjective well-being. Personality and Individual Differences, 13, 573-583.

Costa, P. T., Jr., \& McCrae, R. R. (1995). Domains and facets: Hierarchical personality assessment using the Revised NEO Personality Inventory. Journal of Personality Assessment, 64, 21-50.

Costa, P. T., Jr., Terracciano, A., \& McCrae, R. R. (2001). Gender differences in personality traits across cultures: Robust and surprising findings. Journal of Personality and Social Psychology, 81, 322-331.

Costa, P. T., Jr., \& McCrae, R. R. (1992). NEO-PI-R Professional Manual-Revised NEO Personality Inventory (NEO-PIR) and NEO Five-Factor Inventory (NEO$F F I$ ). Odessa, FL: Psychological Assessment Resources.

Costa, P.T., Jr., McCrae, R. R., \& Holland, J. L. (1984). Personality and vocational interests in an adult sample. Journal of Applied Psychology, 69, 390-400.

Craik, K. (2000). The lived day of an individual. In Walsh, W. B., Craik, K. H., \& Price, R. (Eds.), Person Environment Psychology, $2^{\text {nd }}$ edition (pp. 235-266). Mahwah, NJ: Erlbaum.

Cramer, P. (2000). Development of identity: Gender makes a difference. Journal of Research in Personality, 34, 42-72.

Csikszentmihalyi, M. (1992). Flow: The psychology of happiness. USA: Harper \& Row. 
Csikszentmihalyi, M., \& Rochberg-Halton, E. (1981). The meaning of things: Domestic symbols and the self. Cambridge, England: Cambridge University Press.

Cullen, J. M., Wright, L. W., Jr., \& Alessandri, M. (2002). The personality variable Openness as it relates to homophobia. Journal of Homosexuality, 42, 119-134.

Digman, J. M. (1990). Personality structure: The emergence of the five-factor model. Annual Review of Psychology, 41, 417-440.

Dollinger, S. J. (1993). Personality and music preference: Extraversion and excitement seeking or openness to experience? Psychology of Music, 21, 73-77.

Dollinger, S. J., Ross, V. J., Preston, L. (2002). Intellect and individuality. Creativity Research Journal, 14, 213-266.

Epstein, S. (1979). The stability of behavior: I. On predicting most of the people much of the time. Journal of Personality and Social Psychology, 37, 1092-1126.

Epstein, S. (1983). Aggregation and beyond: Some basic issues on the prediction of behavior. Journal of Personality, 51, 360-392.

Epstein, S., \& O'Brien, E. J. (1985). The person-situation debate in historical and current perspectives. Psychological Bulletin, 98, 513-537.

Fiske, D. W. (1973). Can a personality construct be validated empirically? Psychological Bulletin, 80, 89-92.

Franken, R. E., Hill, R., \& Kierstead, J. (1994). Sport interest as predicted by the personality measures of competitiveness, mastery, instrumentality, expressivity, and sensation seeking. Personality \& Individual Differences, 17, 467-476.

Frederiksen, N. (1972). Toward a taxonomy of situations, American Psychologist, 27, 114-123.

Funder, D. C. (2001). Personality. Annual Review of Psychology, 52, 197-221.

Goldberg, R. (1990). An alternative "description of personality": The Big-Five factor structure. Journal of Personality and Social Psychology, 59, 1216-1229.

Goldberg, L. R. (in press). The comparative validity of adult personality inventories: Applications of a consumer-testing framework. In S. R. Briggs, J. M. Cheek, \& E. M. Donahue (Eds.), Handbook of Adult Personality Inventories.

Gough, H. G. (1979). A creative personality scale for the adjective check list. Journal of Personality and Social Psychology, 37, 1398-1405.

Gough, H. G. (1987). California Psychological Inventory administrator's guide. Palo Alto, CA: Consulting Psychologists Press. 
Gough, H. G., \& Bradley, P. (1992). Comparing two strategies for developing personality scales. In Zeidner, M., \& Most, R. (Eds.), Psychological testing: An inside view (pp. 215-246). Palo Alto, CA: Consulting Psychologists Press

Griffin, M., \& McDermott, M. R. (1998). Exploring a tripartite relationship between rebelliousness, openness to experience, and creativity. Social Behavior and Personality, 26, 347-356.

Gurtman, M. B. (1995). Personality structure and interpersonal problems: A theoreticallyguided item analysis of the inventory of interpersonal problems. Assessment, 2, 343-361.

John, O. P. \& Srivastava, S. (1999). The Big Five trait taxonomy: History, measurement, and theoretical perspectives. In L. A. Pervin \& O. P. John. (Eds.), Handbook of personality: Theory and research (2 ${ }^{\text {nd }}$ edition), (pp. 102-138). New York: Guilford.

Kasser, T., \& Sheldon, K. M. (2000). Of wealth and death: Materialism, mortality salience, and consumption behavior. Psychological Science, 11, 348-351.

Kenrick, D. T., \& Funder, D. C. (1988). Profiting from controversy: Lessons from the person-situation debate. American Psychologist, 32, 23-34.

Kuh, G. D., Hu, S., \& Vesper, N. (2000). "They shall be known by what they do": An activities-based typology of college students. Journal of College Student Development, 41, 228-244.

Larson, R. (1989). Beeping children and adolescents: A method for studying time use and daily experience. Journal of Youth and Adolescence, 18, 511-530.

Lee, M. D. (1985). Life space structure: Explorations and speculations. Human Relations, $38,623-642$.

Lewin, K. (1936). A Dynamic Theory of Personality. New York: McGraw-Hill.

Lewin, K. (1951). Field theory in social science. New York: Harper Torch Books.

Mael, F. A. (1991). A conceptual rationale for the domain and attributes of biodata items. Personnel Psychology, 44, 763-792.

Mael, F. A., \& Hirsch, A. C. (1993). Rainforest empiricism and quasi-rationality: Two approaches to objective biodata. Personnel Psychology, 46, 719-738.

Magnusson, D., \& Torestad, B. (1992). The individual as an interactive agent in the environment. In W. B. Walsh, K. H. Craik, \& R. H. Price (Eds.), Person- 
Environment Psychology: Models and perspectives. Hillsdale, NJ: Lawrence Erlbaum Associates.

Marcus, R. F., \& Reio, T. G., Jr. (2002). Severity of injury resulting from violence among college students: Proximal and distal influences. Journal of Interpersonal Violence, 17, 888-908.

Mayer, J. D. (1998). A systems framework for the field of personality. Psychological Inquiry, 9, 118-144.

Mayer, J. D. (in press). A classification system for the data of personality psychology. Review of General Psychology

Mayer, J. D., Carlsmith, K. M., \& Chabot, H. F. (1998). Describing the person's external environment: Conceptualizing and measuring the life space. Journal of Research in Personality, 32, 253-296.

Mayer, J. D., Salovey, P., \& Caruso, D. (2002). MSCEIT technical manual. Toronto, Canada: Multi-Health Systems.

Mayer, J. D., Salovey, P., Gomberg-Kaufman, S., \& Blainey, K. (1991). A broader conception of mood experience. Journal of Personality and Social Psychology, $28,351-372$.

McAdams, D. P. (1992). The five-factor model in personality: A critical appraisal. Journal of Personality, 60, 329-361.

McCrae, R. R. (1987). Creativity, divergent thinking, and openness to experience. Journal of Personality and Social Psychology, 52, 1258-1265.

McCrae, R. R. (1994). Openness to experience: expanding the boundaries of Factor V. European Journal of Personality, 8, 251-272.

McCrae, R. R. (1996). Social consequences of experiential openness. Psychological Bulletin, 120, 323-337.

McCrae, R. R., \& Costa, P. T. Jr. (1997). Conceptions and correlates of openness to experience. In R. Hogan, J. A. Johnson, \& S. R. Briggs (Eds.), Handbook of personality psychology (pp. 825-847). New York: Academic Press.

McCrae, R. R., \& Costa, P. T., Jr. (1985). Openness to Experience. In R. Hogan \& W.H. Jones (Eds.), Perspectives in personality (pp. 145-172). Greenwich, CT: JAI Press.

McCrae, R. R., \& Costa, P. T., Jr. (1991). Adding liebe und arbeit: The full five-factor model and well-being, Personality and Social Psychology Bulletin 17, 227-232. 
McCrae, R. R., \& Costa, P. T., Jr. (1995). Trait explanations in personality psychology, European Journal of Personality, 9, 231-252.

Meehl, P. E. (1945). The dynamics of "structured" personality tests. Journal of Clinical Psychology, 1, 296-303.

Mischel, W., \& Peake, P. K. (1982). Beyond déjà vu in the search for cross-situational consistency. Psychological Review, 89, 730-755.

Monroe, S. M., \& Steiner, S. C. (1986). Social support and psychopathology: Interrelations with preexisting disorder, stress, and personality. Journal of Abnormal Psychology, 95, 29-39.

Moss, M. S., \& Lawton, M. P. (1982). Time budgets of older people: A window on four lifestyles. Journal of Gerontology, 37, 115-123.

Neugarten, B. L. (1979). Time, age, and the life cycle. American Journal of Psychiatry, $136,887-894$.

North, A. C., Hargreaves, D. J., \& O'Neill, S. A. (2000). The importance of music to adolescents. British Journal of Educational Psychology, 70, 255-272.

O’Malley, P. M., \& Johnston, L. D. (2002). Epidemiology of alcohol and other drug use among American college students. Journal of Studies on Alcohol, 14, 23-39.

Owens, W. A. (1976). Background data. In Dunnette, M. D. (Ed.), Handbook of industrial psychology (pp.609-644). New York: Rand McNally.

Owens, W. A., \& Schoenfeldt, L. F. (1979). Toward a classification of persons. Journal of Applied Psychology, 65, 569-607.

Paulhus, D. (1998). Paulhus Deception Scales. Multihealth Systems: Toronto, Canada.

Paunonen, S. V. (1998). Hierarchical organization of personality and prediction of behavior. Journal of Personality and Social Psychology, 74, 538-556.

Paunonen, S. V. (2003). Big Five factors of personality and replicated predictions of behavior. Journal of Personality and Social Psychology, 84, 411-424.

Paunonen, S. V., \& Ashton, M. C. (2001). Big Five factors and facets and the prediction of behavior. Journal of Personality and Social Psychology, 81, 524-539.

Paunonen, S. V., \& Ashton, M. C. (2001). Big Five predictors of academic achievement. Journal of Research in Personality, 35, 78-90.

Pervin, L A. (1994). A critical analysis of current trait theory. Psychological Inquiry, 5, 13-113.

Pervin, L. A. (1996). The science of personality. New York: Wiley. 
Pettigrew, T. (1997). Personality and social structure. In R. Hogan, J. A. Johnson, \& S. R. Briggs (Eds.), Handbook of personality psychology (pp. 417-439). New York: Academic Press.

Piedmont, R. L. (1998). The revised NEO personality inventory: Clinical and research applications. New York: Plenum.

Rawlings, D., Barrantes i Vidal, N., \& Furnham, A. (2000). Personality and aesthetic preference in Spain and England: Two studies relating sensation seeking and openness to experience to liking for paintings and music. European Journal of Personality, 14, 553-576.

Reiss, S., Wiltz, J., \& Sherman, M. (2001). Trait motivational correlates of athleticism. Personality and Individual Differences, 30, 1139-1145.

Richards, M. H. \& Larson, R. (1989). The life space and socialization of the self: Sex differences in the young adolescent. Journal of Youth and Adolescence, 18, 617626.

Richman, E. L., \& Shaffer, D. R. (2000). "If you let me play sports": How might sport participation influence the self-esteem of adolescent females? Psychology of Women Quarterly, 24, 189-199.

Sadalla, E. K., Linder, D. E., \& Jenkins, B. A. (1988). Sport preference: A selfpresentational analysis. Journal of Sports and Exercise Psychology, 10, 214-222.

Saucier, G. (1992). Openness versus intellect: much ado about nothing? European Journal of Personality, 6, 381-386.

Shedler, J., \& Block, J. (1990). Adolescent drug use and psychological health: A longitudinal inquiry. American Psychologist 45, 612-630.

Stokes, G. S., Mumford, M. D., \& Owens, W. A. (Eds.). (1994). Biodata handbook: Theory, research, and use of biographical information in selection and performance prediction. Palo Alto, CA: Consulting Psychological Press.

Tabachnick, B. G., \& Fidell, L. S. (2001). Using multivariate statistics (4th ${ }^{\text {th }}$ edition). Needham Heights, MA: Allyn \& Bacon.

Trapnell, P. D. (1994). Openness versus intellect: A lexical left turn. European Journal of Personality, 8, 273-290.

University of New Hampshire, (2001). Unpublished data, Health Services.

Wallendorf, M., \& Arnould, E. (1988). My favorite things: A cross-cultural inquiry into object attachment, possessiveness, and social linkage. Journal of Consumer Research, 14, 431-547. 
Watson, D., Clark, L. A., McIntyre, C. W., \& Hamaker, S. (1992). Affect, personality, and social activity. Journal of Personality and Social Psychology, 63, 1011-1025.

Westen, D. (1996). A model and a method for uncovering the nomothetic from the idiographic: An alternative to the Five-Factor Model. Journal of Research in Personality, 30, 400-413.

White, J. W. (2001). Aggression and gender. In J. Worell (Ed.). Encyclopedia of women and gender (pp. 81-93). New York: Academic Press.

Wiggins, J. S. (Ed.). (1996). The five-factor model of personality: Theoretical perspectives. New York: Guilford Press.

Wolfenstein, M., \& Trull, T. J. (1997). Depression and openness to experience. Journal of Personality Assessment, 69, 614-632.

Zeidner, M. (1998) Test anxiety: The state of the art. New York: plenum. 
Table 1

Overview of the Domains, Areas, and Categories of the Life Space

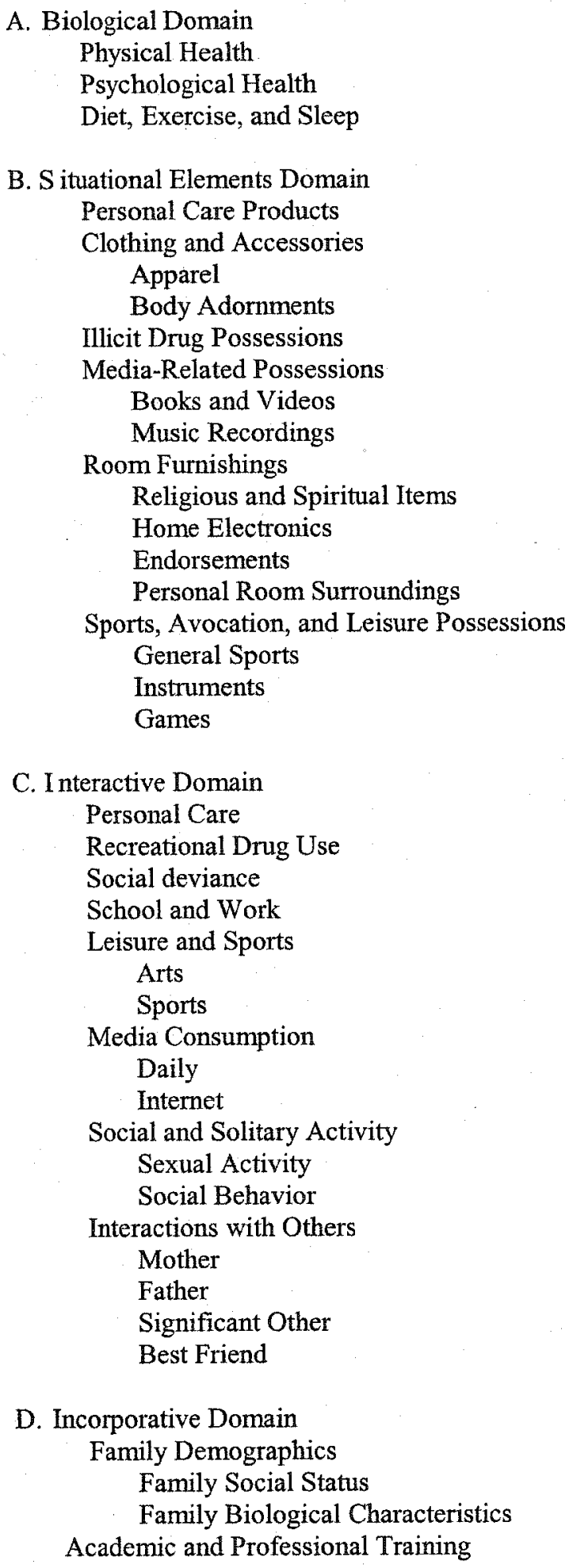


Table 2

Biological Domain: Factor-Based Scales and Preliminary Analyses

\begin{tabular}{llccc}
\hline & Reliability & \multicolumn{3}{c}{ Gender Differences } \\
\hline \multicolumn{1}{c}{$\alpha$} & $\begin{array}{c}\text { Mean } z \text { score } \\
\text { difference }\end{array}$ & $\eta^{2}$ \\
Physical Health & \multicolumn{5}{c}{$t$} & $-8.72^{\mathrm{c}}$ & .075 \\
$\quad$ Somatic Complaints & .82 & -.31 & $-9.11^{\mathrm{c}}$ & .082 \\
$\quad$ Allergy, Sinus, \& Cold & .79 & -.33 & & \\
$\begin{array}{l}\text { Psychological Health } \\
\text { Psychopathology }\end{array}$ & .78 & -.13 & $-3.17^{\mathrm{b}}$ & .010 \\
$\quad$ Nervous Behavior & .60 & -.28 & $-8.63^{\mathrm{c}}$ & .074 \\
Diet/Exercise/Sleep & & & & \\
$\quad$ Physical Fitness & .80 & .52 & $15.73^{\mathrm{c}}$ & .210 \\
$\quad$ Healthy Diet & .73 & -.29 & $-9.98^{\mathrm{c}}$ & .096 \\
$\quad$ Unhealthy Lifestyle & .65 & & -.45 & \\
\hline
\end{tabular}

Note. $N=936($ Males $=326$, Females $=610)$. Negative $t$ values indicate higher mean scores for females. ${ }^{\mathrm{a}} p<.05,{ }^{\mathrm{b}} p<.01,{ }^{\mathrm{c}} p<.001$. 
Table 3

Situational Elements Domain: Factor-Based Scales and Preliminary Analyses

\begin{tabular}{|c|c|c|c|c|}
\hline & \multirow{2}{*}{$\frac{\text { Reliability }}{\alpha}$} & \multicolumn{3}{|c|}{ Gender Differences } \\
\hline & & $\begin{array}{c}\text { Mean } z \text { score } \\
\text { difference }\end{array}$ & $t$ & $\eta^{2}$ \\
\hline \multicolumn{5}{|l|}{ Personal Care } \\
\hline Attention to Appearance (f) & .65 & & & \\
\hline Attention to Appearance (m) & .86 & & & \\
\hline Personal Hygiene (f) & .61 & & & \\
\hline Personal Hygiene (m) & .65 & & & \\
\hline \multicolumn{5}{|l|}{ Drug Possessions } \\
\hline Illicit Drugs & .82 & .00 & .12 & \\
\hline Alcohol & .73 & .00 & -1.43 & \\
\hline Smoking & .76 & .09 & $1.98^{\mathrm{a}}$ & .004 \\
\hline \multicolumn{5}{|l|}{$\begin{array}{l}\text { Sports, Avocation, and Leisure } \\
\text { Possessions }\end{array}$} \\
\hline \multicolumn{5}{|l|}{ General } \\
\hline Popular Masculine Sports & .72 & .47 & $11.89^{\mathrm{c}}$ & .149 \\
\hline Hunting & .77 & .62 & $15.62^{\mathrm{c}}$ & .207 \\
\hline Outdoor Sports & .66 & .18 & $4.71^{\mathrm{c}}$ & .023 \\
\hline \multicolumn{5}{|l|}{ Instrument Ownership } \\
\hline Musical Instruments & .60 & .16 & $4.89^{\mathrm{c}}$ & .025 \\
\hline \multicolumn{5}{|l|}{ Game Ownership } \\
\hline Video Games & .76 & .65 & $13.35^{\mathrm{c}}$ & .160 \\
\hline Challenging Games & .77 & .00 & -1.00 & \\
\hline \multicolumn{5}{|l|}{ Media-Related Possessions } \\
\hline \multicolumn{5}{|l|}{ Music } \\
\hline Nonconforming Music & .79 & .00 & .75 & \\
\hline Popular Music & .71 & -.25 & $-5.88^{c}$ & .036 \\
\hline Alternative Rock Music & .77 & .28 & $6.55^{\mathrm{c}}$ & .044 \\
\hline Books and Videos & & & & \\
\hline Reading Orientation & .85 & .00 & 1.55 & \\
\hline Movie Orientation & .79 & .00 & -.26 & \\
\hline Self-Help Books & .72 & -.38 & $-10.12^{c}$ & .099 \\
\hline \multicolumn{5}{|l|}{ General Room Furnishings } \\
\hline \multicolumn{5}{|l|}{ Religious and Spiritual } \\
\hline Religious & .73 & -.26 & $-5.46^{\mathrm{c}}$ & .031 \\
\hline New Age & .69 & -.19 & $-4.74^{\mathrm{c}}$ & .023 \\
\hline \multicolumn{5}{|l|}{ Home Electronics } \\
\hline General Media & .63 & -.15 & $-3.63^{c}$ & .014 \\
\hline Computer & .60 & .11 & $3.15^{\mathrm{b}}$ & .011 \\
\hline \multicolumn{5}{|l|}{ Endorsements } \\
\hline Liberal Politics & .65 & -.09 & $-2.82^{b}$ & .008 \\
\hline \multicolumn{5}{|l|}{ Personal Room Surroundings } \\
\hline Sentimental Objects & .82 & -.92 & $-30.76^{c}$ & .503 \\
\hline Artistic Objects & .73 & -.36 & $-8.96^{\mathrm{c}}$ & .079 \\
\hline Collectibles & .57 & .07 & $2.30^{\mathrm{a}}$ & .006 \\
\hline
\end{tabular}


Table 3 (Continued)

\begin{tabular}{|c|c|c|c|c|}
\hline & \multirow{2}{*}{$\frac{\text { Reliability }}{\alpha}$} & \multicolumn{3}{|c|}{ Gender Differences } \\
\hline & & $\begin{array}{c}\text { Mean } z \text { score } \\
\text { difference }\end{array}$ & $t$ & $\eta^{2}$ \\
\hline \multicolumn{5}{|l|}{ Clothing and Accessories } \\
\hline \multicolumn{5}{|l|}{ Apparel } \\
\hline Casual Clothing (f) & .86 & & & \\
\hline Casual Clothing (m) & .74 & & & \\
\hline Sophisticated Wear (f) & .75 & & & \\
\hline Sophisticated Wear (m) & .78 & & & \\
\hline Alternative Accessories (f) & .78 & & & \\
\hline Accessories (m) & .78 & & & \\
\hline \multicolumn{5}{|l|}{ Body Adornments } \\
\hline Conventional Earrings & .71 & -.81 & $-23.03^{c}$ & .362 \\
\hline Unconventional Earrings & .63 & .00 & -.98 & \\
\hline
\end{tabular}

Note. $N=936($ Males $=326$, Females $=610)$. Negative $t$ values indicate higher mean scores for females. ${ }^{\mathrm{a}} p<.05,{ }^{\mathrm{b}} p<.01,{ }^{\mathrm{c}} p<.001$ 
Table 4

Interactive Domain: Factor-Based Scales and Preliminary Analyses

\begin{tabular}{|c|c|c|c|c|}
\hline & \multirow{2}{*}{$\frac{\text { Reliability }}{\alpha}$} & \multicolumn{3}{|c|}{ Gender Differences } \\
\hline & & $\begin{array}{l}\text { Mean } z \text { score } \\
\text { difference }\end{array}$ & $t$ & $\eta^{2}$ \\
\hline \multicolumn{5}{|l|}{ Personal Care } \\
\hline Appearance Maintenance & .77 & -.62 & $-18.96^{\mathrm{c}}$ & .278 \\
\hline Cleanliness Orientation & .60 & -.11 & $-3.74^{\mathrm{c}}$ & .015 \\
\hline \multicolumn{5}{|l|}{ Recreational Drug Use } \\
\hline Alcohol Abuse & .88 & .11 & $2.13^{\mathrm{a}}$ & .005 \\
\hline Smoking Addiction & .89 & .00 & .66 & \\
\hline Drug Abuse & .69 & .10 & $2.59^{\mathrm{a}}$ & .007 \\
\hline Illicit Drug Use Lifestyle & .85 & .24 & $5.19^{c}$ & .028 \\
\hline \multicolumn{5}{|l|}{ Social Deviance } \\
\hline Physical Aggression & .64 & .30 & $7.89^{\mathrm{c}}$ & .062 \\
\hline Verbal Aggression & .74 & .10 & $2.39^{\mathrm{a}}$ & .006 \\
\hline Stealing & .68 & .11 & $2.82^{\mathrm{b}}$ & .008 \\
\hline Gambling & .64 & .45 & $9.00^{\circ}$ & .080 \\
\hline \multicolumn{5}{|l|}{ School and Work Activity } \\
\hline Studious Lifestyle & .55 & -.10 & $-2.80^{\mathrm{b}}$ & .008 \\
\hline Delinquent Student & .50 & .23 & $6.36^{\mathrm{c}}$ & .042 \\
\hline Work Ethic & .89 & .00 & -.66 & \\
\hline \multicolumn{5}{|l|}{ Sports and Leisure Activity } \\
\hline \multicolumn{5}{|l|}{ The Arts } \\
\hline Artistic Activity & .78 & -.15 & $-4.18^{c}$ & .018 \\
\hline Musical Ability \& Achievement & .83 & .16 & $3.87^{c}$ & .016 \\
\hline Artistic Expression \& Appreciation & .69 & -.16 & $-4.88^{\mathrm{c}}$ & .025 \\
\hline \multicolumn{5}{|l|}{ Sports } \\
\hline Outdoor Sports Enthusiast & .80 & .13 & $3.50^{\mathrm{c}}$ & .013 \\
\hline Sports Consumption & .70 & .30 & $7.90^{\mathrm{c}}$ & .063 \\
\hline Hunting & .67 & .42 & $9.30^{\mathrm{c}}$ & .085 \\
\hline Military Arts & .48 & .21 & $4.70^{\mathrm{c}}$ & .023 \\
\hline \multicolumn{5}{|l|}{ Media Consumption } \\
\hline \multicolumn{5}{|l|}{ General Media } \\
\hline Book Consumer & .82 & -.15 & $-3.00^{b}$ & .010 \\
\hline Television Consumer & .76 & -.15 & $-3.67^{\mathrm{c}}$ & .014 \\
\hline Movie Consumer & .70 & .20 & $4.68^{\mathrm{c}}$ & .023 \\
\hline News Consumer & .65 & .31 & $7.86^{\mathrm{c}}$ & .062 \\
\hline Music Consumer & .61 & .15 & $3.51^{\mathrm{c}}$ & .013 \\
\hline \multicolumn{5}{|l|}{ Internet } \\
\hline Internet Enthusiast & .80 & -.14 & $-3.58^{c}$ & .014 \\
\hline \multicolumn{5}{|l|}{ Social and Solitary Activity } \\
\hline \multicolumn{5}{|l|}{ Sexual Activity } \\
\hline Promiscuous Lifestyle & .72 & .00 & -.04 & \\
\hline Masturbation & .73 & .87 & $22.79^{c}$ & .357 \\
\hline
\end{tabular}


Table 4 (Continued)

\begin{tabular}{llccc}
\hline & Reliability & \multicolumn{3}{c}{ Gender Differences } \\
\hline & $\alpha$ & $\begin{array}{c}\text { Mean } z \text { score } \\
\text { difference }\end{array}$ & $t$ & $\eta^{2}$ \\
Social Behavior & & & & \\
$\quad$ Conversationalist & .74 & .00 & .01 & \\
Telephone Enthusiast & .75 & -.43 & $-11.47^{\mathrm{c}}$ & .123 \\
Social \& Party Orientation & .72 & .09 & $2.57^{\mathrm{a}}$ & .007 \\
Game-Playing & .72 & .14 & $3.80^{\mathrm{c}}$ & .015 \\
Caring Person & .52 & -.14 & $-3.39^{\mathrm{b}}$ & .012 \\
Solitary Lifestyle & .66 & & -.57 & \\
Interactions with Selected Individuals & & & & \\
Mother and Father & & & & \\
Positive Relations with Mother & .87 & -.48 & $-12.98^{\mathrm{c}}$ & .153 \\
Relationship Conflict with Parents & .79 & .00 & -.68 & .005 \\
Social Activity with Parents & .78 & -.09 & $-2.20^{\mathrm{a}}$ & .034 \\
Positive Relations with Father & .87 & -.23 & $-5.77^{\mathrm{c}}$ & .034 \\
Significant Other & & & & \\
Positive Relations with Partner & .89 & -.30 & $-4.87^{\mathrm{c}}$ & .025 \\
Relationship Conflict with Partner & .75 & -.11 & -1.74 & \\
Social Activity with Partner & .76 & & .98 & \\
Best Friend & & & & \\
Social Activity with Best Friend & .85 & .00 & .07 & \\
Positive Relations with Best Friend & .82 & -.41 & $-9.69^{\mathrm{c}}$ & .091 \\
Relationship Conflict with Best Friend & .75 & .15 & $3.53^{\mathrm{c}}$ & .013 \\
\hline
\end{tabular}

Note. $N=936($ Males $=326$, Females $=610)$. Negative $t$ values indicate higher mean scores for females. ${ }^{\mathrm{a}} p<.05,{ }^{\mathrm{b}} p<.01,{ }^{\mathrm{c}} p<.001$ 
Table 5

Incorporative Domain: Factor-Based Scales and Preliminary Analyses

\begin{tabular}{|c|c|c|c|c|}
\hline & \multirow{2}{*}{$\frac{\text { Reliability }}{\alpha}$} & \multicolumn{3}{|c|}{ Gender Differences } \\
\hline & & $\begin{array}{l}\text { Mean } z \text { score } \\
\text { difference }\end{array}$ & $t$ & $\eta^{2}$ \\
\hline \multicolumn{5}{|l|}{ Family Demographics } \\
\hline \multicolumn{5}{|l|}{ Parents Health } \\
\hline Parents Psychopathology & .61 & -.08 & $-2.15^{a}$ & .005 \\
\hline Parents Poor Physical Health & .54 & -.11 & $-3.03^{b}$ & .01 \\
\hline Family Financial Situation & & & & \\
\hline Family Wealth & .68 & .00 & -.61 & \\
\hline \multicolumn{5}{|l|}{$\begin{array}{l}\text { Academic Setting and Group } \\
\text { Memberships }\end{array}$} \\
\hline Political Action & .71 & & -.25 & \\
\hline Music \& Arts Groups & .76 & -.12 & $-3.40^{b}$ & .012 \\
\hline Academic Achievement & .58 & -.18 & $-5.11^{\mathrm{c}}$ & .027 \\
\hline Self and Other Groups & .61 & -.08 & $-2.35^{\mathrm{a}}$ & .006 \\
\hline Rich Educational Experience & .53 & .00 & 1.40 & \\
\hline Sports Groups & .53 & .30 & $10.56^{\mathrm{c}}$ & .107 \\
\hline
\end{tabular}

Note. $N=936($ Males $=326$, Females $=610)$. Negative $t$ values indicate higher mean scores for females. ${ }^{\mathrm{a}} p<.05,{ }^{\mathrm{b}} p<.01,{ }^{\mathrm{c}} p<.001$ 
Table 6

Global Life Space Dimensions: Factor-Based Scales and Preliminary Analyses

\begin{tabular}{lcccc}
\hline & \multicolumn{3}{c}{ Reliability } & \multicolumn{2}{c}{ Gender Differences } \\
\hline & $\alpha$ & $\begin{array}{c}\text { Mean } z \text { score } \\
\text { difference }\end{array}$ & $t$ & $\eta^{2}$ \\
Positive \& Social Orientation & & -.27 & $-16.12^{\mathrm{c}}$ & .217 \\
Sports Orientation & .77 & .37 & $14.74^{\mathrm{c}}$ & .188 \\
Drug Culture Environment & .79 & .08 & $3.00^{\mathrm{b}}$ & .010 \\
Music \& Arts Achievement & .76 & .01 & .40 & \\
Media Consumer & .70 & .08 & $3.16^{\mathrm{b}}$ & .010 \\
Negative \& Unhealthy Lifestyle & .71 & -.06 & $-3.00^{\mathrm{b}}$ & .010 \\
Intellectual Pursuits & .65 & -.13 & $-6.09^{\mathrm{c}}$ & .037 \\
\hline
\end{tabular}

Note. $N=936$ (Males $=326$, Females $=610)$. Negative $t$ values indicate higher mean scores for females. ${ }^{\mathrm{a}} p<.05,{ }^{\mathrm{b}} p<.01,{ }^{\mathrm{c}} p<.001$ 
Table 7

Correlations Among Global Life Space Dimensions (Males and Females)

\begin{tabular}{llllllll}
\hline & 1 & 2 & 3 & 4 & 5 & 6 & 7 \\
\hline 1. Positive \& Social Orientation & & $.39^{\mathrm{c}}$ & $.22^{\mathrm{c}}$ & $.18^{\mathrm{b}}$ & $.27^{\mathrm{c}}$ & $.47^{\mathrm{c}}$ & $.32^{\mathrm{c}}$ \\
2. Sports Orientation & $.32^{\mathrm{c}}$ & & .04 & .06 & $.26^{\mathrm{c}}$ & $.20^{\mathrm{c}}$ & .07 \\
3. Drug Culture Environment & $.23^{\mathrm{c}}$ & .03 & & .04 & -.05 & $.35^{\mathrm{c}}$ & .06 \\
4. Music \& Arts Achievement & $.16^{\mathrm{c}}$ & $.17^{\mathrm{c}}$ & .01 & & $.28^{\mathrm{c}}$ & $.11^{\mathrm{a}}$ & $.43^{\mathrm{c}}$ \\
5. Media Consumer & $.27^{\mathrm{c}}$ & .26 & $.15^{\mathrm{c}}$ & $.31^{\mathrm{c}}$ & & .08 & $.33^{\mathrm{c}}$ \\
6. Negative \& Unhealthy Lifestyle & $.35^{\mathrm{c}}$ & $.10^{\mathrm{a}}$ & $.37^{\mathrm{c}}$ & $.20^{\mathrm{c}}$ & $.27^{\mathrm{c}}$ & & .10 \\
7. Intellectual Pursuits & $.24^{\mathrm{c}}$ & $.14^{\mathrm{b}}$ & .08 & $.39^{\mathrm{c}}$ & $.24^{\mathrm{c}}$ & $.21^{\mathrm{c}}$ & \\
\hline
\end{tabular}

Note: Correlations for males are above the diagonal and for females below the diagonal. $N=936($ Males $=326$, Females $=610)$.

${ }^{\mathrm{a}} p<.05,{ }^{\mathrm{b}} p<.01,{ }^{\mathrm{c}} p<.001$ 
Table 8

Statistically Significant Correlations Between Brackett's (2001) Life Space Scales and Openness

\begin{tabular}{|c|c|c|c|}
\hline & Male & Female & Full Sample \\
\hline \multicolumn{4}{|l|}{ Biological Domain } \\
\hline Allergy, Sinus, \& Cold & $-.24^{\mathrm{a}}$ & $.15^{\mathrm{a}}$ & .05 \\
\hline Physical Fitness & $-.28^{b}$ & $.18^{\mathrm{b}}$ & .06 \\
\hline \multicolumn{4}{|l|}{ Situational Elements } \\
\hline Casual Clothing & $-.31^{b}$ & .00 & -.10 \\
\hline Pictures \& Sentimental Art & $.21^{\mathrm{a}}$ & $.19^{\mathrm{b}}$ & .10 \\
\hline Religious \& Spiritual Possessions & .15 & $.15^{\mathrm{a}}$ & $.14^{\mathrm{a}}$ \\
\hline Illicit Drug Possessions & .10 & .00 & $-.12^{\mathrm{a}}$ \\
\hline Hunting Equipment & -.01 & $.13^{\mathrm{a}}$ & .09 \\
\hline Art \& Philosophy Books & $.38^{\mathrm{c}}$ & $.28^{\mathrm{c}}$ & $.28^{\mathrm{c}}$ \\
\hline Science Fiction Books & $.30^{\mathrm{b}}$ & $.19^{\mathrm{b}}$ & $.23^{\mathrm{c}}$ \\
\hline Popular Novel Books & $.29^{\mathrm{b}}$ & $.20^{\mathrm{b}}$ & $.19^{\mathrm{c}}$ \\
\hline Blues \& Jazz Recordings & .15 & $.28^{\mathrm{c}}$ & $.25^{\mathrm{c}}$ \\
\hline Pop \& Rap Recordings & .06 & $.15^{\mathrm{a}}$ & $.13^{\mathrm{a}}$ \\
\hline \multicolumn{4}{|l|}{ Interactive Domain } \\
\hline Attention to Appearance & $-.21^{\mathrm{a}}$ & -.09 & $-.14^{\mathrm{a}}$ \\
\hline Smoking Behavior & $.26^{\mathrm{a}}$ & .04 & .10 \\
\hline Self Reflection & $.26^{\mathrm{a}}$ & $.30^{\mathrm{c}}$ & $.29^{\mathrm{c}}$ \\
\hline Solitary Lifestyle & $.23^{\mathrm{a}}$ & -.09 & .00 \\
\hline Music \& Reading Enthusiast & $.42^{\mathrm{c}}$ & $.32^{\mathfrak{c}}$ & $.32^{\mathrm{c}}$ \\
\hline Artistic Activity & $.24^{\mathrm{a}}$ & $.35^{\mathrm{c}}$ & $.29^{\mathrm{c}}$ \\
\hline Artistic Expression and Appreciation & .18 & $.31^{\mathrm{c}}$ & $.28^{\mathrm{c}}$ \\
\hline \multicolumn{4}{|l|}{ Incorporative Domain } \\
\hline Music \& Arts Classes & .15 & $.22^{\mathrm{c}}$ & $.20^{\mathrm{c}}$ \\
\hline Music \& Arts Groups & .02 & $.23^{\mathrm{c}}$ & $.17^{\mathrm{b}}$ \\
\hline Academic Groups & $.28^{b}$ & .03 & $.11^{\mathrm{a}}$ \\
\hline
\end{tabular}

Note. $N=332($ Males $=89$, Females $=242) .{ }^{\mathrm{a}} p<.05,{ }^{\mathrm{b}} p<.01,{ }^{\mathrm{c}} p<.001$ 
Table 9

Preliminary Analyses on Openness Factor and Facet Scales

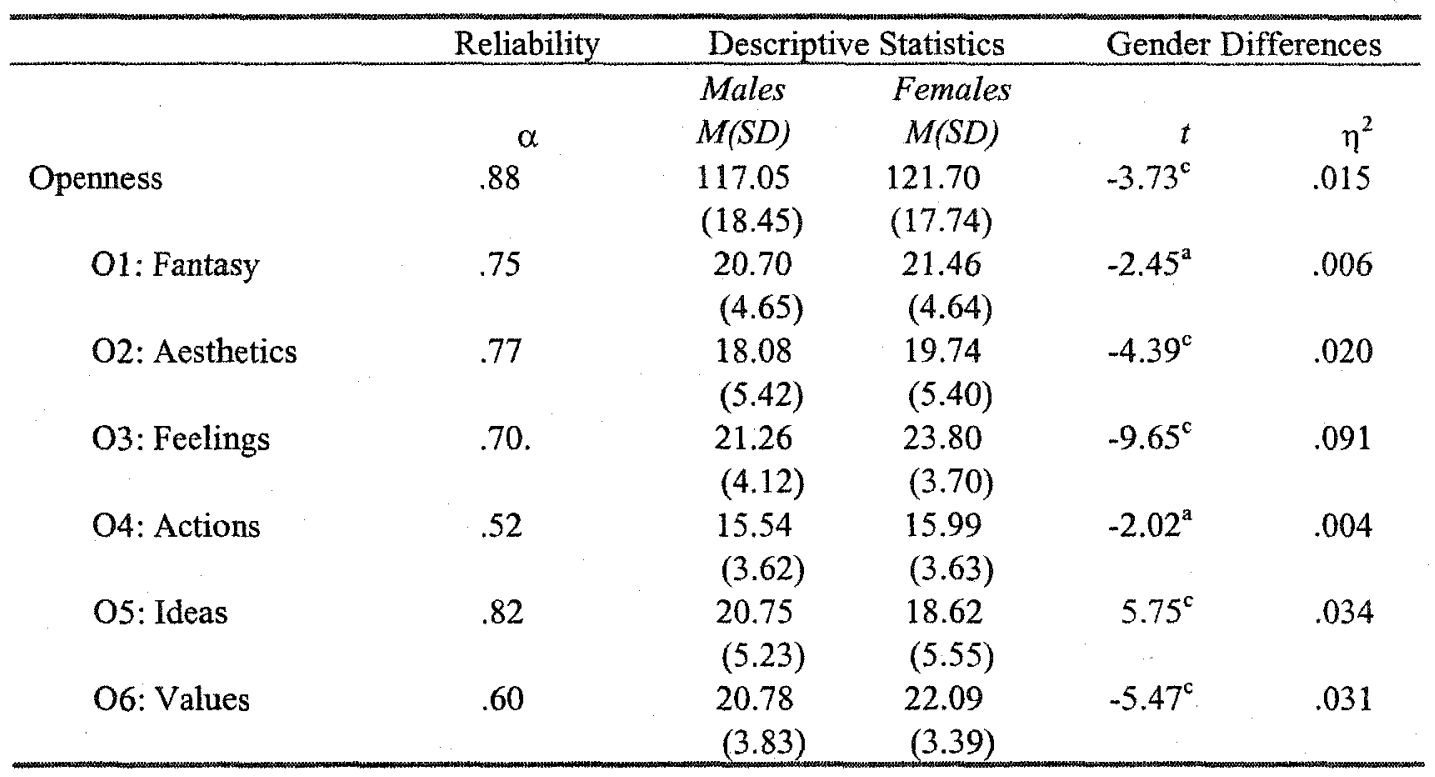

Note. $N=936 .{ }^{\mathrm{a}} p<.05,{ }^{\mathrm{b}} p<.01,{ }^{\mathrm{c}} p<.001$ 
Table 10

Relations Between Scales in the Biological Life Space Domain and Openness

\begin{tabular}{|c|c|c|c|}
\hline & $\begin{array}{c}\text { All } \\
\text { Participants* }\end{array}$ & $\begin{array}{c}\text { Males } \\
\text { Only }\end{array}$ & $\begin{array}{c}\text { Females } \\
\text { Only }\end{array}$ \\
\hline \multicolumn{4}{|l|}{ Physical Health } \\
\hline Somatic Complaints & $.14^{\mathrm{c}}$ & $.16^{\mathrm{b}}$ & $.13^{\mathrm{b}}$ \\
\hline Allergy, Sinus, \& Cold & $.07^{2}$ & .06 & .08 \\
\hline \multicolumn{4}{|l|}{ Psychological Health } \\
\hline Psychopathology & $.13^{\mathrm{c}}$ & $.16^{\mathrm{b}}$ & $.12^{b}$ \\
\hline Nervous Behavior & $.07^{\mathrm{a}}$ & .09 & .07 \\
\hline \multicolumn{4}{|l|}{ Diet/Exercise/Sleep } \\
\hline Physical Fitness & -.04 & $-.14^{\mathrm{a}}$ & .03 \\
\hline Healthy Diet & .06 & -.07 & $.13^{\mathrm{b}}$ \\
\hline Unhealthy Lifestyle & .03 & .02 & .04 \\
\hline
\end{tabular}

Note. $901>N<936$, full sample; $322>N<332$, males; $594>N<604$.

* partial correlations, statistically controlling for sex.

${ }^{\mathrm{a}} p<.05,{ }^{\mathrm{b}} p<.01,{ }^{\mathrm{c}} p<.001$. 
Table 11

Relations Between Scales in the Situational Elements Domain and Openness

\begin{tabular}{|c|c|c|c|}
\hline & $\begin{array}{c}\text { All } \\
\text { Participants* }\end{array}$ & $\begin{array}{l}\text { Males } \\
\text { Only }\end{array}$ & $\begin{array}{c}\text { Females } \\
\text { Only }\end{array}$ \\
\hline \multicolumn{4}{|l|}{ Personal Care } \\
\hline Attention to Appearance (f) & & & -.02 \\
\hline Attention to Appearance (m) & & .04 & \\
\hline Personal Hygiene (f) & & & .02 \\
\hline Personal Hygiene (m) & & -.01 & \\
\hline \multicolumn{4}{|l|}{ Drug Possessions } \\
\hline Illicit Drugs & .05 & .04 & .05 \\
\hline Alcohol & -.01 & -.01 & -.01 \\
\hline Smoking & $.08^{a}$ & $.13^{\mathrm{a}}$ & .05 \\
\hline \multicolumn{4}{|c|}{ Sports, Avocation, \& Leisure Possessions } \\
\hline \multicolumn{4}{|l|}{ General } \\
\hline Popular Masculine Sports & $-.12^{\mathrm{c}}$ & $-.19^{b}$ & -.07 \\
\hline Hunting & $.09^{\mathrm{b}}$ & .07 & $.17^{\mathrm{c}}$ \\
\hline Outdoor Sports & .00 & -.04 & .02 \\
\hline \multicolumn{4}{|l|}{ Instrument Ownership } \\
\hline Musical Instruments & $.22^{\mathrm{c}}$ & $.28^{\mathrm{c}}$ & $.18^{\mathrm{c}}$ \\
\hline \multicolumn{4}{|l|}{ Game Ownership } \\
\hline Video Games & .02 & .03 & .01 \\
\hline Challenging Games & .04 & .06 & .02 \\
\hline \multicolumn{4}{|l|}{ Media-Related Possessions } \\
\hline \multicolumn{4}{|l|}{ Music } \\
\hline Nonconforming Music & $.30^{\mathrm{c}}$ & $.29^{\mathrm{c}}$ & $.32^{\mathrm{C}}$ \\
\hline Popular Music & $.11^{\mathrm{b}}$ & $.12^{\mathrm{a}}$ & $.11^{\mathrm{b}}$ \\
\hline Alternative Rock Music & $.19^{c}$ & $.21^{\mathrm{c}}$ & $.18^{\mathrm{c}}$ \\
\hline \multicolumn{4}{|l|}{ Books and Videos } \\
\hline Reading Orientation & $.31^{\mathrm{c}}$ & $.32^{\mathrm{c}}$ & $.33^{\mathrm{c}}$ \\
\hline Movie Orientation & $.12^{\mathrm{b}}$ & .08 & -.02 \\
\hline Self-Help Books & $.29^{c}$ & $.24^{\mathrm{c}}$ & $.31^{\mathrm{c}}$ \\
\hline \multicolumn{4}{|l|}{ General Room Furnishings } \\
\hline \multicolumn{4}{|l|}{ Religious and Spiritual } \\
\hline Religious & .01 & -.02 & .02 \\
\hline New Age & $.26^{\mathrm{C}}$ & $.18^{\mathrm{b}}$ & $.31^{\mathrm{c}}$ \\
\hline \multicolumn{4}{|l|}{ Home Electronics } \\
\hline General Media & -.02 & .01 & -.03 \\
\hline Computer & .00 & .06 & -.03 \\
\hline \multicolumn{4}{|l|}{ Endorsements } \\
\hline Liberal Politics & $.14^{\mathrm{c}}$ & .07 & $.17^{\mathrm{c}}$ \\
\hline \multicolumn{4}{|l|}{ Personal Room Surroundings } \\
\hline Sentimental Objects & $.17^{\mathrm{c}}$ & $.21^{\mathrm{c}}$ & $.15^{\mathrm{c}}$ \\
\hline Artistic Objects & $.41^{\mathrm{c}}$ & $.41^{\mathrm{c}}$ & $.42^{\mathrm{c}}$ \\
\hline Collectibles & $.09^{\mathrm{b}}$ & $.13^{\mathrm{a}}$ & .07 \\
\hline
\end{tabular}


Table 11 (Continued)

\begin{tabular}{|c|c|c|c|}
\hline & $\begin{array}{c}\text { All } \\
\text { Participants* }\end{array}$ & $\begin{array}{c}\text { Males } \\
\text { Only }\end{array}$ & $\begin{array}{c}\text { Females } \\
\text { Only }\end{array}$ \\
\hline \multicolumn{4}{|l|}{ Clothing and Accessories } \\
\hline \multicolumn{4}{|l|}{ Apparel } \\
\hline Casual Clothing (f) & & & $-.13^{b}$ \\
\hline Casual Clothing (m) & & $.09^{b}$ & \\
\hline Sophisticated Wear (f) & & & .01 \\
\hline Sophisticated Wear (m) & & $.15^{\mathrm{b}}$ & \\
\hline Alternative Accessories (f) & & & $.13^{\mathrm{b}}$ \\
\hline Accessories (m) & & .09 & \\
\hline \multicolumn{4}{|l|}{ Body Adornments } \\
\hline Conventional Earrings & -.01 & $.11^{\mathrm{a}}$ & -.02 \\
\hline Unconventional Earrings & .04 & -.05 & .06 \\
\hline
\end{tabular}

Note. $901>N<936$, full sample; $322>N<332$, males; $594>N<604$.

* partial correlations, statistically controlling for sex.

${ }^{\mathrm{a}} p<.05,{ }^{\mathrm{b}} p<.01,{ }^{\mathrm{c}} p<.001$. 
Table 12

Relations Between Scales in the Interactive Domain and Openness

\begin{tabular}{|c|c|c|c|}
\hline & $\begin{array}{c}\text { All } \\
\text { Participants* }\end{array}$ & $\begin{array}{l}\text { Males } \\
\text { Only }\end{array}$ & $\begin{array}{c}\text { Females } \\
\text { Only }\end{array}$ \\
\hline \multicolumn{4}{|l|}{ Interactive Domain } \\
\hline \multicolumn{4}{|l|}{ Personal Care } \\
\hline Appearance Maintenance & $-.08^{\mathrm{a}}$ & -.02 & $-.11^{b}$ \\
\hline Cleanliness Orientation & $-.07^{\mathrm{a}}$ & $-.13^{\mathrm{a}}$ & -.04 \\
\hline \multicolumn{4}{|l|}{ Recreational Drug Use } \\
\hline Alcohol Abuse & -.03 & -.07 & .01 \\
\hline Smoking Addiction & $.09^{\mathrm{b}}$ & $.12^{\mathrm{a}}$ & .07 \\
\hline Drug Abuse & -.05 & -.07 & -.03 \\
\hline Illicit Drug Use Lifestyle & $.08^{\mathrm{a}}$ & .08 & .08 \\
\hline \multicolumn{4}{|l|}{ Social Deviance } \\
\hline Physical Aggression & -.02 & -.10 & .02 \\
\hline Verbal Aggression & $-.16^{\mathrm{C}}$ & $-.13^{\mathrm{a}}$ & $-.18^{\mathrm{a}}$ \\
\hline Stealing & -.02 & -.04 & .00 \\
\hline Gambling & -.05 & $-.11^{\mathrm{a}}$ & -.01 \\
\hline \multicolumn{4}{|l|}{ School and Work Activity } \\
\hline Studious Lifestyle & $.07^{\mathrm{a}}$ & $.12^{\mathrm{a}}$ & .04 \\
\hline Delinquent Student & .06 & .02 & $.09^{\mathrm{a}}$ \\
\hline Work Ethic & .04 & -.01 & .06 \\
\hline \multicolumn{4}{|l|}{ Sports and Leisure Activity } \\
\hline \multicolumn{4}{|l|}{ The Arts } \\
\hline Artistic Activity & $.33^{\mathrm{c}}$ & $.39^{\mathrm{c}}$ & $.30^{\mathrm{c}}$ \\
\hline Musical Ability \& Achievement & $.24^{\mathrm{c}}$ & $.30^{\mathrm{c}}$ & $.20^{\mathrm{c}}$ \\
\hline Artistic Expression \& Appreciation & $.20^{\mathrm{c}}$ & $.25^{\mathrm{c}}$ & $.16^{\mathrm{c}}$ \\
\hline \multicolumn{4}{|l|}{ Sports } \\
\hline Outdoor Sports Enthusiast & $.14^{\mathrm{c}}$ & $.15^{\mathrm{b}}$ & $.14^{\mathrm{c}}$ \\
\hline Sports Consumption & $-.08^{\mathrm{a}}$ & $-.14^{\mathrm{a}}$ & -.04 \\
\hline Hunting & -.04 & -.07 & .00 \\
\hline Military Arts & .01 & .09 & -.05 \\
\hline \multicolumn{4}{|l|}{ Media Consumption } \\
\hline \multicolumn{4}{|l|}{ General Media } \\
\hline Book Consumer & $.31^{\mathrm{c}}$ & $.32^{\mathrm{c}}$ & $.30^{\mathrm{c}}$ \\
\hline Television Consumer & $-.17^{\mathfrak{c}}$ & $-.16^{b}$ & $-.18^{\mathfrak{c}}$ \\
\hline Movie Consumer & $.18^{c}$ & $.24^{\mathrm{c}}$ & $.15^{\mathfrak{c}}$ \\
\hline News Consumer & .04 & -.06 & $.11^{\mathrm{b}}$ \\
\hline Music Consumer & $.19^{\mathrm{c}}$ & $.23^{\mathrm{b}}$ & $.16^{\mathrm{c}}$ \\
\hline \multicolumn{4}{|l|}{ Internet } \\
\hline Internet Enthusiast & -.01 & -.06 & .02 \\
\hline \multicolumn{4}{|l|}{ Social and Solitary Activity } \\
\hline \multicolumn{4}{|l|}{ Sexual Activity } \\
\hline Promiscuous Lifestyle & .06 & .03 & .08 \\
\hline Masturbation & .07 & .03 & $.14^{\mathrm{c}}$ \\
\hline
\end{tabular}


Table 12 (Continued)

\begin{tabular}{|c|c|c|c|}
\hline \multicolumn{4}{|l|}{ Social Behavior } \\
\hline Conversationalist & $.32^{\mathrm{c}}$ & $.29^{\mathrm{c}}$ & $.33^{\mathrm{c}}$ \\
\hline Telephone Enthusiast & .05 & .10 & .02 \\
\hline Social \& Party Orientation & -.02 & -.04 & -.01 \\
\hline Game-Playing & $.08^{\mathrm{a}}$ & .04 & $.11^{\mathrm{b}}$ \\
\hline Caring Person & .06 & -.05 & $.12^{\mathrm{b}}$ \\
\hline Solitary Lifestyle & $.31^{\mathrm{c}}$ & $.32^{c}$ & $.30^{c}$ \\
\hline \multicolumn{4}{|l|}{ Interactions with Selected Individuals } \\
\hline \multicolumn{4}{|l|}{ Mother and Father } \\
\hline Positive Relations with Mother & .02 & .05 & .01 \\
\hline Relationship Conflict with Parents & -.01 & -.01 & .00 \\
\hline Social Activity with Parents & $.11^{\mathrm{b}}$ & .08 & $.11^{\mathrm{b}}$ \\
\hline Positive Relations with Father & .05 & .08 & .03 \\
\hline \multicolumn{4}{|l|}{ Significant Other ${ }^{e}$} \\
\hline Positive Relations with Partner & .05 & .08 & .03 \\
\hline Relationship Conflict with Partner & $-.12^{\mathrm{a}}$ & $-.20^{\mathrm{a}}$ & -.08 \\
\hline Social Activity with Partner & .04 & .01 & .05 \\
\hline \multicolumn{4}{|l|}{ Best Friend } \\
\hline Social Activity with Best Friend & .00 & .04 & -.02 \\
\hline Positive Relations with Best Friend & $.08^{\mathrm{a}}$ & .06 & $.10^{\mathrm{a}}$ \\
\hline Relationship Conflict with Best Friend &. .06 &. .09 & -.04 \\
\hline
\end{tabular}

Note. $901>N<936$, full sample; $322>N<332$, males; $594>N<604$.

* partial correlations, statistically controlling for sex.

${ }^{\mathrm{a}} p<.05,{ }^{\mathrm{b}} p<.01,{ }^{\mathrm{c}} p<.001$. 
Table 13

Relations Between Scales in the Incorporative Domain and Openness

\begin{tabular}{|c|c|c|c|}
\hline & $\begin{array}{c}\text { All } \\
\text { Participants* }\end{array}$ & $\begin{array}{l}\text { Males } \\
\text { Only }\end{array}$ & $\begin{array}{l}\text { Females } \\
\text { Only }\end{array}$ \\
\hline \multicolumn{4}{|l|}{ Family Demographics } \\
\hline Parents Psychopathology & $.11^{\mathrm{b}}$ & .05 & $.15^{\mathrm{c}}$ \\
\hline $\begin{array}{l}\text { Parents Poor Physical Health } \\
\text { Family Financial Situation }\end{array}$ & .04 & .00 & .07 \\
\hline $\begin{array}{l}\text { Family Wealth } \\
\text { Academic Setting and Group Memberships }\end{array}$ & $.09^{b}$ & $.19^{\mathrm{b}}$ & .03 \\
\hline Political Action & $.11^{\mathrm{b}}$ & -.03 & $.18^{\mathrm{c}}$ \\
\hline Music \& Arts Groups & $.21^{\mathrm{c}}$ & $.19^{\mathrm{b}}$ & $.22^{c}$ \\
\hline Academic Achievement & $.08^{\mathrm{a}}$ & -.04 & $.13^{\mathrm{b}}$ \\
\hline Self \& Other Groups & $.09^{b}$ & -.04 & $.13^{\mathrm{b}}$ \\
\hline Rich Educational Experience & .06 & .05 & .06 \\
\hline Sports Groups & -.04 & $-.13^{\mathrm{a}}$ & .02 \\
\hline
\end{tabular}

Note. $901>N<936$, full sample; $322>N<332$, males; $594>N<604 . \mathrm{f}=$ females only, $\mathrm{m}=$ males only. *partial correlations, statistically controlling for sex. ${ }^{\mathrm{a}} p<.05,{ }^{\mathrm{b}} p<.01,{ }^{\mathrm{c}} p<.001$. 
Table 14

Relations Between Global Life Space Scales and Openness

\begin{tabular}{lccc}
\hline & $\begin{array}{c}\text { All } \\
\text { Participants* }\end{array}$ & $\begin{array}{c}\text { Males } \\
\text { Only }\end{array}$ & $\begin{array}{c}\text { Females } \\
\text { Only }\end{array}$ \\
\hline Positive \& Social Orientation & .07 & $.12^{\mathbf{a}}$ & .05 \\
Sports Orientation & -.02 & -.09 & .04 \\
Drug Culture Environment & .07 & .06 & .07 \\
Music \& Arts Achievement & $.41^{\mathbf{c}}$ & $.45^{\mathbf{c}}$ & $.38^{\mathbf{c}}$ \\
Media Consumer & .09 & $.14^{\mathrm{b}}$ & .06 \\
Negative \& Unhealthy Lifestyle & .03 & -.04 & .03 \\
Intellectual Pursuits & $\mathbf{. 5 5}^{\mathbf{c}}$ &. $\mathbf{4 4}^{\mathbf{c}}$ &. $\mathbf{4 6 ^ { \mathbf { c } }}$ \\
\hline
\end{tabular}

Note. *partial correlations, statistically controlling for sex.

${ }^{\mathrm{a}} p<.05,{ }^{\mathrm{b}} p<.01,{ }^{\mathrm{c}} p<.001 . N=933$ (Males $=324$, females $\left.=609\right)$ 
Table 15

Comparison of Extreme Groups (High versus Low Openness) on Life Space Items for Males (CrossValidation)

\begin{tabular}{|c|c|c|c|}
\hline & & \multicolumn{2}{|c|}{ Cross Validation } \\
\hline Life Space Item & Combined $t$ & Group I & Group II \\
\hline Books of poems (self made) & $-7.54^{c}$ & $-5.34^{\mathrm{c}}$ & $-5.28^{\mathrm{c}}$ \\
\hline Talked about philosophy & $-7.44^{\mathrm{c}}$ & $-4.99^{c}$ & $-5.44^{c}$ \\
\hline Poetry books owned & $-6.62^{c}$ & $-4.78^{c}$ & $-4.89^{c}$ \\
\hline Did arts \& crafts & $-6.31^{\mathrm{c}}$ & $-3.67^{\mathrm{c}}$ & $-5.64^{\mathrm{c}}$ \\
\hline Wrote poetry & $-5.96^{\mathrm{c}}$ & $-2.94^{b}$ & $-6.08^{c}$ \\
\hline Practiced an instrument & $-5.85^{c}$ & $-4.92^{c}$ & $-3.41^{\mathrm{c}}$ \\
\hline Read for pleasure & $-5.56^{\mathrm{c}}$ & $-3.34^{\mathrm{c}}$ & $-2.28^{\mathrm{a}}$ \\
\hline Went to museums & $-5.55^{\mathrm{c}}$ & $-4.59^{\mathfrak{c}}$ & $-3.38^{\mathrm{c}}$ \\
\hline Art \& architecture books & $-5.41^{\mathrm{c}}$ & $-3.99^{c}$ & $-4.03^{c}$ \\
\hline Philosophy books & $-5.13^{\mathrm{c}}$ & $-3.22^{b}$ & $-4.35^{\mathrm{c}}$ \\
\hline Did drawing and sketching & $-5.09^{\mathrm{c}}$ & $-3.46^{\mathrm{c}}$ & $-4.04^{\mathrm{c}}$ \\
\hline Total books owned & $-5.06^{\mathrm{c}}$ & $-3.47^{\mathrm{c}}$ & $-3.75^{\mathrm{c}}$ \\
\hline Total books read & $-5.04^{\mathrm{c}}$ & $-4.23^{\mathrm{c}}$ & $-3.22^{b}$ \\
\hline Novels read & $-4.95^{\mathrm{c}}$ & $-3.85^{c}$ & $-3.54^{\mathrm{c}}$ \\
\hline Can play music by ear & $-4.94^{\mathrm{c}}$ & $-3.90^{\mathrm{c}}$ & $-2.85^{b}$ \\
\hline Wrote a song & $-4.79^{\mathrm{C}}$ & $-3.79^{c}$ & $-2.84^{b}$ \\
\hline Went to hear local band gigs & $-4.76^{\mathrm{c}}$ & $-3.72^{\mathrm{c}}$ & $-3.31^{\mathrm{c}}$ \\
\hline Old diaries or journals & $-4.64^{\mathrm{c}}$ & $-3.90^{\mathrm{c}}$ & $-2.95^{b}$ \\
\hline Acted on stage & -4.59 & $-3.24^{b}$ & $-3.22^{b}$ \\
\hline Jazz music recordings & $-4.50^{\mathrm{c}}$ & $-4.05^{\mathrm{c}}$ & $-2.39^{\mathrm{a}}$ \\
\hline Foreign movies seen & $-4.49^{\mathrm{c}}$ & $-4.78^{\mathrm{c}}$ & $-2.06^{\mathrm{a}}$ \\
\hline Went Hiking & $-4.46^{\mathrm{c}}$ & $-3.92^{c}$ & $-2.63^{b}$ \\
\hline Went to live rock concerts & $-4.39^{\mathfrak{c}}$ & $-3.79^{c}$ & $-2.73^{b}$ \\
\hline Science fiction books & $-4.31^{c}$ & $-3.14^{b}$ & $-3.01^{b}$ \\
\hline Classical literature books & $-4.22^{c}$ & $-2.18^{\mathrm{a}}$ & $-4.04^{c}$ \\
\hline Made fun of a gay person & $4.22^{\mathrm{c}}$ & $2.97^{\mathrm{b}}$ & $3.15^{\mathrm{b}}$ \\
\hline High school acting/drama club & $-4.18^{\mathrm{c}}$ & $-3.30^{b}$ & $-2.75^{\mathrm{b}}$ \\
\hline Posters of art displayed & $-4.16^{\mathrm{c}}$ & $-3.49^{c}$ & $-2.16^{\mathrm{a}}$ \\
\hline Acoustic guitar & $-4.14^{c}$ & $-3.93^{c}$ & $-2.30^{\mathrm{a}}$ \\
\hline Comic/joke books & $-4.14^{\mathrm{c}}$ & $-3.11^{b}$ & $-2.69^{b}$ \\
\hline Talked about culture & $-4.12^{\mathrm{c}}$ & $-2.25^{\mathrm{a}}$ & $-3.28^{\mathrm{c}}$ \\
\hline Wrote lyrics & $-4.05^{\mathrm{c}}$ & $-3.18^{\mathrm{b}}$ & $-2.62^{a}$ \\
\hline Talked about books & $-4.01^{c}$ & $-2.35^{\mathrm{a}}$ & $-3.64^{\mathrm{c}}$ \\
\hline High school football team & $3.96^{\mathrm{c}}$ & $3.13^{b}$ & $2.50^{a}$ \\
\hline Drawings/sketches (self made) & $-3.86^{c}$ & $-2.66^{b}$ & $-3.12^{b}$ \\
\hline Literary fiction books & $-3.85^{c}$ & $-2.61^{a}$ & $-3.03^{b}$ \\
\hline Inspirational literature & $-3.82^{c}$ & $-2.43^{\mathrm{a}}$ & $-3.23^{b}$ \\
\hline Paintings (self made) & $-3.81^{\mathrm{c}}$ & $-2.51^{\mathrm{a}}$ & $-3.08^{b}$ \\
\hline Did macramé or needlepoint & $-3.78^{c}$ & $-2.62^{\mathrm{a}}$ & $-2.93^{b}$ \\
\hline Number of gay friends & $-3.74^{\mathrm{c}}$ & $-3.50^{c}$ & $-2.11^{\mathrm{a}}$ \\
\hline Watched television over weekend & $3.69^{\mathrm{c}}$ & $2.72^{\mathrm{b}}$ & $2.47^{\mathrm{a}}$ \\
\hline Showers taken & $3.65^{\mathrm{c}}$ & $3.22^{\mathrm{b}}$ & $2.00^{\mathrm{a}}$ \\
\hline Saw drama movies & $-3.61^{c}$ & $-2.67^{b}$ & $-2.42^{\mathrm{a}}$ \\
\hline Sight reads music & $-3.60^{c}$ & $-3.15^{b}$ & $-2.11^{\mathrm{a}}$ \\
\hline Raised hand in class & $-3.58^{\mathrm{c}}$ & $-2.70^{b}$ & $-2.35^{\mathrm{a}}$ \\
\hline
\end{tabular}


Table 15 (Continued)

\begin{tabular}{lllll}
\hline & & \multicolumn{2}{c}{ Cross Validation } \\
\hline Life Space Item & Combined t & & Group I & Group II \\
\hline Read for pleasure & $-3.56^{\mathrm{c}}$ & & $-4.57^{\mathrm{c}}$ & $-3.48^{\mathrm{c}}$ \\
Bass guitar & $-3.54^{\mathrm{c}}$ & & $-2.65^{\mathrm{b}}$ & $-2.42^{\mathrm{a}}$ \\
Non-fiction psych books read & $-3.50^{\mathrm{c}}$ & & $-3.42^{\mathrm{c}}$ & $-2.08^{\mathrm{a}}$ \\
Hours listened to music & $-3.50^{\mathrm{c}}$ & $-2.11^{\mathrm{a}}$ & $-3.20^{\mathrm{b}}$ \\
Frequent mood changes & $-3.49^{\mathrm{c}}$ & $-2.14^{\mathrm{a}}$ & $-2.76^{\mathrm{b}}$ \\
Folk music recordings & $-3.43^{\mathrm{c}}$ & $-2.71^{\mathrm{b}}$ & $-2.79^{\mathrm{b}}$ \\
Foreign movies owned & $-3.43^{\mathrm{c}}$ & $-2.34^{\mathrm{a}}$ & $-2.60^{\mathrm{a}}$ \\
Wrote in a journal & $-3.34^{\mathrm{c}}$ & $-2.06^{\mathrm{a}}$ & $-2.86^{\mathrm{b}}$ \\
Rock \& classic rock recordings & $3.27^{\mathrm{c}}$ & $-2.38^{\mathrm{a}}$ & $-2.57^{\mathrm{a}}$ \\
Went camping & $-3.21^{\mathrm{c}}$ & $-2.58^{\mathrm{a}}$ & $-1.99^{\mathrm{a}}$ \\
Read before going bed & $-3.20^{\mathrm{c}}$ & $-2.70^{\mathrm{b}}$ & $-2.21^{\mathrm{a}}$ \\
Incense/sage in room & $-3.20^{\mathrm{c}}$ & $-2.13^{\mathrm{a}}$ & $-2.07^{\mathrm{a}}$ \\
Cut hair & $3.17^{\mathrm{c}}$ & $2.45^{\mathrm{a}}$ & $2.08^{\mathrm{a}}$ \\
Can raise eyebrow & $-3.10^{\mathrm{c}}$ & $-2.38^{\mathrm{a}}$ & $-1.98^{\mathrm{a}}$ \\
History and political books & $-3.06^{\mathrm{c}}$ & $-2.64^{\mathrm{a}}$ & $-2.13^{\mathrm{a}}$ \\
Ate dinner alone & $-3.05^{\mathrm{c}}$ & $-2.11^{\mathrm{a}}$ & $-2.48^{\mathrm{a}}$ \\
Went to place to relax alone & $-3.03^{\mathrm{c}}$ & $-2.30^{\mathrm{a}}$ & $-2.07^{\mathrm{a}}$ \\
Mom diagnosed w/ depression & $-2.73^{\mathrm{c}}$ & $-1.98^{\mathrm{a}}$ & $-2.22^{\mathrm{a}}$ \\
Screamed at significant other & $2.35^{\mathrm{b}}$ & $2.64^{\mathrm{a}}$ & $2.02^{\mathrm{a}}$ \\
\hline
\end{tabular}

Note. Items that overlapped between males and females are in boldface.

${ }^{\mathrm{a}} p<.05,{ }^{\mathrm{b}} p<.01,{ }^{\mathrm{c}} p<.001$. 
Table 16

Comparison of Extreme Groups (High versus Low Openness) on Life Space Items for Females (CrossValidation)

\begin{tabular}{|c|c|c|c|}
\hline \multirow[b]{2}{*}{ Life Space Item } & \multirow[b]{2}{*}{ Combined $t$} & \multicolumn{2}{|c|}{ Cross Validation } \\
\hline & & Group I & Group II \\
\hline Books of poems (self made) & $-10.13^{c}$ & $-7.81^{c}$ & $-6.16^{c}$ \\
\hline Poetry books & $-9.26^{\mathrm{c}}$ & $-7.08^{c}$ & $-5.85^{\mathrm{c}}$ \\
\hline Drawings/sketches (self made) & -9.05 & $-6.92^{c}$ & $-5.88^{\mathrm{c}}$ \\
\hline Wrote poetry & $-7.23^{c}$ & $-4.47^{\mathrm{c}}$ & $-5.57^{\mathfrak{c}}$ \\
\hline Talked about politics & $-6.88^{\mathrm{c}}$ & $-5.68^{\mathrm{c}}$ & $-4.06^{\mathrm{c}}$ \\
\hline Philosophy books & $-6.84^{\mathrm{c}}$ & $-6.00^{\mathrm{c}}$ & $-3.88^{c}$ \\
\hline Mind/body books & $-6.71^{c}$ & $-5.99^{\mathrm{c}}$ & $-3.65^{c}$ \\
\hline Literary fiction books & $-6.71^{\mathrm{c}}$ & $-4.91^{c}$ & $-4.68^{c}$ \\
\hline Classical literature books & $-6.63^{\mathrm{c}}$ & $-6.49^{\mathrm{c}}$ & $-3.31^{\mathrm{c}}$ \\
\hline Inspirational literature & $-6.52^{c}$ & $-4.54^{\mathrm{c}}$ & $-4.63^{c}$ \\
\hline Self-help books & $-6.47^{\mathrm{c}}$ & $-3.54^{\mathrm{c}}$ & $-5.53^{c}$ \\
\hline Paintings (self made) & $-6.37^{\varepsilon}$ & $-4.51^{\mathrm{c}}$ & $-4.65^{\mathrm{c}}$ \\
\hline Read for pleasure & $-6.32^{c}$ & $-6.19^{c}$ & $-2.90^{b}$ \\
\hline Art \& architecture books & $-6.25^{\mathrm{c}}$ & $-4.74^{c}$ & $-4.18^{\mathrm{c}}$ \\
\hline Posters of art displayed & $-6.17^{\mathrm{c}}$ & $-3.97^{\mathrm{c}}$ & $-4.76^{\mathrm{c}}$ \\
\hline Total books owned & $-5.99^{\mathrm{c}}$ & $-5.48^{\mathrm{c}}$ & $-3.08^{b}$ \\
\hline Talked about news & $-5.90^{c}$ & $-4.71^{c}$ & $-3.53^{\mathrm{c}}$ \\
\hline Talked about philosophy & $-5.88^{\mathrm{c}}$ & $-5.17^{\mathrm{c}}$ & $-2.88^{b}$ \\
\hline Did arts \& crafts & $-5.87^{\mathrm{c}}$ & $-5.04^{\mathrm{c}}$ & $-3.18^{b}$ \\
\hline Did drawing \& sketching & $-5.85^{\mathrm{c}}$ & $-4.90^{\mathrm{c}}$ & $-3.35^{\mathrm{c}}$ \\
\hline Old diaries or journals & $-5.85^{\mathrm{c}}$ & $-4.60^{c}$ & $-3.43^{\mathrm{c}}$ \\
\hline Foreign movies seen & $-5.70^{\mathrm{c}}$ & $-4.03^{\mathrm{c}}$ & $-3.64^{\mathrm{c}}$ \\
\hline Novels read & $-5.55^{\mathrm{c}}$ & $-5.48^{\mathrm{c}}$ & $-2.50^{\mathrm{a}}$ \\
\hline Jazz music recordings & $-5.48^{\mathrm{c}}$ & $-3.33^{c}$ & $-4.41^{c}$ \\
\hline Sang by self & $-5.33^{\mathrm{c}}$ & $-2.74^{b}$ & $-4.53^{\mathrm{c}}$ \\
\hline Folk music recordings & $-5.20^{\mathrm{c}}$ & $-4.36^{\mathrm{c}}$ & $-3.08^{b}$ \\
\hline Independent movies owned & $-5.20^{\mathrm{c}}$ & $-3.14^{b}$ & $-4.30^{\mathrm{c}}$ \\
\hline Number of gay friends & $-5.13^{c}$ & $-2.94^{b}$ & $-4.54^{\mathrm{c}}$ \\
\hline Boxes of herbal tea & $-5.09^{c}$ & $-4.79^{c}$ & $-2.57^{\mathrm{a}}$ \\
\hline Laughed out loud by oneself & $-5.08^{c}$ & $-3.34^{\mathrm{c}}$ & $-3.92^{c}$ \\
\hline Plays/screen plays owned & $-5.08^{\mathrm{c}}$ & $-3.11^{b}$ & $-3.96^{\mathrm{c}}$ \\
\hline History \& political books & $-5.01^{\mathfrak{c}}$ & $-3.18^{b}$ & $-4.01^{\mathrm{c}}$ \\
\hline Rock \& classical rock recordings & $-4.92^{\mathrm{c}}$ & $-2.92^{b}$ & $-3.86^{\mathrm{c}}$ \\
\hline Blues music recordings owned & $-4.88^{\mathrm{c}}$ & $-2.95^{b}$ & $-3.94^{\mathrm{c}}$ \\
\hline Talked about book & $-4.87^{\mathrm{c}}$ & $-3.84^{\mathrm{c}}$ & $-3.03^{b}$ \\
\hline Incense/sage & $-4.83^{\mathrm{c}}$ & $-2.81^{b}$ & $-3.69^{c}$ \\
\hline Wrote to people & $-4.70^{\mathrm{c}}$ & $-4.16^{\mathrm{c}}$ & $-2.60^{b}$ \\
\hline Sculptures (șelf made) & $-4.70^{\mathrm{c}}$ & $-2.82^{b}$ & $-4.04^{\mathrm{c}}$ \\
\hline Discussed politics with best friend & $-4.67^{\mathrm{c}}$ & $-3.80^{\mathrm{c}}$ & $-3.00^{b}$ \\
\hline High school acting/drama club & $-4.67^{c}$ & $-2.21^{\mathrm{a}}$ & $-4.76^{\mathrm{c}}$ \\
\hline Non-fiction psychology books & $-4.66^{c}$ & $-4.29^{\mathrm{c}}$ & $-3.71^{\mathrm{c}}$ \\
\hline Talked about the future & $-4.59^{\mathrm{c}}$ & $-3.92^{\mathrm{c}}$ & $-2.63^{b}$ \\
\hline Discussed politics w/ partner & $-4.55^{\mathrm{c}}$ & $-2.75^{b}$ & $-3.76^{\mathrm{c}}$ \\
\hline Discussed book with dad & $-4.42^{\mathrm{c}}$ & $-4.20^{\mathrm{c}}$ & $-2.06^{\mathrm{a}}$ \\
\hline 70 's music recordings owned & $-4.35^{\mathrm{c}}$ & $-2.74^{b}$ & $-3.31^{\mathrm{c}}$ \\
\hline
\end{tabular}


Table 16 (Continued)

\begin{tabular}{|c|c|c|c|}
\hline & & \multicolumn{2}{|c|}{ Cross Validation } \\
\hline Life Space Item & Combined $t$ & Group I & Group II \\
\hline$\overline{\mathrm{AP} \text { exams passed }}$ & $-4.34^{\mathrm{c}}$ & $\overline{-3.74^{c}}$ & $-2.46^{\mathrm{a}}$ \\
\hline Wrote in journal & $-4.26^{\mathrm{c}}$ & $-3.28^{c}$ & $-2.70^{b}$ \\
\hline Fraternity parties attended & $4.23^{\mathrm{c}}$ & $2.55^{\mathrm{a}}$ & $3.15^{b}$ \\
\hline Music courses taken in high school & $-4.15^{\mathrm{c}}$ & $-2.69^{\mathrm{b}}$ & $-2.93^{b}$ \\
\hline Performing arts courses & $-4.09^{\mathrm{c}}$ & $-2.45^{\mathrm{a}}$ & $-3.64^{\mathrm{c}}$ \\
\hline Discussed book with best friend & $-4.09^{\mathrm{c}}$ & $-2.33^{\mathrm{a}}$ & $-3.43^{\mathrm{c}}$ \\
\hline Classical music recordings & $-4.07^{\mathrm{c}}$ & $-2.66^{\mathrm{b}}$ & $-3.10^{b}$ \\
\hline Ate fried foods & $4.05^{\mathrm{c}}$ & $3.08^{\mathrm{b}}$ & $2.56^{\mathrm{a}}$ \\
\hline Pictures taken & $-4.01^{\mathrm{c}}$ & $-3.38^{b}$ & $-3.72^{\mathrm{c}}$ \\
\hline Crystals owned & $-4.01^{\mathrm{c}}$ & $-3.07^{b}$ & $-2.51^{\mathrm{a}}$ \\
\hline Fell asleep with television on & $4.00^{\mathrm{c}}$ & $2.14^{\mathrm{a}}$ & $3.70^{c}$ \\
\hline Checked news online & $-3.99^{\mathrm{c}}$ & $-3.09^{b}$ & $-2.64^{b}$ \\
\hline Pieces of designer clothes & $3.98^{\mathrm{c}}$ & $2.28^{\mathrm{a}}$ & $3.29^{\mathrm{c}}$ \\
\hline Swiss army knife & $-3.94^{\mathrm{c}}$ & $-2.20^{\mathrm{a}}$ & $-3.62^{c}$ \\
\hline Science fiction books owned & $-3.82^{\mathrm{c}}$ & $-3.06^{\mathrm{b}}$ & $-2.42^{\mathrm{a}}$ \\
\hline Bought something a friend had & $3.81^{\mathrm{c}}$ & $2.29^{\mathrm{a}}$ & $2.96^{\mathrm{b}}$ \\
\hline Big band music recordings & $-3.78^{\mathrm{c}}$ & $-2.42^{\mathrm{a}}$ & $-3.07^{b}$ \\
\hline Belonged to high school travel club & $-3.74^{\mathrm{c}}$ & $-2.95^{\mathrm{b}}$ & $-2.08^{\mathrm{a}}$ \\
\hline Pieces of vintage clothing & $-3.72^{\mathrm{c}}$ & $-2.91^{b}$ & $-3.73^{c}$ \\
\hline Funk music recordings & $-3.72^{\mathrm{c}}$ & $-2.87^{b}$ & $-2.42^{\mathrm{a}}$ \\
\hline Read school newspaper & $-3.70^{\mathrm{c}}$ & $-3.44^{\mathrm{c}}$ & $-2.00^{\mathrm{a}}$ \\
\hline Reggae music recordings & $-3.57^{\mathrm{c}}$ & $-2.04^{2}$ & $-2.81^{b}$ \\
\hline Did Painting & $-3.56^{\mathrm{c}}$ & $-2.94^{\mathrm{b}}$ & $-3.11^{b}$ \\
\hline Vitamin bottles & $-3.53^{c}$ & $-2.07^{\mathrm{a}}$ & $-2.63^{b}$ \\
\hline Made fun of a gay person & $3.53^{\mathrm{c}}$ & $2.66^{\mathrm{b}}$ & $2.52^{\mathrm{a}}$ \\
\hline Alternative music recordings & $-3.52^{c}$ & $-1.97^{\mathrm{a}}$ & $-3.55^{\mathrm{c}}$ \\
\hline Went to museums & $-3.51^{c}$ & $-2.46^{\mathrm{a}}$ & $-3.31^{\mathrm{c}}$ \\
\hline Bottles of Soda & $3.42^{\mathrm{c}}$ & $2.91^{\mathrm{b}}$ & $2.04^{\mathrm{a}}$ \\
\hline Equal rights endorsements & $-3.40^{\mathrm{c}}$ & $-2.50^{\mathrm{a}}$ & $-2.25^{\mathrm{a}}$ \\
\hline Photos of Partner & $3.34^{\mathrm{c}}$ & $2.90^{\mathrm{b}}$ & $2.05^{\mathrm{a}}$ \\
\hline Diagnosed with physical illness & $-3.31^{\mathrm{c}}$ & $-3.35^{c}$ & $-2.46^{\mathrm{a}}$ \\
\hline Made oneself center of attention & $-3.31^{c}$ & $-3.12^{b}$ & $-2.08^{\mathrm{a}}$ \\
\hline Cultural event with Partner & $-3.31^{\mathrm{c}}$ & $-2.34^{\mathrm{a}}$ & $-2.61^{a}$ \\
\hline "Must watch" television shows & $3.30^{\mathrm{c}}$ & $2.61^{\mathrm{b}}$ & $2.92^{b}$ \\
\hline Mom diagnosed w/ depression & $-3.29^{c}$ & $-3.11^{b}$ & $-2.69^{b}$ \\
\hline Email addresses stored & $-3.27^{\mathrm{C}}$ & $-3.11^{b}$ & $-2.74^{b}$ \\
\hline Ate dinner alone & $-3.21^{\mathrm{c}}$ & $-2.02^{\mathrm{a}}$ & $-2.42^{\mathrm{a}}$ \\
\hline Raised hand in class & $-3.19^{\mathrm{c}}$ & $-2.70^{b}$ & $-2.11^{\mathrm{a}}$ \\
\hline Discussed book with Partner & $-3.12^{c}$ & $-2.06^{\mathrm{a}}$ & $-2.59^{a}$ \\
\hline Participated in high-risk sports & $-2.88^{\mathrm{c}}$ & $-2.17^{\mathrm{a}}$ & $-1.98^{\mathrm{a}}$ \\
\hline High school environmental groups & $-2.87^{\mathrm{c}}$ & $-2.09^{\mathrm{a}}$ & $-2.66^{b}$ \\
\hline Did sports with best friend & $2.55^{\mathrm{b}}$ & $2.19^{\mathrm{a}}$ & $2.05^{\mathrm{a}}$ \\
\hline
\end{tabular}

Note. Items that overlapped between males and females are in boldface.

${ }^{\mathrm{a}} p<.05,{ }^{\mathrm{b}} p<.01,{ }^{\mathrm{c}} p<.001$. 


\begin{tabular}{|l|l|l|}
\hline $\begin{array}{l}\text { Sociological } \\
\text { Level }\end{array}$ & $\begin{array}{l}\text { Incorporative area: } \\
\text { Socio-cultural groups including and interacting with personality. }\end{array}$ \\
\hline $\begin{array}{l}\text { Psychological } \\
\text { Level }\end{array}$ & $\begin{array}{l}\text { Internal Personality: } \\
\text { Internal components of personality } \\
\text { such as motives, thoughts, feelings, } \\
\text { models of the self and world, and } \\
\text { traits }\end{array}$ & $\begin{array}{l}\text { Interactive area: } \\
\text { External individuals and } \\
\text { situations interacting with } \\
\text { personality. }\end{array}$ \\
\hline $\begin{array}{l}\text { Biological } \\
\text { Level }\end{array}$ & $\begin{array}{l}\text { Biological Life Space: } \\
\text { Brain function and relevant } \\
\text { biological features supporting and } \\
\text { influencing personality. }\end{array}$ & $\begin{array}{l}\text { Situational Elements area: } \\
\text { Individual features of situations } \\
\text { such as settings and props. }\end{array}$ \\
\hline
\end{tabular}

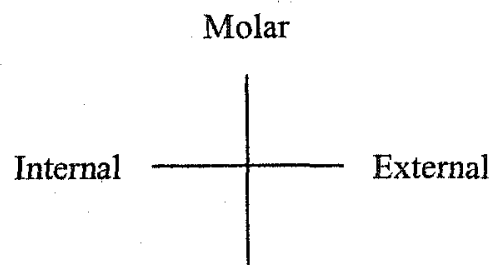

Molecular 


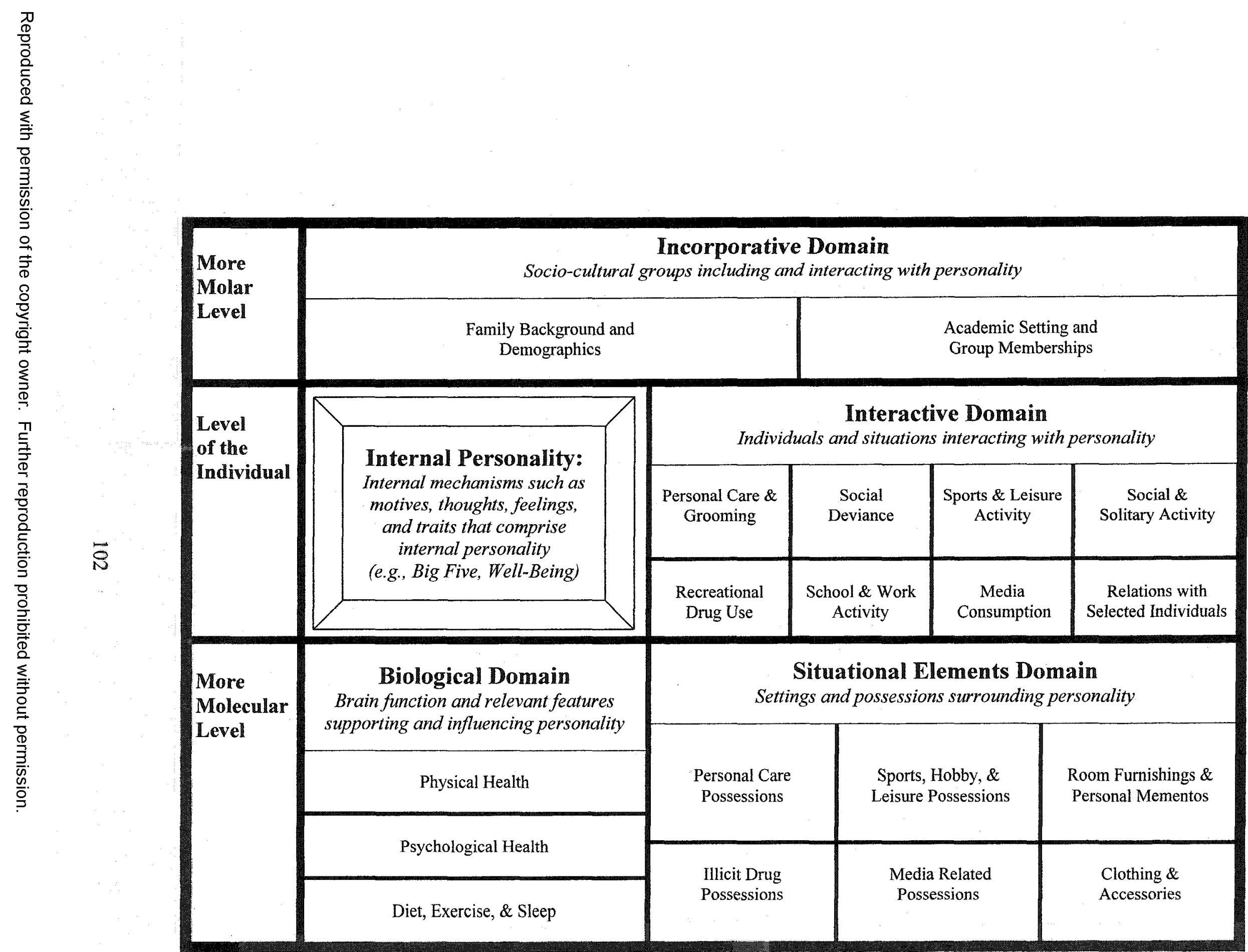


Appendix A

Life Space Scales (first-order) and Reliabilities: Biological Domain

\section{Physical Health}

Somatic Complaints

(15 items, $\alpha=.82$ )

Allergy, Sinus, \& Cold

(12 items, $\alpha=.79$ )

\section{Psychological Health}

Psychopathology

(9 items, $\alpha=.78$ )

Nervous Behavior

(9 items, $\alpha=.60$ )

\section{Diet, Exercise \& Sleep}

Physical Fitness

(13 items, $\alpha=.80$ )

Healthy Diet

(15 items, $\alpha=.73$ )

Unhealthy Lifestyle

(8 items, $\alpha=.65$ )
Stomach ache, nauseated, felt dizzy, had headache, fatigue, sleeping problems, indigestion, neck/back pain, diarrhea, constipated, chest pain, heart palpitation, twitches, heartburn, other physical illness

Allergy medications, inhalers, asthma, allergies, sinus medications, cold medications, antibiotics, prescription medications, pain relievers, stomach medications, ointments, sinus or ear infections

Prescriptions for psychotropic drugs, time taking drugs, depression diagnosis, anxiety diagnosis, time in psychotherapy, eating disorder, ADD/ADHD, manic depression diagnosis, psychiatrically hospitalized

Feelings of restlessness, trouble concentrating, twist hair, chew on pen, tap feet, cried, sweaty palms, cold hands/feet, bite nails

Pounds can bench, number of pushups, outside sport activity per week, lift weights per week, aerobic activity per week, eat extra protein, stretch per week, body building supplements, milk per day, run a mile, meals ate per day, number of crunches, times ate red meat

Keeps water around, vegetables per day, fruits per day, times been on a diet, cut carbohydrates, eat a salad, water per day, eats fried foods (r), takes vitamins, does not eat past 6pm, cups of coffee per day, cups of herbal tea per day, weight control pills, pieces of gum per day

Sleeps less than 5 hours, eats dinner(r), sleeps after 2am, sleeps 7-8 hours(r), eats lunch(r), eats breakfast(r), stays awake all night, takes a nap 
Appendix B

Life Space Scales (first-order) and Reliabilities: Situational Elements Domain

Personal Care Possessions

Attention to Appearance ( $f$ )

(15 items, $\alpha=.86$ )

Attention to Appearance (m)

(11 items, $\alpha=.65$ )

Personal Hygiene (f)

(8 items, $\alpha=.61$ )

Personal Hygiene (m)

(6 items, $\alpha=.65$ )

\section{Drug Possessions}

Illicit Drugs

(7 items, $\alpha=.82$ )

Alcohol

( 5 items, $\alpha=.73$ )

Smoking

(6 items, $\alpha=.76$ )

Sports, Avocation, \& Leisure Possessions

General

Popular Masculine Sports

(10 items, $\alpha=.72$ )

Hunting

( 7 items, $\alpha=.77$ )
Owns: Facial makeup, eye makeup, lipsticks, cover up makeup, moisturizer, hair gels, nail polish, curling irons, perfumes, small mirrors, body lotion, self-tanning lotion, brushes/combs, lip balms, hair dryers

Owns: After shave, shaving cream, lip balms, hair gels, moisturizer, cologne, hair dryers, disposable razors, small mirrors, nail clippers, brushes/combs

Owns: Deodorant, toothbrushes, q-tips, soaps, dental floss, feminine products, shampoos, nail clippers

Owns: toothbrushes, soaps, deodorant, shampoos, electric razors, dental floss

Owns: Cocaine, designer drugs, opiates (heroin), hallucinogens (LSD), sedatives (downers), painkillers, amphetamines

Owns: Bottles of alcohol, wine glasses, bottles of wine, shot glasses, bottles of wine coolers

Owns: Bong/pipe, cigarette lighters, ashtrays, rolling papers, marijuana joints, packs of cigarettes

Owns: Football, basketballs, sports posters, sports movies, sports cards, sports awards, baseball gloves, athletic team endorsements, golf clubs, Frisbees

Owns: Hunting knives, hand guns, bb guns, compasses, Swiss Army knife, fishing rods, flashlights 
Appendix B (Continued)

Outdoor Sports

(8 items, $\alpha=.66$ )

\section{Instruments}

Musical Instruments

(7 items, $\alpha=.60$ )

\section{Games}

Video Games

(4 items, $\alpha=.76$ )

Challenging Games

(4 items, $\alpha=.77$ )

\section{Media Related Possessions}

Music

Nonconforming Music

(12 items, $\alpha=.79$ )

Popular Music

(6 items, $\alpha=.71$ )

Alternative Rock Music

(7 items, $\alpha=.77$ )

\section{Books and Videos}

Reading Orientation

(15 items, $\alpha=.85$ )

Movie Orientation

(6 items, $\alpha=.79$ )

Self Help Books

(8 items, $\alpha=.72$ )
Owns: Roller skates, skis, bicycle, tennis racket, lacrosse stick, skateboard/scooter, hockey stick, scuba equipment

Owns: Acoustic guitar, electric guitar, keyboard, bass guitar, drums, stringed instruments, brass instruments

Owns: Video cartridge, videogame machine, computer games, videogames

Owns: Decks of cards, board games, checker boards, chess sets

Owns: Blues, jazz, folk, big band music, world music, classical, 70's music, funk, opera, show tunes, reggae, gospel

Owns: R\&B, pop, hip hop/rap, soft rock, 80's music, rock/ classic rock

Owns: Hardcore, hard rock, punk, alternative music, ska/new wave, techno, gothic

Owns: Science fiction, comic/joke, history or political, philosophy, classical literature, computer, art/architecture, fiction- action, plays/screen play, biography/ autobiography, entrepreneurial, movieforeign, fiction- literary, reference books, fictionmystery

Owns: Comedy, drama, action, cartoon, science fiction, documentary movies

Owns: Relationship, fiction- romance, self-help, $\mathrm{mind} / \mathrm{body}$, diet/health/fitness, poetry, nonfiction psychology, writing skills 
Appendix B (Continued)

\section{General Room Furnishings \\ Religious and Spiritual \\ Religious \\ (5 items, $\alpha=.73$ )}

New Age

(6 items, $\alpha=.69$ )

Home Electronics

General Media

(6 items, $\alpha=.63$ )

Computer

(6 items, $\alpha=.60$ )

Endorsements

Liberal Politics

( 7 items, $\alpha=.65$ )

Personal Room Surroundings

Sentimental Objects

(10 items, $\alpha=.82$ )

Artistic Objects

(7 items, $\alpha=.73$ )

Collectibles

(11 items, $\alpha=.57$ )
Owns: Rosary beads, crosses, religious pendants, religious crucifixes, bible type books

Owns: Occult objects, pagan writings, crystals, incense/sage, meditation record, new age spiritual

Owns: Television, VCR/DVD, stereo, walkman, answering machine, boom box

Owns: Web camera, owns computer, CD burner, scanner, MP3 music, camcorder

Owns: Environmental issues, world peace, equal rights, capital punishment, aids awareness, prochoice, political party, evolution

Owns: Photographs of friends, photo albums, photographs of family, candles (non-religious), scrap book, stuffed animals, letters from friends, dried silk flowers, old love letters, old diaries/journals

Owns: Old diaries/ journals, Drawings/sketches made, paintings you made, sculptures made, books/poems made, posters art, posters landscapes

Owns: Bottle caps, autographs of famous people, coins, model sets, stamp, old concert tickets, posters of musicians, stolen signs, service awards, posters of poems, naked posters, posters of actors 
Appendix B (Continued)

\section{Clothing and Accessories Apparel \\ Casual Clothing (f) \\ (15 items, $\alpha=.86$ )}

Casual Clothing $(\mathrm{m})$

(15 items, $\alpha=.74$ )

Sophisticated Wear (f)

(12 items, $\alpha=.75$ )

Sophisticated Wear (m)

(13 items, $\alpha=.78$ )

Alterative Accessories ( $f$ )

(14 items, $\alpha=.78$ )

Accessories (m)

(15 items, $\alpha=.78$ )
Owns: Workout clothes, $\mathrm{t}$-shirts, sweaters, sweat shirts, dress pants, shorts, skirts, jeans, ladies bras, coats/jackets, bathing suits, belts, pants, designer clothes, dresses

Owns: Workout clothes, shorts, baseball caps, sandals, hats, UNH clothes, sweat shirts, sneakers, casual clothes, jock straps, winter boots, shirts (button), pairs of socks, pants, jeans

Owns: Gold rings, gold necklaces, gold bracelets, suits, blazers, rings with gems, causal clothes(r), high-heeled shoes, lingerie, turtle-necks, engagement rings, costume jewels, stockings

Owns: Blazers, suits, dress shoes, dress socks, coats/jackets, dress pants, wallets, dress ties, bathrobes, pajamas, belts, watches, gloves

Owns: Vintage clothes, other necklaces, hemp necklaces, silver necklaces, shell necklaces, silver bracelets, anklets, silver rings, bandanas, handmade clothes, pendants, hats, earrings (pair)

Owns: Silver bracelets, earring (one), silver necklace, pendants, silver rings, other necklace, other bracelets, gold necklace, earrings (pair), gold bracelets, hemp necklaces, bandanas, rings with gems, gold rings, shell necklaces

Owns: Left ear lobe, right ear lobe, ear (cartilage), belly button ring, nose, tongue

Owns: Lip, lower genitalia, self-made burns, selfmade cuts, hole in ear, nipple 
Appendix C

Life Space Scales (first-order) and Reliabilities: Interactive Domain

\section{Personal Care}

Appearance Maintenance

(10 items, $\alpha=.77$ )

Cleanliness Orientation

(11 items, $\alpha=.60$ )

\section{Recreational Drug Use}

Alcohol Abuse

( 8 items, $\alpha=.88$ )

Smoking Addiction

(5 items, $\alpha=.89$ )

Drug Abuse

(8 items, $\alpha=.69$ )

Illicit Drug Use Lifestyle

( 8 items, $\alpha=.85$ )
Looking in mirror, jewelry wearing, time choosing clothes, self-denigrating remark, time getting ready, money spent on clothes, cologne/perfume, color hair, duration of bathing, bought something friend had

Clean room, changed sheets, clothing on floor, shower/bath, made bed, floss, showers taken, cut hair, done laundry, brush teeth, iron clothes

Greatest amount of alcohol consumed, five + alcohol, one alcoholic beverage, alcohol in the summer, drinking game, loss of memory while drinking, passed out drunk, vomit because drunk

Packs of cigarettes smoke, cigarettes smoked yesterday, smokes (yes/no), smoke before eating, times tried to quit smoking

Missed classes because of drug use, drugs in the morning, over-the-counter, sat alone and drank, used designer drugs, used drugs to sleep, went to class drunk, huffed

Times smoked marijuana, sold illegal drugs, use of drugs over the summer, money spent on drugs, mixed drugs and alcohol, different illicit, use heroin/crack, have friends who use drugs

Fights in last two years, physical fights, thrown something in fight, nasty verbal fights, been arrested, knocked unconscious in a fight

Made fun of someone's looks, made fun of someone, made fun of gay people, hurt someone's feelings, gossiped, made a racist comment, spread a rumor 
Appendix $\mathrm{C}$ (Continued)

Stealing

( 6 items, $\alpha=.68$ )

Gambling

( 3 items, $\alpha=.64$ )

\section{School and Work}

Studious Lifestyle

(7 items, $\alpha=.55$ )

Delinquent Student

(6 items, $\alpha=.50$ )

Work Ethic

(3 items, $\alpha=.89$ )

Sports and Leisure Activity

The Arts

Artistic Activity

(12 items, $\alpha=.78$ )

Music Ability \&

Achievement

(10 items, $\alpha=.83$ )

Artistic Expression and Appreciation

(11 items, $\alpha=.6$ )
Stolen something, switched tags, ate food then didn't pay, stolen large item, sneaked in theater, vandalized something

Money lost gambling, money gambled, lottery tickets purchased

Studied alone for 3 hours, hours studied over weekend, emailed or met with professor, studied with a group, read over notes from class, raised hand in class, arrived at least 5 minutes early to class

Arrived late to class, intentionally skipped class, handed in an assignment late, fell asleep in class, hours studied over weekend(r)

Money earned per week, hours of work per week, number of jobs

Arts and crafts, drawing/ sketching, painting, sculpting, public exhibit of art, took pictures, designed clothing/jewelry, macramé/needlepoint, art/architecture, graphic arts, photography magazines, wrote short story

Composed music, wrote a song, wrote lyrics, played in band, sang in a band, practiced an instrument, play by ear, published music, sight reads music, published a song

Plays (other), Broadway plays, museums, operas or ballets, acted on stage, danced in a production, comedy show, theme parks, choreographed, local band gigs, sang in choir 
Appendix C (Continued)

\author{
Sports \\ Outdoor Sports Enthusiast \\ (12 items, $\alpha=.80$ ) \\ Sports Consumption \\ ( 7 items, $\alpha=.70$ ) \\ Hunting \\ (4 items, $\alpha=.67$ ) \\ Military Arts \\ (3 items, $\alpha=.48$ ) \\ Media Consumption Area \\ Book Consumer \\ (6 items, $\alpha=.82$ ) \\ Television Consumer \\ ( 8 items, $\alpha=.76$ )
}

Movie Consumer

( 6 items, $\alpha=.70$ )

News Consumer

( 6 items, $\alpha=.65$ )

Music Consumer

(6 items, $\alpha=.61$ )

\section{Internet}

Internet Enthusiast

(11 items, $\alpha=.80$ )
Kayaking/canoeing, hiking, camping, boating/sailing, high risk sports, bike riding, downhill skiing, swimming, water skiing, scuba/snorkeling, cross country skiing, ice skating

Sports with friends, sports event, sports magazines, professional sports events, two friends sports, tennis/racquetball, golf, jogging/running

Hunting, gun shooting, fishing (lake), fishing (ocean)

Wrestling event, martial arts, boxing/wrestling

Read for pleasure, read before bed, novels read, number of books, time read for pleasure, nonfiction read

Different "must" watch T. V. shows, watched evening sitcoms, hours of T.V. per day, hours of T.V. on weekend, watched reality based shows, watched music videos, saw movies on T.V., watched day soaps

Has seen: Comedy movies, drama movies, action/horror movies, independent movies, documentaries, foreign movies

Read local paper, checked news on line, read newspaper, read school newspaper, watched news, watched sports shows

Hours listened to music, most time listened to music, songs knows lyrics to, songs downloaded, music magazines read, used headphones

Time spent on line, most time spent on line, Times IM people each week, most IM messages on screen, different IM messages, Times changed profile, times checked email each day, different email accounts, emails received, number of email addresses, emails sent 
Appendix C (Continued)

\section{Social and Solitary Activity \\ Sexual Activity \\ Promiscuous Lifestyle \\ (6 items, $\alpha=.72$ )}

Masturbation

(5 items, $\alpha=.73$ )

Social Behavior

Conversationalist

( 8 items, $\alpha=.74$ )

Telephone Enthusiast

(9 items, $\alpha=.75$ )

Social and Party Orientation

(11 items, $\alpha=.72$ )

Game-Playing

(10 items, $\alpha=.72$ )

Caring Person

(5 items, $\alpha=.52$ )

Solitary Lifestyle

( 8 items, $\alpha=.66$ )
Number of different partners, number of one night stands, times cheated on partner, different "dates", number of romantic relationships, most amount of times broke up and got back together

XXX websites, times masturbated in last week, watched adult tapes, number of porno pictures on computer, read adult magazines

Talked about: news, politics, philosophy, pop culture, the future, school, sex, books

Time spent on phone, different people talk to, longest phone conversation, number of people who called, amount of last phone bill, phone numbers stored, bought a card or gift, shopping, out to eat

Number of good friends, times socialized with a group, off campus parties attended, frat parties attended, had dinner with 5 people, best friends, center of attention, dancing/clubbing, told joke, jokes, go to beach

Times played: Board games, solitaire, cards with friends, chess or checkers, crossword puzzles, jigsaw puzzles, on-line interactive games, number of card games knows, video games, hand-held video games

Volunteer work, prayed or meditated, given to charity, written to people, been to church

Spent a day entirely alone, had dinner alone, danced by self in room, laughed out loud, place to relax, decline invitation, sang by self, written in journal 
Appendix C (Continued)

\section{Interactions with Others}

Mother and Father

Positive Relations with

Mother

(15 items, $\alpha=.87$ )

Relationship Conflict with

Parents

(15 items, $\alpha=.79$ )

Social Activity with Parents

( 9 items, $\alpha=.78$ )

Positive Relations with

Father

(15 items, $\alpha=.87$ )

\section{Significant Other}

Positive Relations with

Partner

(15 items, $\alpha=.89$ )

Relationship Conflict with

Partner

(12 items, $\alpha=.75$ )

Social Activity with Partner

(13 items, $\alpha=.76$ )
Discuss personal issues, says I love you, talk, laugh, 20 minute conversations, display affection, T.V., shop, eat meal, advice, cry, discuss politics, home to visit, buy card for, visit at unh

Scream at by dad, screamed at, didn't speak to for 1 week, dad verbal argument, mom scream at, dad hit, mom get screamed at, hit dad, dad drugs, mom hit by, mom verbal argument, mom no speak 1 week, dad avoid, mom avoid, mom drugs, mom borrow money

Mom concert, dad concert, mom cultural event, mom movie, dad movie, dad cultural event, dad discuss book, mom discuss book, dad sports event

Talk, 20 minute conversation, laugh, discuss personal issues, I love you, advice, display affection, discuss politics, eat meal, T.V., shop, cry, borrow money, visit at unh, home to visit

Discuss feelings, laugh, 30 minute, seek advice, call, hold hands, I love you, hang out, make love, public affection, gossip, cuddle, day alone with, help with problem, massage, cry

Get screamed at, scream at, verbal argument, avoid contact, talk about, intentionally cheat, criticize, invade privacy, hit/throw, no speak 1 week, drugs, smoke

Concert, sport, gym, religious, cultural, sports, double date, movies, vacation, shop, homework with, discuss book, borrow money 
Appendix C (Continued)

\section{Best Friend}

Social Activity with Best

Friend

(14 items, $\alpha=.85)$

Positive Relations with Best Friend

(9 items, $\alpha=.82$ )

Relationship Conflict with

Best Friend

(7 items, $\alpha=.75$ )
Party, hang out with group, drink alcohol, hang T.V., sport, gym, movies, shop, sports, concert, along with, drugs, gossip, homework, borrow money

Advice, 30 minute, call, help with problem, cry, laugh, display affection, travel with, email

Get screamed at, scream profanities, avoid contact, talk badly about, no speak for 1 week, argue, criticize dress; cultural, discuss book 


\section{Appendix D}

\section{Life Space Scales (first-order) and Reliabilities: Incorporative Domain}

\section{Family Demographics}

Parent's Health

Parents Psychopathology

(7 items, $\alpha=.61$ )

Parents Poor Physical Health

(7 items, $\alpha=.54$ )

Family Financial Situation

Family Wealth

(9 items, $\alpha=.68$ )
Mom anxiety, mom depression, dad anxiety, dad addiction, mom psychological hospitalization, dad depression, mom addiction

Dad weight control, dad high cholesterol, dad hypertension, dad diabetes, dad circulatory, mom cholesterol, mom weight control, mom diabetes

Income, receive financial aid(r), own loans for college(r), mom education, dad education, total monetary value, parents pay for education, size of residence, parents give money

Political action, campus concerns, minority, student government, environmental, sharp, culture/language, international group, color guard, dorm staff, school newspaper, gay/lesbian

Music courses, high school band, high school orchestra, acting/drama, high school choir, college band, music awards, college music/theater, performing arts courses, college choir/singing, college drama/acting, high school church choir

Academic scholarship, national honor society, AP exams passed, merit based scholars, high school homecoming, high school student government, college level courses in high school, college honor society 
Appendix D (Continued)

Self and Other Help Groups

(9 items, $\alpha=.61$ )

College Track Courses

( 8 items, $\alpha=.53$ )

Sports Groups

(10 items, $\alpha=.53$ )
High school 12-step, HS 12-step family, HS gay/lesbian, HS drug awareness, HS-SADD, Hs peer counseling, HS racial/ ethnic group, HS debate team, HS environmental

English courses, social science courses, science courses, math courses, math courses, fine arts courses, computer courses, humanities, business courses

Sports awards, college intercollegiate sports, HS basketball, HS soccer, HS track, HS football, industrial/organizational courses, hours worked in HS(r), HS cheerleading(r), college intramural sports 
Appendix E

Hierarchical (Second-Order) Factor Analysis of First-Order Scales

\begin{tabular}{|c|c|c|c|c|c|c|c|c|c|}
\hline \multirow[t]{2}{*}{ First-order scale } & \multicolumn{9}{|c|}{ Principal components with oblique rotation } \\
\hline & & I & II & III & IV & $\mathbf{V}$ & VI & VII & VIII \\
\hline Positive Relations Mother & ID & .686 & & & & & & & \\
\hline Positive Relations Father & ID & .665 & & & & & & & \\
\hline Social Activity with Parents & ID & .535 & & & & & & & \\
\hline Positive Relations with Best Friend & ID & .484 & & & & & & & \\
\hline Telephone Enthusiast & ID & .469 & & & & & & & \\
\hline Social \& Party Orientation & ID & .456 & & & & & & & \\
\hline Social Activity with Best Friend & $\mathrm{ID}$ & .454 & & & & & & & \\
\hline Appearance Maintenance & $\mathrm{ID}$ & .438 & & & & & & & \\
\hline Family Wealth & $\mathrm{G}$ & & & & & & & & \\
\hline Clean Lifestyle & ID & & & & & & & & \\
\hline Physical Fitness & $\mathrm{B}$ & & .739 & & & & & & \\
\hline Sports Groups & $\mathrm{G}$ & & .678 & & & & & & \\
\hline Sports Consumption & ID & & .639 & & & & & & \\
\hline Masculine Sports Orientation & $\mathrm{S}$ & & .601 & & & .404 & & & \\
\hline Outdoor Sports Equipment & $S$ & & .552 & & & & & & \\
\hline Outdoor Sports Enthusiast & ID & & .515 & & & & & & \\
\hline Hunting & ID & & .460 & & & & & & \\
\hline Hunting Equipment & $\mathrm{S}$ & & .452 & & & & & & \\
\hline Caring Person & ID & & & & & & & & \\
\hline Military Arts & ID & & & & & & & & \\
\hline Illicit Drug Abuse Lifestyle & ID & & & .770 & & & & & \\
\hline Smoking Possessions & $\mathrm{S}$ & & & .753 & & & & & \\
\hline Smoking Addiction & $\mathrm{ID}$ & & & .593 & & & & & \\
\hline Alcohol Abuse & $\mathrm{ID}$ & & & .571 & & & & & \\
\hline Promiscuous Lifestyle & $\mathrm{ID}$ & & & .488 & & & & & \\
\hline Drug Abuse & $\mathrm{ID}$ & & & .481 & & & & & \\
\hline Illicit Drug Possessions & $\mathrm{S}$ & & & .474 & & & & & \\
\hline Alcohol Possessions & $\mathrm{S}$ & & & .413 & & & & & \\
\hline Delinquent Student & ID & & & .358 & & & & & \\
\hline Music Ability \& Achievement & $\mathrm{ID}$ & & & & .666 & & & & \\
\hline Musical Instrument Ownership & $\mathrm{S}$ & & & & .564 & & & & \\
\hline Artistic Expression \& Appreciation & $\mathbb{D}$ & & & & .533 & & & & \\
\hline Music \& Arts Groups & $\mathrm{G}$ & & & & .524 & & & & \\
\hline Artistic Activity & $\mathrm{D}$ & & & & .476 & & & & \\
\hline Nonconforming Music & $\mathrm{S}$ & & & & .434 & & & & \\
\hline Music Consumer & ID & & & & .306 & & & & \\
\hline Television Consumer & ID & & & & & & & & \\
\hline
\end{tabular}


Appendix E (Continued)

\begin{tabular}{|c|c|c|c|c|c|c|c|}
\hline \multirow[t]{2}{*}{ First-order scale } & \multicolumn{7}{|c|}{ Principal components with oblique rotation } \\
\hline & I & II & III & IV & $\mathbf{V}$ & VI & VII VIII \\
\hline General Media & $\mathrm{S}$ & & & & .656 & & \\
\hline Challenging Games & $\mathrm{S}$ & & & & .643 & & \\
\hline Movie Consumer & $\mathrm{S}$ & & & & .591 & & \\
\hline Video Game Possessions & $\mathrm{S}$ & & & & .561 & & \\
\hline Computer Equipment & $\mathrm{S}$ & & & & .527 & & \\
\hline Popular Music & $\mathrm{S}$ & & & & .437 & & \\
\hline Alternative Rock Music & $\mathrm{S}$ & & & & .423 & & \\
\hline Collectibles & $\mathrm{S}$ & & & & .377 & & \\
\hline College Track Courses & $\mathrm{G}$ & & & & & & \\
\hline Religious Possessions & $\mathrm{S}$ & & & & & & \\
\hline Nervous Behavior & $\mathrm{B}$ & & & & & .585 & \\
\hline Somatic Complaints & $\mathrm{B}$ & & & & & .561 & \\
\hline Relationship Conflict with Parents & ID & & & & & .503 & \\
\hline Verbal Aggression & ID & & & & & .485 & \\
\hline Physical Aggression & $\mathrm{ID}$ & & & & & .413 & \\
\hline Unhealthy Lifestyle. & $\mathrm{B}$ & & & & & .400 & \\
\hline Internet Enthusiast & $\mathrm{ID}$ & & & & & .387 & \\
\hline Stealing & ID & & & & & .383 & \\
\hline Relationship Conflict Best Friend & ID & & & & & .338 & \\
\hline Allergy, Sinus \& Cold & $\mathrm{B}$ & & & & & .323 & \\
\hline Unconventional Earrings & $\mathrm{S}$ & & & & & & \\
\hline Parent Poor Health & $\mathrm{G}$ & & & & & & \\
\hline Book Consumer & ID & & & & & & .548 \\
\hline Self-Help Books & $\mathrm{S}$ & & & & & & .532 \\
\hline Reading Orientation & $\mathrm{S}$ & & & & .375 & & .472 \\
\hline Political Action & $\mathrm{G}$ & & & & & & .441 \\
\hline Conversationalist & $\mathrm{ID}$ & & & & & & .432 \\
\hline Solitary Lifestyle & $\mathrm{ID}$ & & & & & & .392 \\
\hline Studious Lifestyle & $\mathrm{ID}$ & & & & & & .381 \\
\hline Psychopathology & $\mathrm{B}$ & & & & & & .373 \\
\hline Artistic Objects & $\mathrm{S}$ & & & & & & .360 \\
\hline Liberal Political Endorsements & $\mathrm{S}$ & & & & & & $: 358$ \\
\hline Work Ethic & ID & & & & & & .336 \\
\hline New Age Possessions & $\mathrm{S}$ & & & & & & \\
\hline Parent Psychopathology & $\mathrm{G}$ & & & & & & \\
\hline Academic Achievement & $\mathrm{G}$ & & & & & & \\
\hline Self and Other Help Groups & $\mathrm{G}$ & & & & & & \\
\hline
\end{tabular}


Appendix E (Continued)

First-order scale

Masturbation

Sentimental Objects

Conventional Earrings

News Consumer

Gambling

Healthy Diet

Game Playing

Movie Consumer
Principal components with oblique rotation

I

II III

ID

.435

VI VII VIII

$-.514$

.494

.489

$-.482$

ID

$-.469$

B

.378

Note. Factor loadings below \pm .35 are suppressed unless included on a global dimension. $\mathrm{B}=$ Biological Domain, $\mathrm{S}=$ Situational Elements Domain, $\mathrm{ID}=$ Interactive Domain, $\mathrm{G}=$ Incorporative Domain. I. Positive \& Social Orientation, II. Sports Orientation, III. Drug Culture Environment, IV. Music \& Arts Achievement, V. Media Consumer, VI. Negative \& Unhealthy Lifestyle, VII. Intellectual Pursuits. 


\section{Appendix F}

University of New Hampshire.

Institutional Review Boart for the Protection of Human Subjects in Research Departmental Review Committee Exemption Classification Sheet

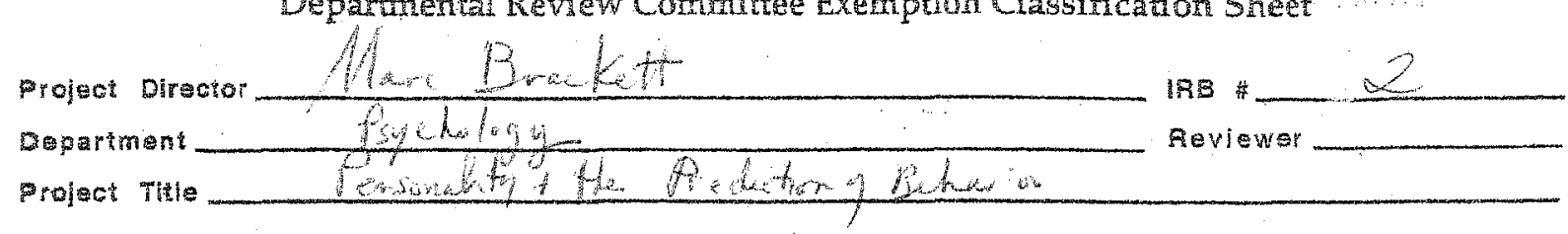

Reviewer. Please write comments or contingencies of approval, if any, on a separate shest of paper, and attach to this form. Plece the complated form on file with the appication for rowlew, in the Deparmentai Feview Committee files. Protocol applications and review forms with be forwarded to the Office of Sponsared Fesearch each semester for reporing purposes.
Trotocol
ciesoription:
$-46.101(b)(4)$ Study of existing data
$-46.101(b)(5)$ Study of public benefits or service programs
$-46.101(b)(b)$ Taste and food studies

46.101(b)(1) Research conducted in estabilshed educationai setting using normal educational procedures

46. 101 (b)(2) Educational tests, surveys, Interviews, observation of public behaviorho risk

46.101(b)(3) Educational tests, surveys, interviews, observation of public behavior not exempt under Subsection 2, above, if public official or if confidentiality mandaled by feceral statutes

7 Reter protocol to the regular IAB for EXPEDTED review under the following subsecton (check one):

- $46.110(\mathrm{~b})(1)$ Clinical studies of drugs/medical devices not requining investigational new drug/device applications.

46.110(b)(2) Collection of blood samples by inger, heel or ear stick, or venipuncture in healthy adulte $>1$ to tos., or others and children, considering age, weight, heatth, collection procedure, frequency and amount of collection.

$46.110(b)(3)$ Prospective collection of biological specimens for fesearch purposes by norinvasive means, and in a non-disflguring manner: hair and nail clippings, teeth, sweat, saliva, placenta (after delivery), amniotic fluid (ar membrane rupture/abor), dental plaque/calculus, mucosal/skin cells, sputum (after saline nebulization)

46.110 (b)(4) Collection of date through norinvasive means routinely employed in clinical practice (excluding $x$-rays and microwaves, and devices not approved for.marketing): physical sensors applied to the skin, weighing, tests of visual acuity; MRI. EKG, EEG, ultrascund, etc., and moderate exercise by healthy volunteors.

46.110(b)(5) Non-exempt pesaarch involving data, documents, records or specimens that have been/will be coltected solely ior nonresearch purposes (e.g., medical treatment or diagnosis).

$46.110(b)(6)$ Collection of data from voice, video, digital, or Image recordings made for research purposes.

46.110(b)(7) Non-exempt research on individual or group behavior or charecteristios of individuals, such as studies of perception, cognition, motivalion, identity, language, communication, cultural beliefs or practices, and social behavior, or research employing surveys, interviews, oral histories, tocus groups, program evaluation, human factors avaluation, or quality assurance methodologies.

$46,110(b)(8)$ Continuing review of research such as studies permanently dosed to enrollment of new subjects, or for which research related interventione are completed, or for which only longterm follow-up of subjects remains, or for which no subjects have been enrolled and no additional risks have been identified, or for which data analysis is the only remaining research activity.

48.110 (b)(9) Continuing review of research (not conducted under investigational drug/device appications or exemption) where categories 2 through $\varepsilon$, above, do not apply, and for which the APB has determined that the researoh involves no greater than minimal risk, and no additional rigks have been identified.

Feter protocol to the regular IFE for FULL BOAFO action (cite reason on saparate shegt)

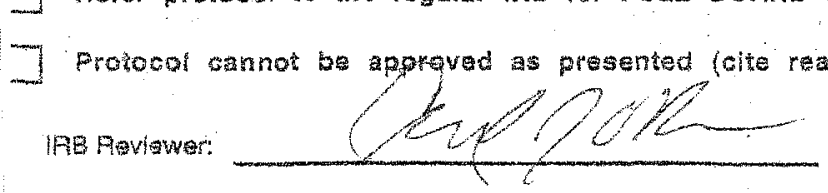

Dete:

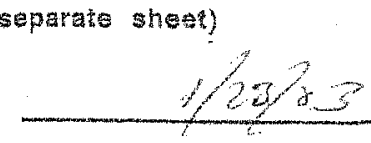

